University of South Florida

DIGITAL COMMONS

Digital Commons @ University of

@ UNIVERSITY OF SOUTH FLORIDA

South Florida

3-31-2015

\title{
A Conceptual Analysis of Perspective Taking in Support of Socioscientific Reasoning
}

Sami Kahn

University of South Florida, samikahn@mail.usf.edu

Follow this and additional works at: https://digitalcommons.usf.edu/etd

Part of the Curriculum and Instruction Commons, and the Science and Mathematics Education Commons

\section{Scholar Commons Citation}

Kahn, Sami, "A Conceptual Analysis of Perspective Taking in Support of Socioscientific Reasoning" (2015). USF Tampa Graduate Theses and Dissertations.

https://digitalcommons.usf.edu/etd/5513

This Dissertation is brought to you for free and open access by the USF Graduate Theses and Dissertations at Digital Commons @ University of South Florida. It has been accepted for inclusion in USF Tampa Graduate Theses and Dissertations by an authorized administrator of Digital Commons @ University of South Florida. For more information, please contact digitalcommons@usf.edu. 
A Conceptual Analysis of Perspective Taking in Support of Socioscientific Reasoning

by

\author{
Sami Kahn \\ A dissertation submitted in partial fulfillment \\ of the requirements for the degree of \\ Doctor of Philosophy \\ in Curriculum and Instruction with an emphasis in \\ Science Education \\ Department of Teaching and Learning \\ College of Education \\ University of South Florida
}

Major Professor: Dana L. Zeidler, Ph.D.

Benjamin C. Herman, Ph.D.

J. Randy McGinnis, Ph.D.

Cheryl R. Ellerbrock, Ph.D.

Date of Approval:

March 31, 2015

Keywords: Socioscientific Issues, Scientific Literacy, Socioscientific Perspective Taking, Theoretical Inquiry

Copyright (C 2015, Sami Kahn 


\section{Dedication}

In loving memory of my sister,

Lisa 


\section{Acknowledgments}

I begin by thanking the University of South Florida's Graduate School for enabling me to pursue my doctoral dreams, as well as the USF College of Education faculty and staff for providing unparalleled support and expertise. In addition, I am grateful to Dr. Gregory P. Stefanich and Dr. Sharon J. Sherman for being compassionate mentors, role models, and friends throughout my career.

I could never have imagined a more spectacular doctoral “dream team” to guide me through this profound and transformative experience. I offer my deepest thanks to: Dr. Benjamin C. Herman, for his kindness, intellect, and humor... and for being far too young to be that accomplished; Dr. Cheryl R. Ellerbrock, for showing me, through her example, that an Ethic of Care is the most powerful teaching tool; Dr. J. Randy McGinnis, for his tireless passion in advocating for quality science education for all students and for considering me a worthy colleague in that crusade; and Dr. Dana L. Zeidler, for his steadfast support, wisdom, and humor as a mentor, colleague and friend, his superb scholarship and professionalism, his insightful understanding of this fellow native "New Yawker," and for the privilege of being "Zeidlerized" by the master himself. Dana, I look forward to many more collaborations and cheesecakes!

I thank my parents for having shown me the value of intellect and common sense, my best friend, Kim, for believing in me since seventh grade, and my wonderful husband, Sandy, for providing love, support, advice, and endless Midwest patience. Finally, I thank my beautiful daughter and hero, Rachel, whose tenacity and strength of character inspires me to be a better mother, teacher, scholar, and person, and whose smile makes my day...every day. 


\section{Table of Contents}

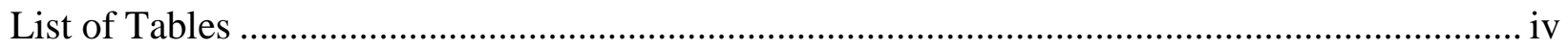

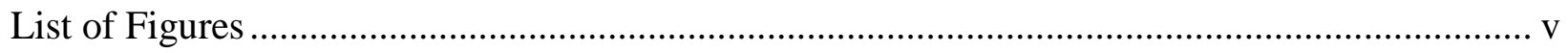

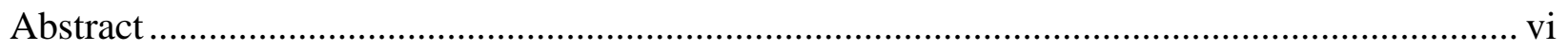

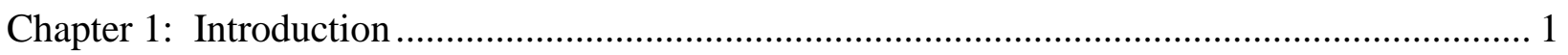

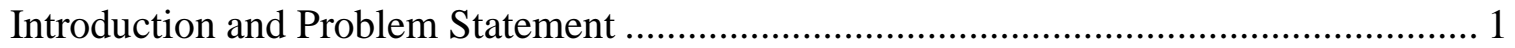

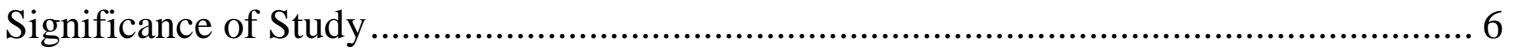

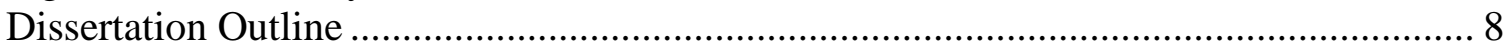

Timeliness of the Study in Light of Science Education Reform ................................... 9

Overview of Inquiry Framework ....................................................................... 11

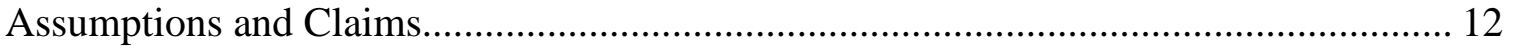

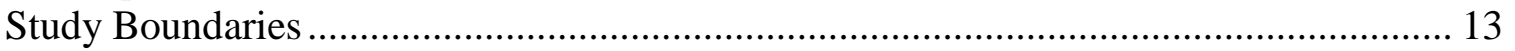

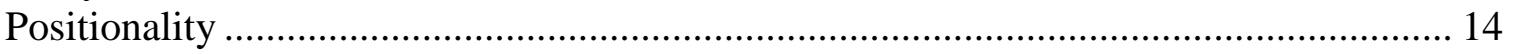

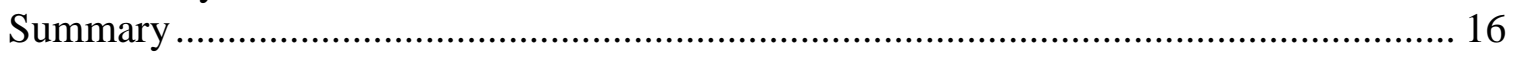

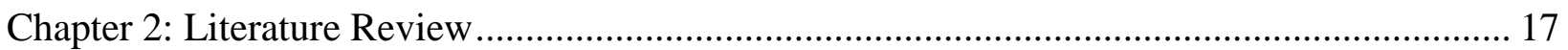

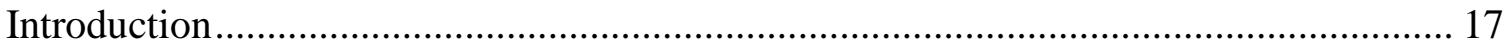

Contemporary Views of Scientific Literacy ........................................................... 17

A Route to Functional Scientific Literacy: SSI and SSR ............................................ 19

Perspective Taking - An Essential Yet Messy Construct............................................. 22

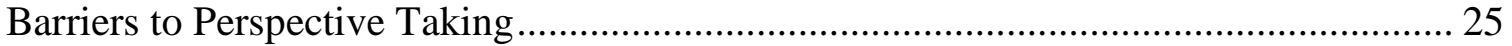

Contributions of This Study to the Literature on SSI and Perspective Taking................ 27

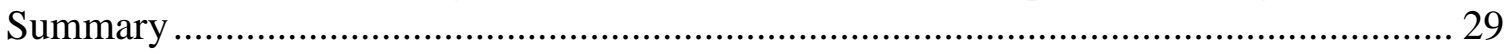

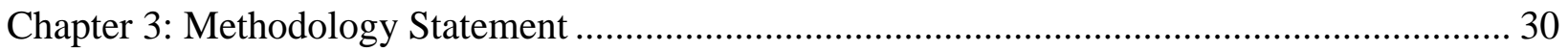

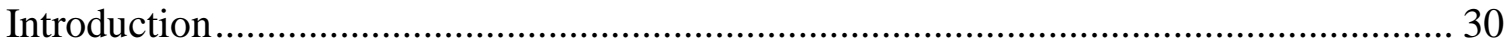

History and Models of Conceptual Analysis ............................................................ 32

Generic-type conceptual analysis. ............................................................ 34

Differentiation-type conceptual analysis. .................................................... 39

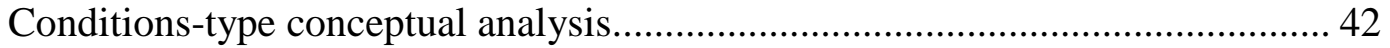

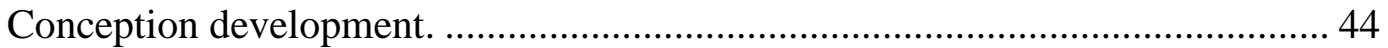

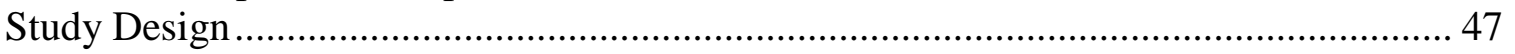

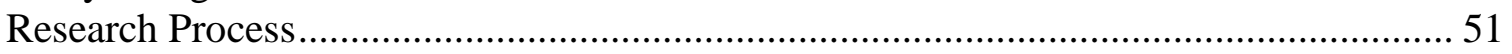

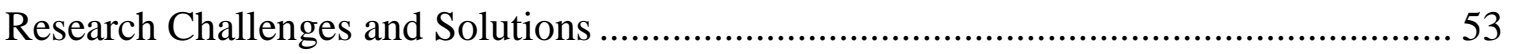

Criteria for Judging Study Completion and Quality ................................................. 55

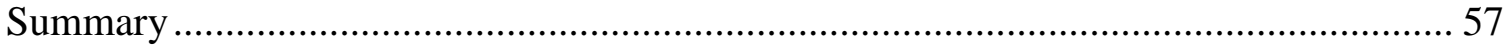


Chapter 4: Conceptual Analysis of Perspective Taking …………........................................... 58

Introduction......................................................................................................... 58

Cinematic Saints to Psychopaths - Generic and Conditions Analyses of Perspective

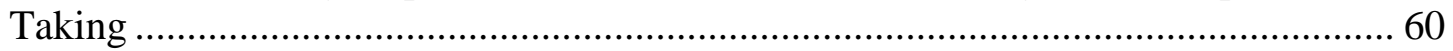

Generic Analysis of Perspective Taking............................................................ 60

Conditions Analysis of Perspective Taking....................................................... 67

Differentiation Analysis to Distinguish Perspective Taking from Related Constructs .... 76

Elevator Thinking and Perspective Taking........................................................ 76

A Typology of Perspective Taking......................................................................... 78

A Word About Perspectives, Orientations, and Positions .................................................. 84

Conception Development to Form a New Construct: Socioscientific Perspective

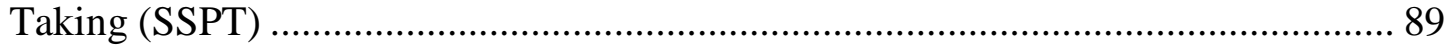

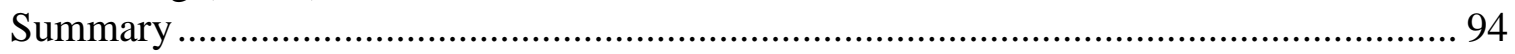

Chapter 5: Finding Common Ground: Theoretical Application of Perspective Taking

Frameworks from Non-Science Fields to SSI ………....................................................... 96

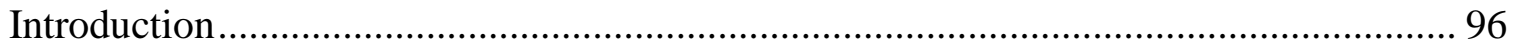

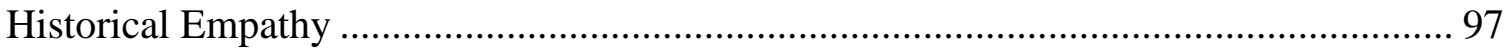

Use of Historical Controversies.......................................................................... 102

Use of Primary Sources. ................................................................................... 104

Section Summary...................................................................................... 104

Method Acting (Theater Education) ……………………............................................. 105

Comparative Analysis of Method Acting and SSI Frameworks......................... 106

Substitution. ................................................................................................ 108

Section Summary...................................................................................... 112

Autism Interventions from Special Education................................................................ 112

Comparative Analysis of Autism Education and SSI Frameworks.................... 113

Use of video modeling..................................................................................... 115

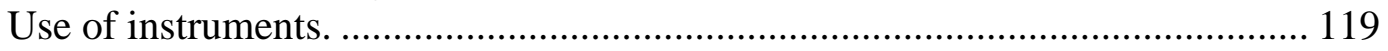

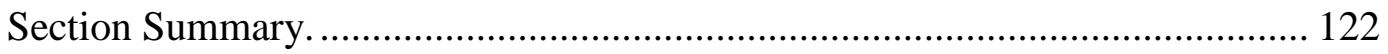

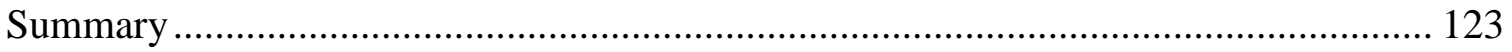

Chapter 6: Implications for Science Education Research and Practice .......................................... 125

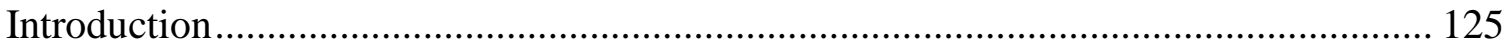

Implications for Science Education Research.................................................................. 126

Implications for Science Education Practice ................................................................ 129

Concluding Statement ....................................................................................................... 131

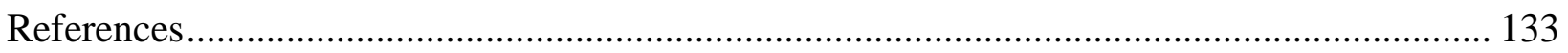

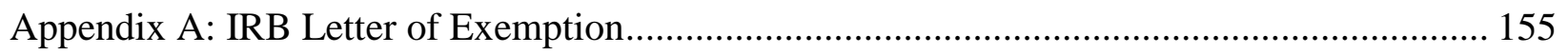

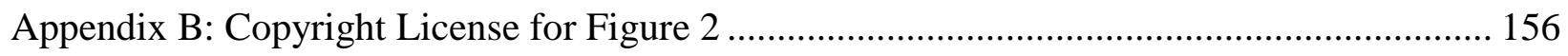

Appendix C: Copyright License for Figure 5 …………….................................................. 157 
Appendix D: Copyright License for Figure 14 …….............................................................. 158

Appendix E: Letter Confirming Open Source Status of Clipart in Figure 15 .............................. 159 


\section{List of Tables}

Table 1. Dissertation Overview .................................................................................. 9

Table 2. Selman’s Coordination of Social Perspectives ................................................... 23

Table 3. Summary of Conceptual Analysis Techniques ............................................... 47

Table 4. Summary of Conceptual Analysis Techniques Utilized in this Chapter................... 59

Table 5. Generic Analysis of Perspective Taking Characters............................................ 66

Table 6. Conditions Analysis of Model and Invented Perspective Taking Characteristics ...... 74

Table 7. A Typology of Perspective-Taking Constructs................................................... 84

Table 8. Comparison of Prospective Evaluations in Historical Empathy and SSI ................ 101

Table 9. Comparison of Method Acting and SSI........................................................... 108

Table 10. Comparison of Key Elements Between Autism Intervention and SSI ................... 115

Table 11. Key Findings From Theoretical Inquiry Into Study Frameworks ......................... 124 


\section{List of Figures}

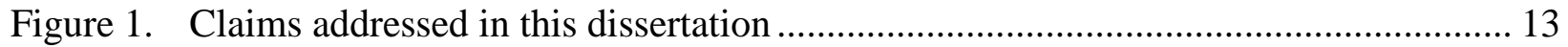

Figure 2. Socioscientific elements of functional scientific literacy. ................................. 20

Figure 3. Generic features of X derived from generic-type analysis. .................................... 35

Figure 4. Types of X derived from a differentiation-type analysis ..................................... 40

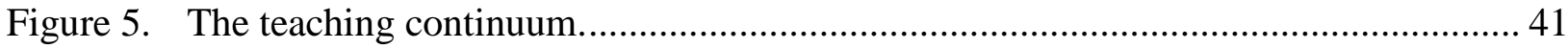

Figure 6. Context conditions of $\mathrm{X}$ derived from a conditions-type analysis........................... 42

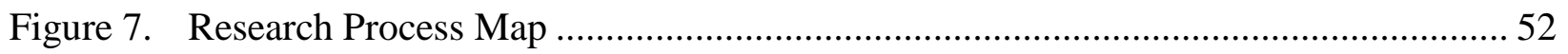

Figure 8. Necessary and Sufficient Conditions for Perspective Taking in (a.) Generic

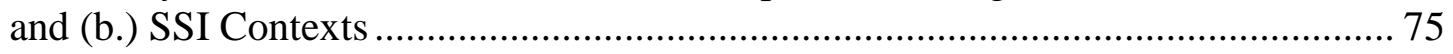

Figure 9. The Components of Perspective Taking .......................................................... 83

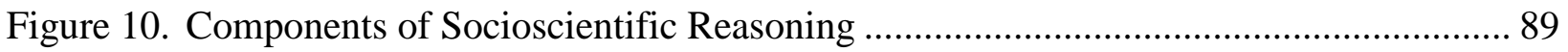

Figure 11. Patterns of Informal Reasoning in SSI...................................................... 91

Figure 12. Socioscientific Perspective Taking .................................................................. 93

Figure 13. Context/Action/Consequence Model Applied to Historical Empathy and SSI ........ 100

Figure 14. The Sally-Anne Test of Perspective-taking/False Belief..................................... 120

Figure 15. The SSI Conceptual Perspective-Taking Test .................................................. 122 


\begin{abstract}
Scientific literacy is concerned with the informed citizens' ability to negotiate scientificallyrelated societal issues. The suite of skills necessary to negotiate these complex issues is referred to as Socioscientific Reasoning (SSR). SSR requires, among other things, perspective-taking abilities in order to consider the multi-faceted nature of these open-ended, debatable socioscientific issues (SSI). Developing interventions and instruments to foster and measure perspective taking in support of SSR is therefore critical to the promotion of functional scientific literacy through both research and practice. Although widely studied in many disciplines, perspective taking is a particularly tangled construct that has been used to describe a range of activities representing different psychological domains and applied interchangeably with related constructs such as role taking, empathy, and theory of mind. This ambiguity makes it difficult to ensure construct validity and prevents science education researchers from honing in on the precise skills they wish to study and promote. To clarify the construct of perspective taking, this study undertook a conceptual analysis to operationalize perspective taking, drawing comparisons and distinctions between it and related constructs. Further, by applying a method known as conception development, perspective taking was positioned in the context of SSR, particularly as it relates to moral development, in order to devise a more precise construct relating perspective taking to SSR called socioscientific perspective taking (SSPT). It is asserted that SSPT requires engagement with others or their circumstances, an etic/emic shift, and a moral
\end{abstract}


context comprised of reflective and reflexive judgment. Finally, in order to identify promising interventions for promoting SSPT in the science classroom, the newly-developed SSPT construct was applied to a series of extensively researched curricular frameworks that promote perspective taking in three non-science disciplines including historical empathy (social studies education), method acting (theater education), and autism intervention (special education). The aim of this theoretical inquiry was to translate successful perspective-taking interventions into SSI contexts, yielding an array of promising approaches for fostering SSPT while assessing the feasibility of each of these fields as potential sources for novel and expansive work in SSI to promote scientific literacy. Implications for science education research and practice are discussed. 


\section{Chapter 1:}

\section{Introduction}

\section{Introduction and Problem Statement}

One need not look further than the halls of Congress, or perhaps the halls of one's own home, to recognize that seeing circumstances from other's perspectives and having one’s circumstances appreciated by others is necessary for the resolution of controversy and fundamental to human communication and socialization (Batson, 1991; Clark \& Marshall, 1981). Yet perspective taking remains an ongoing challenge in society at large, in personal relationships, and in the education of students. Perspective taking is a particularly salient construct in science education, as current conceptualizations of scientific literacy demand that students develop as an informed citizenry prepared to negotiate complex societal issues related to science (Roberts, 2007, 2011; Zeidler \& Sadler, 2011). This contemporary view of "functional scientific literacy" (Zeidler, 2014; Zeidler \& Keefer, 2003; Zeidler, Sadler, Simmons \& Howes, 2005) integrates the understanding of science content within the context of real-world socioscientific issues (SSI) which are controversial, and therefore by definition, incorporate multiple viewpoints. The negotiation of these SSI requires, in part, a suite of skills known as Socioscientific Reasoning (SSR) (Sadler, Barab, \& Scott, 2007), a component of which is perspective taking. The critical role of perspective taking in the resolution of multi-faceted SSI, as well as its foundational role in 
argumentation and human understanding, provides tremendous incentives for science educators to foster this skill in an effort to promote SSR and ultimately, scientific literacy.

As critical as perspective taking is to science education, a glaring challenge emerges when one tries to operationalize this construct. Perspective taking has been used to describe a range of behaviors from visual/perceptual perspective taking (seeing what others see) (Flavell, 1968), communicative perspective taking (understanding another person’s mental state during communications) (Nilson \& Fecica, 2011), affective perspective taking (feeling what another person feels) (Vilardaga, 2009) and cognitive perspective taking (knowing what others know) (Kurdek, 1977). Ruby \& Decety (2003) suggest that to truly understand others’ perspectives, one must integrate the “visual, affective, and conceptual domains” (p. 2475). To further complicate matters, in considering perspective taking, one must differentiate it from other related constructs such as role-taking (Selman, 1971), empathy (Vilardaga, 2009) and "theory of mind,” (Premack \& Woodruff, 1978), which some authors use interchangeably (Demurie, De Corel, \& Roeyers, 2011), while others claim are quite different (Coke, Batson, \& McDavis, 1978; Davis, 1983). Whether identified in psychology (Mead, 2009), education (Heagle \& Rehfeldt, 2008), or management science (Boland \& Tenkasi, 1995), perspective taking emerges as a sweeping “catch-all” phrase used in many contexts with many different boundaries and referents. In some ways, social scientists have utilized the same test as Justice Potter Stewart did in his attempt to define obscenity: “I know it when I see it” (Jacobellis v Ohio, 1964).

Specifically in the context of SSR, perspective taking has been identified as a particularly difficult practice to operationalize, with researchers concluding that current conceptualizations most likely under-represent the true range of activities that are associated with the negotiation of SSI (Sadler, Klosterman, \& Topcu, 2011). A review of the manner in which perspective taking has been measured in the context of SSR reveals a lack of 
consistency, with measures including the number of different "reasoning modes” (Wu \& Tsai, 2007, p. 1172), the extent to which one considers diverse opinions and imagines oneself in another's situation (Lee, et al., 2013), whether arguments represent personal, societal, or global concerns (Lee, Chang, Choi, Kim, \& Zeidler, 2012), the ability to formulate counterpositions and rebuttals (Sadler \& Donnelly, 2006), and the ability to conceptualize a problem beyond one’s own personal framework (Sadler, Barab, \& Scott, 2007). Clarification of the perspective taking construct would undoubtedly assist researchers in understanding the gaps in their work as well as overlaps between their works and those of others studying related constructs. Perhaps a more pressing issue is the fact that nowhere in the SSR construct, which currently cites as its features “complexity, multiple perspectives, inquiry, and skepticism,” (Sadler, Barab, \& Scott, 2007, p. 374) is any mention of an appreciation of the consequences of one’s actions, reflective and reflexive judgment, moral sensitivity, and the like. These would seem to be necessary components of reasoning that purports to aid in the negotiation of controversial issues within SSI given that the framework is premised upon the promotion of moral development (Zeidler, 2014; Zeidler \& Keefer, 2003). Is it that the SSR construct is missing a necessary "moral" component, or is it that the "multiple perspectives" aspect subsumes the many activities of moral reasoning that are tacitly implied? It is argued that this question requires methodical analysis of perspective taking, both within and outside of the SSR context, in order to identify the activities and outcomes reasonably attributed to perspective taking and explicitly delineate those activities that are necessary for perspective taking in SSR.

Therefore, the purpose of this study is to perform a conceptual analysis to "remove the “fuzz” (Krathwohl, 1993, p. 148) from the fuzzy construct of perspective taking. Using a philosophical approach which applies cases (Green, 1971; Wilson, 1963) to identify the boundaries and referents of constructs, perspective taking will be operationalized by drawing 
comparisons and distinctions between it and related constructs including theory of mind, empathy, and role taking. Further, perspective taking will be positioned in the context of SSR, particularly as it relates to moral development, through a method known as conception development (Coombs \& Daniels, 1991), constructing a typology or concept map for a new construct called, socioscientific perspective taking (SSPT) in order to identify the specific components, characteristics, and activities associated with perspective taking in SSR. Finally, in order to identify promising interventions for promoting SSPT in the science classroom, the newly-developed SSPT construct will be applied to a series of extensively researched curricular frameworks that promote perspective taking in three non-science disciplines including historical empathy (Foster, 2001), method acting (Verducci, 2000), and autism interventions (BaronCohen, Leslie, \& Frith, 1985). The ultimate goal of this analysis is to yield a series of promising interventions and instruments for fostering SSPT while assessing the feasibility of each of these fields as potential sources for novel and expansive work in SSI to promote scientific literacy. Accordingly, three research questions will be addressed in this study:

RQ 1. What are the boundaries and referents of perspective taking?

RQ 2. What central role does perspective taking play in the exercise of SSR?

RQ 3. What frameworks from other disciplines can inform curriculum development and research to promote socioscientific perspective taking (SSPT)?

\section{Rationale:}

The rationales underlying each of the research questions are as follows:

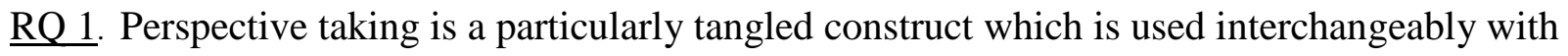
several other related constructs such as empathy, theory of mind, and role taking (Coke, Batson, \& McDavis, 1978; Davis, 1983; Demurie, De Corel, \& Roeyers, 2011; Selman, 1971). This ambiguity makes it difficult to ensure construct validity and identify the precise skills that 
are being studied and promoted (Cronbach \& Meehl, 1955). Explication of the necessary and sufficient conditions for perspective taking and differentiation from related constructs through conceptual analysis (Green, 1971; Wilson, 1963) will lay the groundwork for further examination and operationalization of the construct specifically within science education. RQ 2. The SSR construct cites incorporation of multiple perspectives as a necessary component (Sadler, Barab, \& Scott, 2007). Review of the literature and instruments regarding perspective taking within the SSR construct suggests tremendous ambiguity in the current conceptualization of perspective taking activities (Lee, Chang, Choi, Kim, \& Zeidler, 2012; Lee, et al., 2013; Sadler, Klosterman, \& Topcu, 2011). Moreover, there exists an implication that perspective taking within the context of SSR relates to moral development (Zeidler, 2014; Zeidler, Berkowitz, \& Bennett, 2013), yet neither explicit connections nor models for the relationship exist. This lack of an articulated link between perspective taking and moral development renders the SSR construct inadequate to support the foundational element of moral reasoning development within the SSI framework. Examination of the relationship between SSR and perspective taking, with particular emphasis on moral development, will strengthen the SSR construct, provide clarity for research, and allow for principled SSI curriculum development (Boulter \& Buckley, 2000).

RQ 3. Although interest in perspective taking is relatively new to science education, many other educational fields have developed and empirically tested instruments and interventions to measure and promote perspective taking (Baron-Cohen, Leslie, \& Frith, 1985; Foster, 2001; Verducci, 2000). It would seem plausible that science educators might be informed by the substantial body of work regarding perspective taking in these other fields (Sawyer, 2006). A theoretical inquiry into the manner in which perspective taking is operationalized and promoted within these fields, compared to the newly-operationalized construct of perspective 
taking within SSR (SSPT), can yield promising curricular interventions as well as an analysis of the feasibility of these fields as sources for more expansive research in SSI (Grove \& Short, 1991).

\section{Significance of Study}

This exploration has the potential to significantly impact science education. A conceptual analysis of perspective taking will lay the groundwork for further research and practice in SSI. By identifying the boundaries and referents of this construct, specifically in the context of SSR, shared operational definitions among instruments can be defined, thereby making construct validity (Cronbach \& Meehl, 1955) possible. In addition, a conceptual analysis will serve as a prerequisite for future theories and models (Bozeman \& Feeney, 2007), which in the context of SSR, will further elucidate the precise elements that should be emphasized in research and in the classroom. Clarifying the perspective taking construct will also allow science education researchers to better identify and understand the gaps and commonalities among their works on related constructs, such as empathy, character, and orientations, and perspective taking. For example, in their study of SSI as a vehicle for developing character and values for global citizenship, Lee, Chang, Choi, Kim, \& Zeidler, (2012) suggest that participation in discussions or debates increase students' awareness of the “different perspectives” (p. 8) that are involved, citing the work of Furberg \& Ludvigsen, (2008) as empirical evidence for this claim. Furberg \& Ludvigsen (2008), however, used the term "orientations" (p. 1790) to describe the variety of approaches students took to analyze their SSI. Are perspectives equivalent to orientations? If not, what are the boundaries of each? Does SSR demand an appreciation of different perspectives and orientations? Can one change one's perspective without shifting their orientation, and vice versa? This is just one example of 
the many overlaps that exist between perspective taking and related constructs. Parsing them out through conceptual analysis will no doubt assist researchers in refining and extending their work. Some of the additional sub-questions that will be addressed include: 1) Is "examining issues from multiple perspectives” (Sadler, Barab, \& Scott, 2007, p. 374) the same as perspective taking? 1) Are multiple perspectives necessarily varied perspectives? 3) Does perspective taking require another person? 4) Is a position equivalent to a perspective? 5) Does one need to know another's viewpoint to take their perspective, or is conjecture sufficient? 5) How does perspective taking relate to an inclusive (McGinnis, 2003) view of scientific literacy?

A conceptual analysis will also allow for precise comparison between the elements of perspective taking in the context of SSI with the elements of perspective taking for argumentation in science. Argumentation, whether utilized to evaluate scientific claims or debate SSI, necessitates the ability to ground one’s positions with claims, warrants, and rebuttals (Erduran, Simon, \& Osborne, 2004; Toulmin, 1958; Walker \& Zeidler, 2007), the latter of which is considered an indicator of the incorporation of multiple perspectives (Simonneaux, 2008). Articulating the precise role of perspective taking within socioscientific argumentation will significantly pave the way for more targeted interventions and measures.

Moreover, development of a typology or concept map of socioscientific perspective taking will allow for principled curriculum development (Boulter \& Buckley, 2000). The examination of related frameworks from other fields that seek to promote perspective taking, including historical empathy (Foster, 2001), method acting (Verducci, 2000), and autism intervention (Baron-Cohen, Leslie, \& Frith, 1985) will provide science education researchers and practitioners with extensively researched and validated intervention and assessment tools that may be re-contextualized in SSI to promote perspective taking. Once perspective taking 
for SSR is operationalized, theoretical connections will be made between the various frameworks so that science educators will not have to reinvent the wheel in order to remedy the absence of interventions that specifically target perspective taking. Further, by explicitly identifying the connections between these bodies of research and SSI, researchers in the field of social studies education, drama education, and special education might be inspired to look to SSI to inform their research and practice, thus promoting "cross-fertilization" between fields. In their discussion of the interdisciplinary nature of SSI, Eastwood, Sadler, \& JimenezAleixandre (2011) question how the SSI community might become more connected with other disciplines trying to accomplish many of the same goals. The authors suggest that the emergence of the learning sciences movement, which "draws on the expertise of multiple, previously isolated disciplines or subdisciplines” (p. 130) including the cognitive sciences, information technology, math and science education, among others, serves as an example for SSI researchers seeking to build on learning from other disciplines. The approach advanced in this dissertation responds to these authors' concerns by developing a process for sharing and recontextualizing a common skill. Hence, on a meta-level, this dissertation research will provide a heuristic for analyzing, operationalizing, and sharing "fuzzy" constructs within and across disciplines. It is then that we will not only be able to say that we promote perspective taking, but that we actually practice it ourselves.

\section{Dissertation Outline}

In attending to these issues of theoretical and eventual practical significance, and to fully address the research questions above, Table 1 on page 9 presents the conceptual outline for this study. Part one focuses on the actual conceptual analysis of perspective taking with an eye toward the development of a socioscientific perspective taking construct (SSPT), while 
part two offers a theoretical inquiry into promising interventions that can promote curricula and practice in relation to SSPT, and well as the broader domain of SSI.

Table 1. Dissertation Overview

\begin{tabular}{|l|l|}
\hline $\begin{array}{l}\text { Part I. Conceptual Analysis of Perspective Taking and Development of a Socioscientific } \\
\text { Perspective Taking (SSPT) }\end{array}$ \\
\hline Chapter 1. Introduction & $\begin{array}{l}\text { Problem Statement, Study Significance, Timeliness in Light of } \\
\text { Science Education Reform, Overview of Inquiry Framework, } \\
\text { Assumptions, Boundaries, Positionality }\end{array}$ \\
\hline Chapter 2. Literature Review & $\begin{array}{l}\text { Functional Scientific Literacy and the SSI Framework. } \\
\text { Socioscientific Reasoning, Perspective Taking }\end{array}$ \\
\hline Chapter 3. Methods & $\begin{array}{l}\text { History and Models of Conceptual Analysis, Study Design and Work } \\
\text { Flow, Challenges }\end{array}$ \\
\hline $\begin{array}{l}\text { Chapter 4. Conceptual Analysis of } \\
\text { Perspective } \\
\text { Taking }\end{array}$ & $\begin{array}{l}\text { Generic Analysis of PT, Conditions Analysis of PT, Differentiation } \\
\text { Analysis of PT, Conception Development of SSPT }\end{array}$ \\
\hline
\end{tabular}

\begin{tabular}{|c|c|}
\hline rt II. Development of Promising & erventions to Promote SSPT via Theoretical Inquiry \\
\hline $\begin{array}{l}\text { Chapter } 5 \text {. Theoretical } \\
\text { Application of Perspective Taking } \\
\text { Frameworks From Non-Science } \\
\text { Fields to SSI }\end{array}$ & $\begin{array}{l}\text { Review of Method Acting (Theater Education), Historical Empathy } \\
\text { (Social Studies Education), Autism Intervention (Special Education) } \\
\text { and Assessment of Feasibility of Interventions and Assessments to } \\
\text { Promote SSPT }\end{array}$ \\
\hline $\begin{array}{l}\text { Chapter 6. Implications for } \\
\text { Science Education Theory, } \\
\text { Research, and Practice }\end{array}$ & $\begin{array}{l}\text { Promoting and Assessing Perspective Taking, Overcoming Barriers } \\
\text { to Perspective Taking, Directions for Future Research }\end{array}$ \\
\hline
\end{tabular}

\section{Timeliness of the Study in Light of Science Education Reform}

The present study is particularly timely given the recent release of the Next Generation Science Standards [NGSS] (Achieve, 2013) and their focus on contextualized, inclusive science education. The NGSS articulate several conceptual shifts that support current views of scientific literacy including emphases on real-world, applied science knowledge, deep understanding of content and skills, connections with other disciplines through alignment with Common Core State Standards, and ensuring that science is accessible and culturally sensitive to the needs of diverse learners. Yet, while these standards seek to prepare students for the application of science to real-world contexts, they fail to address the need for students to consider the moral consequences of their socioscientific decisions. One need not scour the 
history of scientific and technological advancements to recognize the folly of arming students with the content knowledge to "do science" without promoting the development of a moral compass that guides their actions. Arguably, SSI is an ideal vehicle for achieving the NGSS' goals while remedying this shortcoming as it is a framework premised upon a notion of Vision II scientific literacy (Roberts, 2007) that emphasizes contextualized, student-centered science learning as preparation for informed citizenship in an increasingly diverse society. Moreover, SSI's extends its framework to include the promotion of moral development and reflective reasoning as students grapple with the ethical implications of their decisions. This emphasis on “functional scientific literacy” (Zeidler \& Sadler, 2011) compels students toward better moral choices that reflect "internal consistency, respect for multiple perspectives, and tolerance for dissenting voices” (p. 181). As the field of science education seeks effective inclusive, interdisciplinary, sociocultural approaches in curriculum and pedagogy, the importance of SSR, and specifically, perspective-taking abilities becomes critical in the education of K-12 science students and their teachers. A thorough understanding of perspective taking in the context of SSR and a theoretical application of interdisciplinary interventions to promote it will advance the very core of cutting-edge research and practice in science education, foster character and values for global citizenship (Lee, Chang, Choi, Kim, \& Zeidler, 2011; Lee, et al., 2013) and align with visionary science education classroom practice in a manner that amplifies and fills a critical "moral gap" in the NGSS. Further explication of the relationship between the SSI framework, functional scientific literacy, moral development, and perspective taking will be addressed in Chapter 2 . 


\section{Overview of Inquiry Framework}

The choice of method in any study is driven by the research questions (Short, 1991). The focus of the present research is on clarifying a construct that has become what Thomas Green would have likely called a "dead metaphor" (Green, 1971, p. 62) in that it is so overused in conventional speech, we have lost recognition of it even being a metaphor. After all, do we really take another's perspective? The traditional method of analyzing constructs in order to decipher their boundaries and referents is through conceptual analysis (Barrow, 1990; Coombs \& Daniels, 1991; Soltis, 1978; Wilson, 1963). Conceptual analysis is a form of inquiry that challenges the researcher to develop examples, or cases, that help to clarify constructs and distinguish them from related terms. Some examples of educational concepts that have been analyzed through this method include “disciplines” (Neumann, Parry, \& Bescher, 2002), “null curriculum” (Flinders, Noddings, \& Thornton, 1986), “critical thinking,” (Ennis, 1991), “reflection” (Rogers, 2001), and “teaching” (Green, 1971; Komisar; 1968; Smith, 1960).

Scholars use a variety of approaches to conduct their conceptual analyses, including those outlined by Soltis (1978): 1) Generic Type; 2) Differentiation Type; and 3) Conditions Type. Another form of conceptual analysis, called conception development (Coombs \& Daniels, 1991), is designed to develop and defend a conceptual structure. This will allow for the development of a typology and/or a concept map of socioscientific perspective taking to demonstrate a defensible view of the construct by clearly delineating the components, conditions, activities, and characteristics of socioscientific perspective taking. These approaches, as well as their specific application to this study, will be described in more detail in Chapter 3. When these analyses are completed and articulated in Chapter 4, a set of coherent tools will be available for the development of instruments, interventions, and more precise 
understanding of the nature of perspective taking in socioscientific contexts. An example of the utility of these tools will be demonstrated through their theoretical application to perspective taking frameworks from non-science education fields in Chapter 5 , with further implications for science education research and practice addressed in Chapter 6, thus bringing this scholarly investigation full circle from critically analyzing perspective taking in order to clarify its basic understandings and boundaries to synthesizing a new, more precise and contextualized construct that will be utilized to develop meaningful classroom interventions. This breaking down (analysis)/building up (synthesis) pattern is indicative of classical conceptual analysis (Beaney, 2014) and exemplifies the practical utility of an approach often mistakenly considered distant from pragmatic application.

\section{Assumptions and Claims}

As is the case in any research project, this work is based upon several underlying assumptions regarding the theoretical context. These assumptions will not be the focus of argument but rather, will be stipulated at the outset of the project. The key assumptions for this work are as follows:

1) Scientific literacy is a desired goal of science education research and practice;

2) Perspective-taking abilities vary among individuals and can be promoted through intervention;

3) The recognition of perspective taking as a fundamental and desirable human feature by multiple disciplines suggests that knowledge about perspective taking from other fields can inform science educators' research and practice.

However, the following claims delineated in Figure 1 (below) are sequential in nature, and will be developed and argued forming the logic sequence for this project. 
Socioscientific Reasoning (SSR) fosters negotiation of Socioscientific Issue (SSI) and therefore promotes functional scientific literacy

\section{Perspective taking is a component of SSR}

The lack of clarity of the perspective taking construct leads to problems with construct validity and inadequate conceptualizations of perspective taking in socioscientific contexts

Clarifying the boundaries and referents of perspective taking can lead to a model specific to SSR ("Socioscientific Perspective Taking" or "SSPT") which will aid in research and curriculum development

Many non-science fields have developed instruments and interventions for assessing and promoting perspective-taking skills

Theoretical inquiry into the overlaps between these instruments and interventions and SSPT can inform science educators on promising practices and areas for more expansive research in SSI.

Figure 1. Claims addressed in this dissertation

\section{Study Boundaries}

Perhaps equally important as the delineation of study processes and products is an explication of what this research will not do. While conceptual analysis helps educational philosophers to clarify and explicate concept boundaries, it does not portend to develop the definition of a concept. In fact, many philosophers caution researchers from assuming that there can ever be one definition, given the fact that there are a variety of types of definitions, including stipulative, descriptive, and programmatic (Scheffler, 1960, Soltis, 1978). The 
present study, therefore, will not produce a "one size fits all contexts” definition of the construct; rather, it will develop a conception of perspective taking that will allow researchers to operationalize perspective taking within the context of SSR, distinguish it from related constructs, and compare and contrast perspective taking for SSR with perspective taking promoted in other fields.

Of course, another limitation of this study is that it will not produce empirical data regarding the efficacy of the proposed curricular interventions. Rather, this study will lay the theoretical groundwork for extensive future research in that area, as well as broader research in SSI curriculum development and pedagogy and SSR instrument development.

\section{Positionality}

Researchers do not come to their work as blank slates, nor is research conducted in a vacuum. It is, therefore, incumbent upon me to disclose my positionality both in order to provide the reader with a sense of the lens through which I view my work and to strengthen my own awareness of my subjectivities in approaching this study. I consider myself to be a "critical constructivist,” believing that reality has many conceptualizations and that people learn and develop their understanding of knowledge and reality through the interplay between experiences and ideas (Piaget, 1926). Yet I also believe that many of the constructs society develops reflect the presence of hegemony and that it is my responsibility as a researcher and educator to expose those inequities in power and authority (Horkheimer, 1982). These beliefs have had tremendous influence on my teaching as well as my research agenda. As a veteran science educator, I have focused my teaching on encouraging students to engage with a variety of materials, grapple with challenging scientific concepts, and interact with each other, in order to foster understanding of the natural world through experience and discourse. Central to my teaching has been an 
emphasis on co-construction of shared knowledge, a key element of which is argumentation (Zeidler, Osborne, Erduran, Simon, \& Monk, 2003). As a licensed attorney, I frequently utilize my training to guide students through the difficult task of developing logical arguments and thus, it is not surprising that a framework such as SSI which is premised upon dialogic interaction is of particular interest to me. I have also used my legal training to advocate for the environment as well as marginalized groups including women, minorities, and persons with disabilities. Injustice pains me and to that end, I view functional scientific literacy as a conduit of empowerment and critical to a just society. It is my hope that by fostering engagement in science-related issues through the SSI framework, all students, regardless of their propensity toward science as a vocation, will nonetheless recognize and intelligently engage in decisions that tap into scientific understanding and thus promote democratic ideals. Understanding the construct of perspective taking holds particular appeal to me, for I have personally witnessed the social challenges of children with autism who struggle with this skill. Early in my doctoral study, I viewed SSI as a potential intervention for students with autism in order to promote perspective taking. However, after reflecting upon my belief in the social model of disability (Oliver, 1983), I instead thought not of these students as persons in need of "curing," but rather, as guides to how we in science education could promote perspective taking by understanding what has empowered them. For me, perspective taking within the SSI context incorporates tenets of constructivism (e.g., gaining knowledge through interacting with others' viewpoints) and critical theory (e.g., exposing potential inequitable consequences of socioscientific decision making; giving voice to all prospective stakeholders), and therefore, reflects a perfect uniting of logic and emotion, an essential combination for the construction of knowledge (Kincheloe, 2005). 
While I acknowledge that I have strong subjectivities regarding this research, I believe I can begin to "tame" them (Peshkin, 1988, p. 20) first through honest and forthright admission to my readers. A confession, however, is not enough. I intend to provide highly detailed descriptions of my analyses so that their complexities and rationales are evident, thus allowing readers to construct their own understandings. I have also maintained a journal of my perceptions and thought processes throughout the research, which has allowed me to experience, question, and reflect upon my analyses. While these strategies will not free my work from bias, they should provide the reader with ample tools to decide on the quality and trustworthiness of the work for themselves.

\section{Summary}

This introductory chapter advanced the claim that perspective taking is an essential yet tangled construct that has the potential to promote functional scientific literacy if clarified and contextualized within SSR. Moreover, this chapter identified “moral gaps” in the SSR construct and the NGSS which, it is argued, can be filled by clearer explication and targeted intervention of perspective taking particularly in relation to moral development. The following chapter will provide the reader with the substantive grounding to position perspective taking in relation to SSI, moral development, and scientific literacy. 


\section{Chapter 2:}

\section{Literature Review}

\section{Introduction}

The importance of perspective taking to science education and the need for operationalizing the construct can best be understood within a framework of scientific literacy, socioscientific issues, and perspective taking theory. A review of literature in these areas is presented in this chapter to better situate this thesis. The chapter begins by positioning the socioscientific issues framework within contemporary visions of scientific literacy and proceeds by examining the critical role of perspective taking to enacting that vision. Further review of the literature exposes the challenge of operationalizing the perspective taking construct, thus leading to underrepresentation of its critical nature in science education research and practice.

\section{Contemporary Views of Scientific Literacy}

The recently released Next Generation Science Standards (NGSS; NGSS Lead States, 2013) attempt to repair the leaky STEM pipeline in our nation by engaging and maintaining students' interests in science-related issues, while providing them with the content knowledge and practical skills to apply science in their everyday lives. The opening paragraph of the NGSS articulates this goal with the following statement:

There is no doubt that science and, therefore, science education is central to the lives of all Americans. Never before has our world been so complex and science 
knowledge so critical to making sense of it all. When comprehending current events, choosing and using technology, or making informed decisions about one’s healthcare, science understanding is key. (NGSS Lead States, 2013, p.1)

The Framework for Science Education (National Research Council, 2011), upon which the NGSS were premised, clearly foreshadowed an emphasis on the application of science to citizens' everyday lives:

Citizens now face problems from pandemics to energy shortages whose solutions require all the scientific and technological genius we can muster. Americans are being forced to increasingly make decisions_-including on health care and retirement planning —-where literacy in science and mathematics is a real advantage. (National Research Council, 2011, para. 5)

These sentiments echo the National Science Teachers Association's (NSTA) official position statement entitled, “Teaching Science and Technology in the Context of Societal and Personal Issues" (NSTA, 2010) which advocates "that we not only know, understand, and value scientific and technological concepts, processes, and outcomes, but that we are able to use and apply science and technology in our personal and social lives” (para. 2). It is apparent that scientific literacy has emerged as a sweeping concept which encompasses the development of an informed citizenry who are able to consider and negotiate complex science-related societal issues (Roberts, 2007, 2011; Zeidler \& Sadler, 2011). Far from early constructs of science literacy, which involved learning decontextualized, canonical lists of facts, a contemporary view of "functional scientific literacy” (Zeidler \& Keefer, 2003; Zeidler, Sadler, Simmons, \& Howes, 2005) integrates the understanding of science content within the context of real-world socioscientific 
issues (SSI). Understanding how the use of SSI in the classroom promotes functional scientific literacy requires exploration of the SSI framework.

\section{A Route to Functional Scientific Literacy: SSI and SSR}

SSI are controversial, ill-structured social issues that relate to science (Sadler, 2004). SSI are used in the classroom to provide students with issues that are "personally meaningful and engaging to them, require the use of evidence-based reasoning, and provide a context for understanding scientific information” (Zeidler \& Nichols, 2009). Common examples of SSI

studied in the classroom include genetic engineering, the use of animals in research, fluoridation of tap water, and nuclear energy, among many others. Advocates of SSI assert that providing students with contextualized opportunities for argumentation about scientific issues prepares students for participatory citizenship as adults. Unlike other pedagogical approaches that connected science to societal issues, such as Science, Technology, and Society (STS; Yager, 1996), SSI considers students' psychological and epistemological development, as well as the development of character and virtue (Zeidler, 2005; Zeidler, Sadler, Simmons, \& Howes, 2005). Premised on a notion of Vision II scientific literacy (Roberts, 2007) that emphasizes contextualized, student-centered science learning as preparation for informed citizenship in an ever-changing society, SSI extends its framework to include the promotion of moral development and reflective reasoning as students grapple with the ethical implications of their decisions. This "functional scientific literacy" (Zeidler \& Sadler, 2011) is "contextually and culturally sensitive to the needs of the learner” (p. 180) through the use of socially relevant issues selection, and compels students toward better moral choices by placing emphasis on the consequences of their decisions, thus promoting "internal consistency, respect for multiple 
perspectives, and tolerance for dissenting voices” (p. 181). Figure 2 depicts the SSI elements of functional scientific literacy.

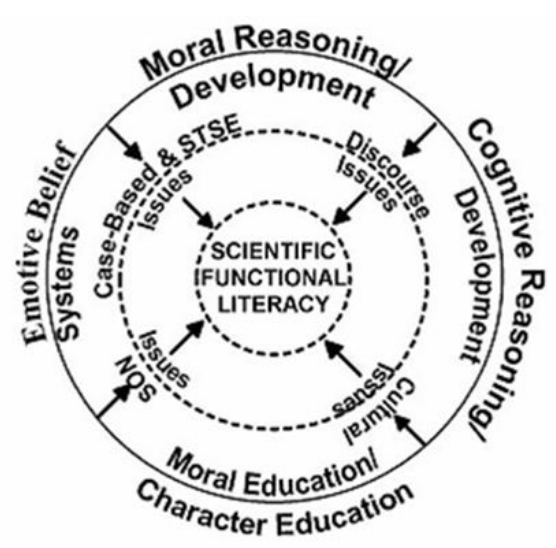

Figure 2. Socioscientific elements of functional scientific literacy. Note. From "The Role of Moral Reasoning and the Status of Socio-scientific Issues in Science Education” by D.L. Zeidler and M. Keefer, 2003, In D. L. Zeidler (Ed.), The role of moral reasoning on socio- scientific issues and discourse in science education, p. 12. Springer and Kluwer Academic Publishers. Copyright 2003. Reprinted with kind permission from Springer Science and Business Media.

The emphasis on considering multiple perspectives stems from a classical, "virtue-ethic" (Zeidler, 2003, p. 24) account of moral reasoning that necessitates discourse and debate in order to allow the players to articulate and clarify values. Virtue ethics has its roots in works by Plato and Aristotle, and essentially asks the question, "What would a good person do in a particular situation?” (Hodson, 2011, p. 201). Virtue ethicists posit that a virtuous life, one guided by pursuit of arête or moral excellence, reaps the intrinsic rewards of eudaimonia, which roughly translates from Greek as happiness and fulfillment (Zeidler, Berkowitz, \& Bennett, 2014). Aristotle identified several moral virtues, such as courage, patience, and compassion, and intellectual virtues, such as wisdom, common sense, and sound judgment. The development of phronesis, or the practical wisdom to act thoughtfully in challenging situations (Hodson, 2011) is of particular import to understanding the relationship between SSI and character development as SSI intentionally challenges students to collaboratively interact with ill-structured dilemmas. 
Productive sociomoral discourse occurs when one student's reasoning influences another's, thus forming transactive discussions that enhance students’ reasoning (Berkowitz, 1997; Zeidler \& Keefer, 2003). Through this discourse, open-mindedness and respect for others' opinions, both desirable scientific habits of mind, are promoted by overcoming students' natural inclination to become entrenched in their own points of view (Zeidler, 1997). By emphasizing the "messiness" of decision-making in real-world issues (Zeidler \& Keefer, 2003) thereby activating cognitive and moral dissonance (Zeidler \& Nichols, 2009), students not only become better prepared to engage in these issues as adults through experiences in negotiation and conflict resolution but may also translate this epistemological orientation to the Nature of Science as well (Abd-ElKhalick, 2006; Sadler, Chambers, \& Zeidler, 2004). Empirical evidence also exists for SSI’s success in mediating argumentation (Chinn \& Brewer, 1993), moral and character development (Zeidler \& Sadler, 2008), moral sensitivity (Fowler, Zeidler, \& Sadler, 2009), as well as cultural perspectives necessary for responsible global citizenship (Lee, Chang, Choi, Kim, \& Zeidler, 2012).

Typical SSI curriculum proceeds by introducing the problem to students, having them identify the parties involved, research the issues, reflect upon their values orientation, engage in discourse with others through debates, role play, in-person or online discussion platforms, and/or writings, and reach a decision or consensus. Students are prompted to question their existing beliefs, collect and examine evidence through multiple research experiences, and develop arguments. They are exposed to different thought processes through discussions, debates, and readings, and are encouraged to, "approach decisions in an open unbiased way, respecting and acknowledging different perspectives, views, beliefs, and other ways of knowing (NSTA, 2010, para. 8). An important aspect of the SSI curriculum is that, although moral/ethical issues are 
integrated, teachers do not instruct students in what to believe but rather, they help students to acquire flexibility, open-mindedness, and perspective taking abilities so that they can integrate content knowledge with emotive, ethical, and intuitive influences. Teachers accomplish this by emphasizing and assessing students' ability to integrate information from a variety of sources, evaluate the quality of those sources, understand the impact of their decisions on others, and reflect upon their own epistemological stances (Zeidler \& Kahn, 2014).

Of particular interest to researchers is the manner in which students reason through SSI scenarios. Sadler, Barab, and Scott (2007) defined the construct socioscientific reasoning (SSR) in order to describe the complex mode of thought required for the negotiation of SSI. In defining SSR as a construct, Sadler and colleagues identify four practices that promote informed decisionmaking in socioscientific contexts: 1) Recognizing complexity within SSI; 2) Incorporating multiple perspectives; 3) Appreciating the ongoing, open-ended nature of scientific inquiry; and 4) Demonstrating skepticism. Insofar as perspective taking is a necessary component of SSR, the authors state, "We suggest that advanced practice should entail the ability to analyse SSI and potential solutions from diverse perspectives and recognize substantive challenges to one’s own espoused position.” (p. 376). The authors' reference to perspective taking makes clear that this skill is essential for sophisticated levels of SSR, yet the definition of perspective taking is not delineated in the text. While one might argue for a prima fascia interpretation of perspective taking, one that simply harkens to seeing other viewpoints, this may be insufficient particularly when one considers the long and tangled history of this complex construct.

\section{Perspective Taking - An Essential Yet Messy Construct}

Perspective taking is an essential skill in human communication and socialization (Batson, 1991; Clark \& Marshall, 1981). It represents one’s ability to grasp the perspectives of 
others thereby allowing for empathy and understanding (Titchener, 1915) and contributing to the resolution of controversy (Corcoran \& Mallinckrodt, 2000). It allows humans to socially construct knowledge by interpreting and reaching agreement on how others think, feel, know and believe (Kraus \& Fussell, 1996). The complexity of perspective taking becomes evident when seen as a dynamic process of "taking another's perspective implies the ability to differentiate the other's view from one's own, and the ability to shift, balance, and evaluate both perceptual and cognitive object input” (Selman, 1971, p. 1722). Selman (1971) utilized Piaget’s genetic epistemological approach to developmental stages of cognitive development as well as Kohlberg's (1968) stages of moral development to conceive of his model for “Coordination of Social Perspectives” in which he maps five stages for perspective taking summarized below in Table 2.

Table 2. Selman’s Coordination of Social Perspectives (Adapted from Selman, 1981)

\begin{tabular}{|l|l|}
\hline Stage & Description \\
\hline 0: Undifferentiated & $\begin{array}{l}\text { Recognition of self vs. others, but frequently confuse perspectives. Low reflective } \\
\text { interpersonal understanding. } \\
\text { “'Initial level of failure to clearly differentiate between the social (i.e., intentional) } \\
\text { perspectives of self and others" }\end{array}$ \\
\hline $\begin{array}{l}\text { 1: Social } \\
\text { Informational }\end{array}$ & $\begin{array}{l}\text { Different perspectives come from different information } \\
\text { “Comprehends that another person's subjective thoughts, feelings, and intentions are distinct } \\
\text { from the self” (early childhood) }\end{array}$ \\
\hline 2: Self-Reflective & $\begin{array}{l}\text { Can reflect on how another may view them; can take the other's point of view. } \\
\text { "that the other person can reflect upon and consider as distinct the self s subjective } \\
\text { attitudes, feelings, and motives (middle childhood)" }\end{array}$ \\
\hline 3: Third-Person & $\begin{array}{l}\text { Can reflect on how a third party may view both self and another } \\
\text { "That self and other can view self s and other's psychological points of view mutually and } \\
\text { simultaneously. (preadolescence)" }\end{array}$ \\
\hline 4: Societal & $\begin{array}{l}\text { Can reflect on how society as a whole may influence individuals' perspectives } \\
\text { “general integrated social viewpoint that transcends individual perspectives and involves } \\
\text { a mutual understanding of deeper psychic processes within and between } \\
\text { persons(adolescence)" }\end{array}$ \\
\hline
\end{tabular}

Like Piaget and Kohlberg, Selman suggests that children proceed through a series of qualitative levels, which each level moving the child away from an egocentric to a multipleperspective stance. Each level builds upon the prior one so that the earlier skills are retained, a theory was supported empirically through longitudinal studies (Gurucharri \& Selman, 1982). 
Selman (1977) theorized that levels of perspective taking were "necessary but not sufficient” (p.

4) for achieving parallel levels of moral development, a sentiment that was empirically supported by Walker (1980) who utilized interview instruments of both Kohlberg and Selman to substantiate this conclusion. Martin, Sokol, and Elfers (2008) extended and revised Selman's model to reflect a more "holistic" approach to perspective taking that integrates, "perceptual, affective, cognitive, intentional, and experiential dimensions” (p. 313). The authors embedded Selman's model in the second of three overarching stages: Pre-reflective Interactivity (infant/toddler), Reflective Intersubjectivity (integrates all five of Selman’s levels), and metareflective sociality (including “idealized” communal problem-solving and “dialogical engagement” defined as being open to all positions and creative solutions). This taxonomy overlaps with the levels of reflective thinking delineated in the Reflective Judgment Model (RJM) (King \& Kitchener, 1994), which describes the progression of individual's decisionmaking through ill-structured problems as they move through increasingly reflective stages. Of particular note is that both models share a common definition of reflection, which refers to the ability to construct knowledge based on one's own assumptions and evidence while remaining open to new perspectives and revaluation. The higher levels in all models also exhibit decentering (Piaget, 1926) meaning movement away from egocentric interpretations of one’s interactions to more inclusive ones. This evolution of self towards others and society is a foundational element of the SSI framework and its emphasis on moral development (Zeidler, 2003).

In addition to being foundational for moral development, perspective taking is also a key condition for argumentation, a process that reflects the manner in which the practice of science proceeds (Latour \& Woolgar, 1986), prompts externalization of reasoning (Kuhn, 1992), and 
enculturates students into scientific discourse (Duschl \& Osborne, 2002). Argumentation, whether utilized to evaluate scientific claims or debate SSI, necessitates the ability to ground one’s positions with claims, warrants, and rebuttals (Erduran, Simon, \& Osborne, 2004; Toulmin, 1958; Walker \& Zeidler, 2007). In assessing the quality of argumentation, Sadler \& Donnelly (2006) and Erduran, et al. (2004) emphasize the ability of students to build rebuttals to propel their arguments as they require the incorporation of multiple perspectives (Simonneaux, 2008) a skill that is particularly challenging yet indicative of higher order argumentation. Arguments that require students to become cognizant of others' perspectives not only facilitate persuasive debate but also promote cognitive development and logical thinking (Johnson \& Johnson, 1979). Häkkinen and Järvelä (2006) demonstrated that higher level conversations about educational issues in an online environment, characterized by the inclusion of theories, questions, new points, and examples, were associated with higher levels of perspective taking using Selman’s framework. Research on perspective taking, therefore, suggests an intertwining with argumentation and moral development such that moral reasoning may arise out of discourse and argument (Zeidler \& Sadler, 2008), and both argument and moral reasoning are dependent on the existence of perspective taking. Yet as fundamental as perspective taking is to social communication, argumentation, and moral reasoning, it is surprisingly fraught with numerous sources of error in the way that people assess others' views.

\section{Barriers to Perspective Taking}

One of the barriers to accurate perspective taking is referred to as the "egocentric assumption of shared perspectives” (Fenigstein \& Abrams, 1993, p. 287) which refers to people's tendency to assume that others see, feel, and know as they do. Overcoming this default setting in the human mind requires “executive inhibition” (Perner \& Lang, 1999, p. 338), or the 
ability to suppress one’s own perspective, and “cognitive flexibility” (Ruby \& Decety, 2003, p. 2475) which combines executive control with the need to distinguish self and other's thoughts. Finally, mental simulation, or the ability to make sense of others' mental processes by simulating them in ourselves, has been proposed as also necessary to give a complete picture of another's perspective (Perner,1998). Saxe (2005) suggests the addition of "explicit reflective mediation" (p. 178) along with simulation, to create a hybrid theory that explains people's ability to mirror scenarios in their mind while also reflecting on theory to form their understandings of others. The reflection necessary to remain open to others' perspectives can be particularly challenging when one's own perspectives are deeply rooted. Specifically in the context of science, barriers to perspective taking take the form of resistance to anomalous data (Chinn \& Brewer, 1993) in order to protect prior beliefs. Studies have demonstrated that when students are presented with arguments (alternative perspectives) contrary to their core beliefs, the more entrenched they become in them. (Chinn \& Brewer, 1993; Zeidler, 1997; Zeidler, 2002).

All of these challenges inherent to perspective taking have not dissuaded researchers and educators from trying to foster this essential skill. Successful interventions for promoting perspective taking have reaped tremendous benefits including higher intelligence and understanding, increased problem-solving abilities, stronger social skills, and less impulsivity (Viladarga, 2009). Interventions in scientific argumentation and authentic decision-making on SSI have also increased students' abilities to consider multiple perspectives (Erduran, Simon, \& Osborne, 2004; Ibáñez-Orcajo \& Martínez-Aznar, 2007; Lee et al., 2013; Tal, Kali, Magid \& Madhok, 2011). And although once thought to be the domain of early child development, studies on brain neuroplasticity now indicate that the portions of the brain responsible for perspective-taking tasks continue to grow at least throughout childhood, adolescence, and young 
adulthood (Blakemore \& Chouhoudry, 2006; Goldstein, Wu, \& Winner, 2010), adding to the impetus to promote perspective taking through intervention. Yet while neuroscientists debate the mechanics of perspective taking at the cellular level, with some attributing it primarily to mirror neurons (Rizzolatti \& Fabbri-Destro, 2010) and others to shared neural activations (Lamm \& Majdandzic, 2015), the biggest challenge to successful interventions remains the question of what exactly perspective taking means, particularly in the context of science education.

\section{Contributions of This Study to the Literature on SSI and Perspective Taking}

Lack of clarity regarding perspective taking exists within the field of science education as evidenced by the array of measures of perspective taking including the number of different “reasoning modes” students utilize (Wu \& Tsai, 2007, p. 1172), the extent to which one considers diverse opinions and imagines oneself in another's situation (Lee, et al., 2013), whether arguments represent personal, societal, or global concerns (Lee, Chang, Choi, Kim, \& Zeidler, 2012), one’s ability to formulate counterpositions and rebuttals (Sadler \& Donnelly, 2006), and the ability to conceptualize a problem beyond one's own personal framework (Sadler, Barab, \& Scott, 2007). The impact of this lack of clarity in the perspective taking construct becomes particularly underscored when studies relate to, but do not specifically focus on perspective taking. For example, Zeidler, Berkowitz, and Bennett (2014) have called for scientifically responsible thinking through the development of character, a construct that appears to relate to perspective taking by requiring consideration of the consequences of one's actions on others; however, the precise nature of the relationship between character development and perspective taking remains unclear. Similarly, research on moral sensitivity in the context of SSI (Fowler, Zeidler, \& Sadler, 2009) suggests some overlap with perspective taking in that moral 
sensitivity requires one to be "attuned to the feelings and reactions of others" (p. 281). Yet, we are still left wondering whether moral sensitivity, character development, empathy, and so on, are precursors, products, or simply other names for perspective taking. Clarification of perspective taking is therefore necessary to fill significant gaps in the literature by explicating the boundaries and referents of perspective taking, distinguishing it from related constructs, examining its contextual requirements, and positioning it squarely within the SSR construct.

Lack of clarity in the perspective-taking construct is also evidenced by the fact that some authors utilize perspective taking interchangeably with related constructs including theory of mind (ToM), role taking, and empathy (Baron-Cohen \& Wheelright, 2004; Demurie, De Corel, \& Roeyers, 2011; Taylor, Cartwright, \& Bowden, 1991) while others do not (Coke, Batson, \& McDavis, 1978; Davis, 1983). ToM is often used to describe one’s ability to understand another's mental state, which includes their emotions, desires, and intentions (Baron-Cohen \& Wheelright, 2004). Empathy, on the other hand, has been described as an affective response that essentially mirrors another’s feelings (Eisenberg, 2000). Role taking (Mead, 2009; Franks, 2013) involves assessing what others are (or may be) thinking and then attempting to experience the other's circumstances for themselves. As is the case in science education literature, it is not clear whether these constructs, frequently used across the social sciences, are synonymous with, subconstructs of, or prerequisites for perspective taking. Some of the most extensive research on perspective taking is found in special education literature as lack of perspective-taking skills is associated with autism, a spectrum disorder characterized by deficits in communication and socialization (Heflin \& Alaimo, 2007). Autism intervention frequently focuses on helping students to develop awareness and understanding of what others know, think, or believe (BaronCohen, Leslie, \& Frith, 1985). Yet the question of whether interventions successfully used to 
foster perspective taking in this population could be applied to socioscientific contexts to promote SSR remains unanswered since lack of specificity in the construct leaves doubt as to whether we are even trying to foster the same skill set. Clarifying the construct of perspective taking will allow science educators to determine whether the interventions and instruments from special education, as well as other disciplines, warrant further examination and perhaps adoption.

\section{Summary}

This examination of the literature on SSI, SSR, perspective taking, and scientific literacy highlighted both the evidence of perspective taking's importance to science education as well as the confusion surrounding its operationalization. Moreover, this review suggests that lack of clarity of the construct may cause researchers and practitioners to underrepresent the true nature of perspective taking in the context of SSR, particularly in regard to moral development. The following chapter will discuss the manner in which conceptual analysis may be used to remedy these situations by bringing greater clarity and utility to the perspective taking construct, thus making it ripe for more targeted interventions and investigations. 


\section{Chapter 3:}

\section{Methodology Statement}

\section{Introduction}

While much research has been conducted on perspective taking both within and outside the SSR context, no studies have critically analyzed or developed its definition. Rather, studies seek ways to promote it without ever reaching agreement as to what "it" is. This phenomenon is not unique to perspective taking, as social scientists are reputed for interpreting concepts for which they have not yet examined use or meaning (Coombs \& Daniels, 1991). In order for a concept to be measureable, some agreement must be reached as to the definition and understanding of that concept, thus ensuring construct validity (Cronbach \& Meehl, 1955). Clarity in definition is also necessary for developing theories and frameworks around that construct (Bozeman \& Feeney, 2007). Yet one might wonder why simply consulting a dictionary isn’t sufficient for garnering a definition. Gorovitz and Williams (1965) point out that dictionaries describe how words are used, but not their meanings. As a specific example, the authors point to a dictionary definition of "beautiful" that describes an object as "having beauty" or "positive aesthetic merit” (p. 77), yet these definitions bring us no closer to the meaning of beautiful; they are imprecise and circular. Hence, operationalization is necessary when precision is required. Yet not every concept requires operationalization. In their analysis of null curriculum, Flinders, Noddings, and Thornton (1986) suggested criteria for whether a concept was suitable for operationalization for empirical study, positing that: 
If a term is involved in empirical claims such as "Individualization secures desirable outcomes of the kind X," then that term should be suitably operationalized for empirical research. If, on the other hand, a writer sets out to describe a set of methods generally referred to as "intuitive" or a set of exercises that might be given over to students for exploration and possible "discovery," there seems to be no compelling reason to define these terms unambiguously. Indeed, to do so would be to diminish their power to evoke imaginative thinking. (p. 39)

Given that claims regarding students’ perspective taking abilities revolve around measureable outcomes such as increased empathy, argumentation quality, and the like, perspective taking appears to be a suitable concept for operationalization. In order to operationalize perspective taking, a form of philosophical inquiry known as “conceptual analysis” will be applied. Conceptual analysis describes a set of techniques which philosophers use to clarify meanings and boundaries of concepts to promote understanding and support future research (Coombs \& Daniels, 1991; Soltis, 1978; Wilson, 1963). Philosophical forms of inquiry, rather than empirical studies, are particularly useful when trying to identify the underlying conceptual structure of arguments and justifications as, "what is often seen as a straightforward empirical matter is often fraught with problems that are philosophical in nature—unclear concepts, questionable assumptions about verification of conclusions, naive ideas about social facts and reality, and above all, unexamined notions of an educational practice” (Pring, 2004, p. 162). Yet the use of conceptual analysis to clarify concepts is not without its detractors. While advocates argue that the use of thought experiments, intuitions, and the like are standard procedures in philosophy (Bealer, 1998), viewing philosophical inquiry as primarily an a priori discipline (Jackson, 1998), 
critics, many of whom are associated with the naturalist tradition (Papineau 1993, Kornblith 2002), view philosophy as more aligned with science and its emphasis on evidence and a posteriori knowledge. This debate about the nature and sources of knowledge is perhaps among the most contentious in modern philosophy (Margolis \& Laurence, 2014) yet conceptual analysis remains a cornerstone in philosophical inquiry. As the present study utilizes conceptual analysis as its methodology, the following sections will attempt to provide the reader with sufficient grounding to position conceptual analysis in a historical context and provide some structure for what is a quite fluid and creative endeavor.

\section{History and Models of Conceptual Analysis}

It is perhaps surprising that the roots of conceptual analysis are often attributed to Socrates and his student, Plato, even though neither ever utilized the term. The word "analysis" is derived from the ancient Greek term, "analusis” which roughly means "loosening up" or “dissolution” (Harper, 2014). In ancient Greece, the term was used to mean solving a problem in geometry or philosophy. Socrates' interest in understanding definitions through analysis influenced both Plato, who incorporated it into his method of division, and Aristotle, who applied it in analytics (Beaney, 2014). The early Greeks used an approach referred to as a regressive conception of analysis, whereby they worked backwards by assuming that what was sought was true, and then used the elements that supported that structure to work back to the original question through a process called, synthesis, much the same way that geometric proofs are performed. This approach remained dominant until the scientific revolution of the seventeenth century, which brought with it an emphasis on decompositional analysis (Riffert, 2012). Descartes’ Discourse on Method (1637/1968) described four rules typically used in decompositional analyses for understanding and adding clarity to issues: 1) Base truth upon 
evidence; 2) Divide issues into as many parts as possible; 3) Examine them from the smallest to the largest; and, 4) Examine them completely so that nothing is left unexplained. The influence of this decompositional approach to conceptual analysis is still evident today in the Oxford Dictionary of Philosophy which defines 'analysis' as “the process of breaking a concept down into more simple parts, so that its logical structure is displayed” (Blackburn, 1996, p.13). While decompositional analysis prevailed through the eighteenth and nineteenth centuries, the turn of the twentieth century brought philosophers including Frege and Russell who introduced a more interpretive, or transformative conception; that is, a belief that concepts needed to first be situated within a theoretical framework or translated into some format before they could be subject to further analysis (Beaney, 2014). This approach is much akin to the manner in which geometric shapes are translated into algebraic terms before they are solved in analytic geometry. Together, decompositional, regressive, and transformative approaches are used today to derive meaning from concepts through a set of techniques referred to as conceptual analysis.

Conceptual analysis is a method of analyzing constructs in order to decipher their boundaries and referents (Barrow, 1990; Coombs \& Daniels, 1991; Soltis, 1978; Wilson, 1963). It is a form of inquiry that challenges the researcher to develop examples, or cases, that help to clarify constructs and distinguish them from related terms. Scholars use a variety of techniques to conduct their conceptual analyses, including those outlined by Soltis (1978): 1) Generic Type; 2) Differentiation Type; and 3) Conditions Type. These are discussed below, along with another form of conceptual analysis, called conception development (Coombs \& Daniels, 1991), which is designed to develop and defend conceptual structures. It should be noted that scholars don't typically designate their analyses as belonging to one of these types; rather, these techniques are utilized in rather elegant and imaginative manners, or sometimes in blended ways, to derive a 
claim or a conclusion. In this light, conceptual analysis procedures are much like the techniques an artist might use to paint a picture, such as chiaroscuro, pointillism, or spattering; these elements may be identifiable within the completed work yet the work is gauged by the overall effect. Thus, while exemplars of specific techniques will be noted in the following section, the works themselves were at best identified by the authors as simply conceptual analyses, not as specific types of analysis. Therefore, to some extent, the categorizing of exemplars into specific models is somewhat artificial, as elements of more than one type may be present in a given work.

Generic-type conceptual analysis. A generic type of conceptual analysis is used to identify the necessary and sufficient conditions of a concept. Essentially, this type of analysis determines what features $\mathrm{x}$ ( $\mathrm{a}$ case under consideration) must have to be called an $\mathrm{X}$ (a generic example of a concept). Soltis (1978) describes the steps of a generic-type analysis as follows:

1. Select standard or model cases, as well as contrary cases of X;

2. Draw necessary features from standard cases;

3. Test for necessity and sufficiency by using examples and counterexamples;

4. Keep, modify, or reject the features on the basis of the tests.

Wilson (1963) expanded on the use of cases to include borderline, or fuzzy cases that don't quite fit the model case of a concept yet aren’t contrary cases, or non-examples either, as well as invented cases, which are not within our lived experiences yet allow us to test the boundaries of concepts beyond the limits of reality. The products of this type of analysis are the generic features of X. Soltis (1978) provides the following graphical depiction (Figure 3 on page 35) of the "target" or product of a generic analysis, where the letters "a," "b," and "c" represent the generic features of $\mathrm{X}$ : 


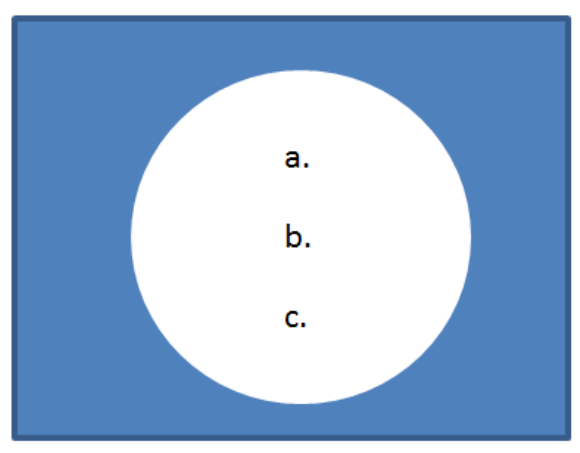

Figure 3. Generic features of X derived from generic-type analysis (Soltis, 1978).

A very simple example of a generic-type analysis could be used to determine what is meant by the concept of a "bird.” The prior question we are trying to answer is what features must an animal have to be called a bird? To answer this, we would first draw upon our general knowledge of model cases of birds to identify possible necessary features such as: (1) A bird must have wings. Next, we would test this feature for necessity by asking whether we can think of a bird that doesn't have wings. If not, then having wings is a necessary condition of being a bird. While wings may be a necessary condition of being a bird, we need to test for sufficiency by the use of contrary cases or counterexamples. Since flies, butterflies, and bats all have wings and are not birds, we know that having wings is not sufficient for the concept of a bird. We would then need to consider other distinguishing characteristics such as having a backbone, or vertebrae. The test for necessity would be, can we think of a bird that isn't a vertebrate? If not, then being a vertebrate is a necessary condition of being a bird. To test for sufficiency, we ask can we can think of an animal that is a vertebrate with wings that isn't a bird? Ah, those pesky bats! Bats also satisfy these conditions, and they are not birds, so these conditions are not yet sufficient for being a bird. What about feathers? Since we can’t think of any birds without feathers (at least those that haven’t been plucked!), feathers are a necessary condition for birds. 
And if we are unable to think of a vertebrate that has wings and feathers that isn't a bird, we may have identified the necessary and sufficient conditions for being a bird. Of course, we would continue this logical process until all necessary and sufficient features of birds are identified. To aid us in ensuring a complete analysis, we could test the margins of our analysis by considering cases that meet our conditions yet still are somewhat odd. For example, emus and penguins meet all of our criteria for birds, yet they are unusual because they don't fly. Is flight a condition of being a bird? Clearly, flight isn’t a necessary condition of being a bird as we are all familiar with the fact that these feathered friends are birds nonetheless. Yet they are funny examples of birds in the sense that, if a person who had never seen a bird asked, “Can you show me a bird?” you would be reluctant to use penguins or emus as examples as they are not model cases of birds in the way sparrows or finches are. These birds on the edge of bird-ness are what philosophers would call borderline cases as they meet the necessary conditions yet are still somehow misfits. In fact, penguins and emus are such misfits that they are often referred to specially as "flightless birds” to call attention to their atypical grounded lives. By focusing on the conditions that make these borderline cases different from model cases, we can more specifically refine our concept of what is and isn't necessary for a complete concept of a bird. A related technique is to ensure that the absence of our necessary conditions leads to a contrary case of a bird. In our analysis, we would look at invertebrate, wingless, featherless animals to see if there is any way that they could be construed as birds. Since snails, jellyfish, earthworms, and other spineless creatures could never be considered birds, they meet the criteria as contrary cases as they clearly represent, conceptually speaking, the absence of bird-ness. One last permutation of case analysis is to consider examples that are not within our lived experience, so-called invented cases that help us to further clarify our concepts. In the case of birds, we could imagine biologists on a remote 
island discovering an animal that has a vertebrae, wings, and feathers, but also has fur and teeth. Would such an animal be classified as a bird? Would we need to reevaluate our conditions? By examining invented cases, we gain clarity in our understanding of actual cases.

Generic-type conceptual analyses have been used by many scholars to clarify concepts in education. The following excerpt from Ayer's (1956), The Problem of Knowledge, provides a flavor of generic analysis as the author grapples with the definition of knowledge: The first requirement is that what is known should be true, but this is not sufficient; not even if we add to it the further condition that one must be completely sure of what one knows. For it is possible to be completely sure of something which is in fact true, but yet not to know it. The circumstances may be such that one is not entitled to be sure. For instance, a superstitious person who had inadvertently walked under a ladder might be convinced as a result that he was about to suffer some misfortune; and he might in fact be right. But it would not be correct to say that he knew that this was going to be so. He arrived at his belief by a process of reasoning which would not be generally reliable; so, although his predication came true, it was not a case of knowledge. Again, if someone were fully persuaded of a mathematical proposition by a proof which could be shown to be invalid, he would not, without further evidence, be said to know the proposition, even though it was true. (p. 33-34)

Ayer uses this line of reasoning through necessary and sufficient conditions to determine that knowledge requires that: 1) a proposition is true; 2) a person is sure that the proposition is true; and 3) a person has the right to be sure that a proposition is true. Fenstermacher (1994) later 
applied Ayer's analysis to operationalize teacher performance knowledge by examining cases of knowing how and knowing that:

Consider the example of my claiming to know how to play bridge. In making this claim, I am also asserting that I know that hearts and spades take precedence over diamonds and clubs, I know that a one no trump bid overrides a one spade bid, and so forth. It may equally be true that the knowing-that/knowing-how connection works in the other direction, such that we cannot know that without knowing how. For example, to know that all electrical outlets in my home supply a 115-volt current, I have to know how to use a voltmeter (or know how to read the scale of a voltmeter operated by someone else I follow around the house). There is also the question of how much knowing that we could have in the way of scientific information without the knowing how of scientific methods. The point to be made here is that, apparently, one cannot opt for performance knowledge without also understanding that one has "acquired" propositional knowledge in the bargain, and vice versa. (p. 27)

It is interesting to note that both of these examples demonstrate the characteristic use of familiar scenarios (e.g., superstitious people, bridge playing, and home circuitry) to test the boundaries of concepts in order to arrive at their necessary and sufficient conditions.

Wilson (1963) adroitly utilized borderline cases when analyzing the meaning of the word, "punishment" when he queried:

Suppose a child touches an electric wire which he has been told is dangerous, and then gets a shock: is the shock 'punishment'? It has some features in common with model cases of punishment, but perhaps not enough: we then look to see 
which is the important feature that is missing. Is it perhaps that there is no person who gives the punishment? Then we might think of the case when we talk of a boxer 'taking plenty of punishment": are we serious in using the word 'punishment' here, or are we using it as a metaphor? Then what about someone like Macbeth in Shakespeare’s play, who acted wickedly and suffered for it - can we say that 'he brought his own punishment upon himself'? Or is this also a metaphor? (p. 31)

Wilson uses these borderline cases to highlight the nuances between them and more definitive uses of the word "punishment" in order to gain clarity on what features make model cases true models.

Differentiation-type conceptual analysis. Unlike a generic analysis, a differentiation type of conceptual analysis asks not “what are a concept's general features?” but instead asks, “what are the different basic meanings of X?” In other words, this technique seeks to differentiate between the different uses of a term. In this way, we are able to develop a schema to distinguish between different types of $\mathrm{X}$. To perform this type of analysis, the researcher would:

1) Search for dominant use of the concept $X$ through examples;

2) Classify or categorize the uses into types;

3) Search for distinctions to classify the types;

4) Test the typology developed with examples and counterexamples.

A graphical depiction of this target, or product, is shown in Figure 4 on page 40, where the numbers “1,” “2,” and “3” represent three different types of X: 


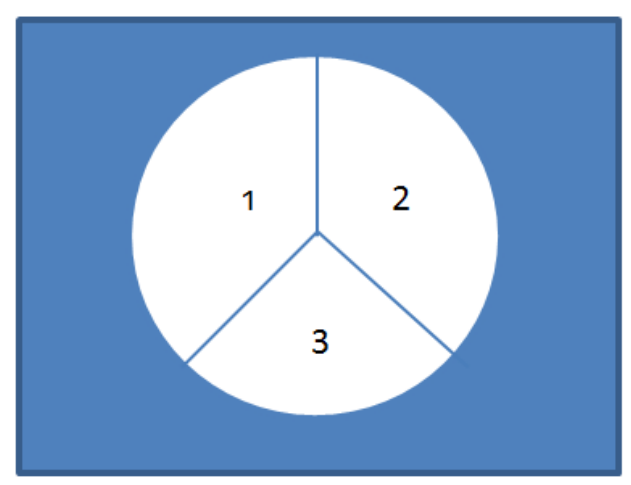

Figure 4. Types of X derived from a differentiation-type analysis (Soltis, 1978)

Continuing with our earlier animal classification exercise, instead of asking what the generic features are of birds, we might wonder to what sorts of creatures the word "birds" commonly refers. If we fail to do this, communication would certainly be hampered given that one person's conception of a bird would mean ostrich while another's might mean sparrow. In order to examine the distinguishing characteristics among the uses of the word, "bird," we would think about examples, such as wrens, cardinals, puffins, ducks, chickens, and emus, and begin to intuitively develop useful patterns based on common characteristics. For example, we might notice that some birds are aquatic, others sing lovely songs, and some simply taste good! We could continue to group and regroup our categories until we developed a classification system, or typology, of the use of the word, birds.

In perhaps one of the most compelling differentiation-type analyses, Green (1964) examines the concept of teaching by considering the distinctions between teaching, training, and instructing, ultimately deriving a topology or spectrum of teaching activities. To arrive at this schema, Green utilizes the case of teaching a dog tricks:

Nonetheless teaching and training are not identical. Training is only a part of teaching. There are contexts in which it would be a rank distortion to substitute the one concept for the other. For example, it is more common, and perhaps more 
accurate, to speak of training an animal than to speak of teaching him. I do not mean there is no such thing as teaching a dog. I mean only that it is more accurate in this context to speak of training. We can, indeed, teach a dog to fetch, to heel, to point, and to pursue. There is in fact a common saying that you cannot teach an old dog new tricks. The use of the word "teaching” in each of these cases has its explanation. It has to do with the fact that that the actions of a trained dog are expressive of intelligence; they involve obedience to orders. Indeed, a welltrained dog is one which has passed "obedience trials.” ... Instruction must also be included in the family of activities related to teaching...For example, it is acceptable, and even correct, to speak of teaching a dog to heel, to sit, or to fetch. It is, however, less acceptable, more imprecise, and perhaps even incorrect to speak of instructing a dog in sitting and fetching. (p. 286-288)

Green's analysis using the case of dog training led him to focus on elements of indoctrination, conditioning, and belief systems to develop a continuum of the teaching concept as shown in Figure 5 below.

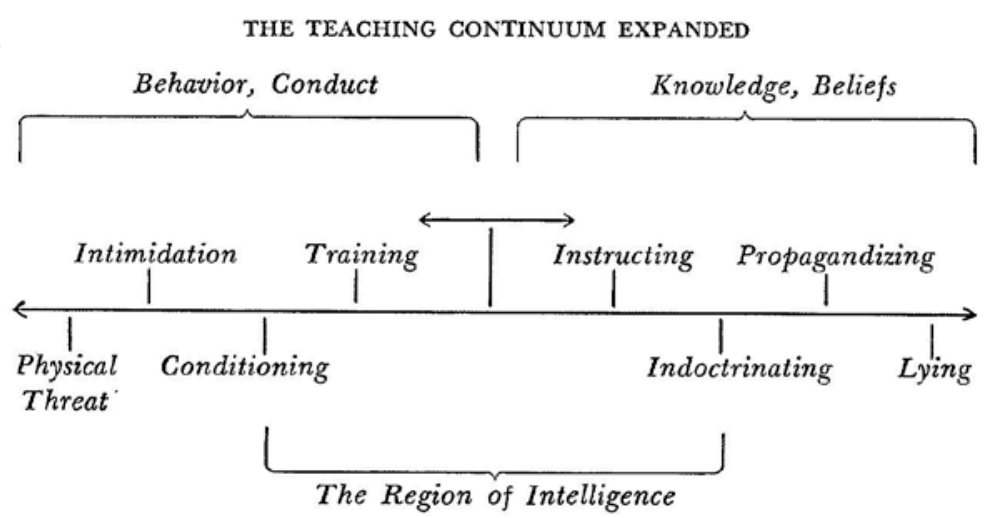

Figure 5. The teaching continuum. Note. From “Typology of the Teaching Concept” by T. F. Green, 1964, Studies in Philosophy and Education, 3(4), p. 292. Springer. Copyright 1964. Reprinted with kind permission from Springer Science and Business Media. 
Conditions-type conceptual analysis. A conditions-type of conceptual analysis asks yet a different question from both generic and differentiation-type analyses. In a conditions-type analysis, the researcher is interested in answering, "what context conditions govern the use of X?” This approach is used to understand concepts where model cases are particularly unclear and the researcher is interested in identifying the conditions required to properly use the concept. For example, while the concept of "bird" may have been fairly straightforward insofar as finding model examples of birds and non-birds, the concept of "flying" might be more challenging, given the range of uses such as soaring through the air like a bird, traveling in an airplane, or as a result of mind-altering drugs! To fully understand the use of the term, "flying," we need to understand the conditions that make it feasible in whichever case we use. A conditions-type conceptual analysis follows the following general format:

1) Identify good candidates for necessary conditions of $X$;

2) Alter the context to find an example where the condition holds, but $X$ is not present;

3) Revise the condition to meet the context problem or tease out a new condition;

4) Test the necessity and sufficiency of all conditions.

The product of a conditions-type analysis can be depicted in Figure 6, with letters “a,” "b,” “c,” and "d" representing context conditions for X, as follows:

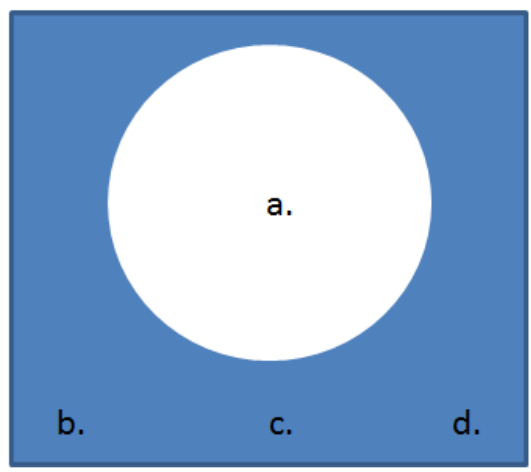

Figure 6. Context conditions of X derived from a conditions-type analysis (Soltis, 1978) 
In the flying example, one could begin by asserting that a necessary context condition of flight is boarding an airplane. Of course, it is possible to be onboard an airplane (i.e., the “airplane condition”) yet not be flying, perhaps while it is taxying or waiting for a gate. Therefore, the airplane condition is not sufficient for flight. To fulfill the status of flying, a plane must also leave the ground, an action that requires several additional context conditions (e.g., aerodynamic lift, propulsive thrust, etc...) that we might call the "physics conditions." We would then question whether the airplane condition and the physics conditions combined formed sufficient conditions for flight. While one might believe these conditions to be sufficient, an interesting twist to consider is whether a material object can be said to be flying under these conditions. For example, if baggage is loaded on an airplane that leaves the ground, is the baggage flying? If not, then perhaps one might say that in the context of flying on an airplane, a "living condition" is also required such that the conditions that need to be met are: 1) Airplane condition; 2) Physics condition; and 3) Living condition. Yet this begs the question of whether a plant or a pig on an airplane can be said to be flying? And of course, we have yet to consider the non-airplane contexts for flight. Clearly, this type of analysis demands careful scrutiny of various contexts, yet the payoff is a lucid understanding of a concept's contextual dimensions. Soltis (1967) utilized conditions-type analyses to clarify the contextual dimensions of visual perception, specifically, “seeing.” The author began his analysis as follows: We may begin with the question, what minimally must one know to be able to visually recognize or identify something? Obviously, one need not know the object's name or label or anything else about it. He need only know what it looks like, or put another way, he must possess a perception recipe for the object. Passing by a shop window, one can recognize the odd-looking object there as the 
same one (or similar to the one) he saw as he passed the window yesterday. He need not know what its appropriate name or label is nor anything else about it, just as a witness to a murder could identify the murderer without knowing his name. Basically then, recognition and identification involve the possession and proper utilization of knowledge of the looks of a thing, but need not involve any further knowledge about the thing seen... The reverse side of this coin is interesting to examine from the point of view of education. Suppose, for instance, that one did indeed know (has learned) a lot about combustion, but was unable to visually recognize an instance of combustion whenever he came upon one. The knowledge he does possess would be blocked from use because he fails to possess the basic knowledge of a perception recipe. (p. 88)

Soltis (1967) continued by considering the logical conditions for using the word, "seeing” to include not only the ability to view with one's eyes, but also to be able to perceive, since objects may not be too distant to be within one’s visual field, and also to discriminate between things that are seen, such as snakes and wires. Additionally, he posited that flexibility in the interpretation of things that are seen is a condition for successful "seeing," so that, for example, one might recognize that a necktie can be “seen” as a tourniquet in an emergency. Ultimately, the author identified a variety of contextual circumstances that lead to either correct or false beliefs related to visual perception and discussed their implications for educators and psychologists.

Conception development. A conception development (Coombs \& Daniels, 1991) formulates new concepts by modifying or restructuring aspects of existing conceptual structures. It is a process that seeks to remedy shortcomings in existing conceptions in order to make them 
more usable in guiding curriculum development either by making them less vague, reducing dichotomies, or systematically organizing concepts that were previously loosely related. Some conceptions specify descriptive criteria, such as Hirst’s (1974) conception of liberal education, while others categorize related sets of phenomena, such as Bloom's (1956) conception of cognitive development. There are no standard procedures for conception development, but Coombs and Daniels (1991) recommend the following guidelines:

1) Be clear about the problem the conception is being developed to solve;

2) Preserve the core meaning of the original concepts’ usage;

3) Use conceptual analysis of constituent words (such as "liberal" and "education" for the concept of liberal education) when deriving conceptions of technical terms;

4) Provide solid justifications for believing that the new conception is superior to the existing conceptions.

In the earlier example regarding birds, a generic conceptual analysis led us to interpret current conceptualizations of birds as having necessary conditions such as feathers and backbones. But what if it is determined that animals previously thought to be reptiles were actually bird-like, yet don’t quite fit current conceptualizations of birds? Dinosaurs, for example, were initially believed to be reptiles (Gk. deinos, “fearfully great,” plus sauros, “lizard”), yet many appear to have traits such as warm-bloodedness, nesting and brooding behaviors, feathers, and other specific anatomical features that lead the scientific community to consider today’s birds to be living dinosaurs, or at the very least, close cousins. Might a new conception of birds be needed to fully appreciate the diversity of this class of animals? Arguably, a new taxonomy of birds would be helpful to understand the relationships between living and extinct species. This 
type of reconceptualization formulated in order to address an inadequacy in current understandings of a concept is precisely the goal of conceptual development.

One of the most widely cited scholarly examples of conception development is Ennis’ (1991) conception of critical thinking. In it, the author reflects upon his participation as a juror on a murder trial to consider the mental processes expected of the jurists, which he determined involved twelve "dispositions" and sixteen "abilities.” Some of the dispositions included attributes such as clarity, focus, and precision, while the abilities included items such as induction, deduction, observation, and argument analysis. To provide a flavor for the manner in which the author utilizes his experience to derive his conception, the following description of "argument analysis" as a critical thinking ability is offered:

The written murder charge made it easier for us to analyze the prosecutor's argument for murder, but we still needed to be able to see how the parts fit together. We had to be able to see that each of the three major conditions was a necessary condition, and that the prosecutor had to show this. When the defense attorney was arguing that none of the six conditions for the second necessary condition had been proved beyond a reasonable doubt, we had to be able to pick out this conclusion, and see how it bore on the total charge for murder. And we had to be able to see that he was trying to show that since the blow was only of moderate force, it had not been proved beyond a reasonable doubt that the defendant knew that there was a strong probability of great bodily harm. (p. 15) Ennis (1991) artfully weaves through his memories of the jury deliberations to ultimately develop a taxonomy of attributes and skills that together provide a cohesive structure for what were previously considered loosely-related concepts. Moreover, his analysis created the 
foundation for measures of critical thinking, as the dispositions and abilities he identified together formed the basis for operationalization of the concept and evaluation of existing assessment tools (Ennis, 1993; Facione, 2000; Ku, 2009).

The various techniques and goals of conceptual analysis just discussed are summarized in Table 3. The section immediately following describes how these techniques will be applied in the proposed study.

Table 3. Summary of Conceptual Analysis Techniques

\begin{tabular}{|l|l|l|}
\hline Technique & Question & Intended Result \\
\hline Generic-Type & $\begin{array}{l}\text { What features must } \mathrm{x} \text { have to } \\
\text { be an X? }\end{array}$ & $\begin{array}{l}\text { A clearer idea of what is essential to being } \\
\text { an X. }\end{array}$ \\
\hline $\begin{array}{l}\text { Differentiation- } \\
\text { Type }\end{array}$ & $\begin{array}{l}\text { What are the different } \\
\text { meanings of X? }\end{array}$ & $\begin{array}{l}\text { A clearer idea of the logical terrain covered } \\
\text { by different meanings of a concept. }\end{array}$ \\
\hline Conditions-Type & $\begin{array}{l}\text { Under what context } \\
\text { conditions would it be true to } \\
\text { say that X is present? }\end{array}$ & $\begin{array}{l}\text { A clearer idea of the contextual dimension } \\
\text { of a concept's meaning }\end{array}$ \\
\hline $\begin{array}{l}\text { Conception } \\
\text { Development }\end{array}$ & $\begin{array}{l}\text { How can X be modified to } \\
\text { make it a more usable } \\
\text { concept? }\end{array}$ & $\begin{array}{l}\text { A modification or restructuring of X's } \\
\text { existing conceptual structures. }\end{array}$ \\
\hline
\end{tabular}

\section{Study Design}

This study will incorporate each of the conceptual analysis techniques discussed in the prior section to analyze and synthesize concepts of perspective taking for SSR. Generic conceptual analyses identify the necessary conditions of a concept by developing model, contrary, and borderline cases and testing for necessity and sufficiency of the features of each. In the present study, generic analysis will identify the necessary and sufficient conditions of perspective taking. Differentiation conceptual analyses are used to develop the distinctions between related concepts by examining the dominant uses and meanings of them. In the present study, this analysis will help to distinguish perspective taking from related constructs such as 
empathy and role-taking. Conditions conceptual analyses are used to identify the context conditions that govern the use of the concept. This analysis will allow for a methodical study of perspective taking within the context of SSR in order to identify the necessary and sufficient contextual conditions for socioscientific perspective taking. Finally, since conception development modifies existing conceptual structures, this process will be utilized to develop a new conception of perspective taking specific to SSR (i.e., SSPT) based on the results of the above analyses.

There are, of course, other methods besides conceptual analysis that can be used to determine the manner in which constructs are used. Hermeneutic analysis (Gadamer, 1977; Smith, 1991), for example, would provide an understanding of the meanings of perspective taking in their common usage in text or conversation. This type of analysis, however, would not provide us with the boundaries and referents, but rather, would help us to understand how perspective taking is understood by its users. While this would yield insights into the many ways perspective taking is used within and across disciplines, it would fail to clarify the construct for operationalization, which is a central aim of this study. Similarly, a meta-synthesis (Finfgeld, 2003) could provide insight into the manner in which perspective taking is defined in various studies, since meta-synthesis does with qualitative data what meta-analysis does for quantitative data. However, a meta-synthesis would fail to give guidance as to the conditions under which perspective taking is used appropriately, nor does it allow for the clarification between related constructs. Therefore, a meta-synthesis would fail to adequately address the research questions. Because the focus of this research is specifically to analyze and clarify the construct of perspective taking, conceptual analysis fits squarely within the form of inquiry needed in order to address RQ 1 (“What are the boundaries and referents of perspective taking?") and RQ 2 (“What central role does perspective taking play in the exercise of SSR?”). 
Insofar as RQ 3 (“What frameworks from other disciplines can inform curriculum development and research to promote socioscientific perspective taking [SSPT]?”), a theoretical inquiry to compare the constitutive and structural concepts that relate perspective taking in the context of SSR with the frameworks of other disciplines will provide researchers and curriculum developers with the basis for novel and expansive work in SSI. At this time, no such undertaking relating these frameworks has been published. The "product" of this inquiry will be an assessment of the potential usefulness of these related frameworks as sources of interventions and instruments to promote and measure perspective taking for SSR. In addition, specific examples of such interventions and instruments will be contextualized into the SSI framework so that researchers and practitioners alike can explore their efficacy. As theoretical inquiry seeks to develop the relationships between components within and among curricular frameworks (Grove \& Short, 1991), this is the appropriate choice of inquiry to address this research question. The three non-science frameworks selected (historical empathy, method acting, and autism intervention) each focus on enhancing perspective-taking abilities and are supported by extensive research. Social studies educators use historical empathy (Foster, 2001) to help students and teachers appreciate the perspectives of various historical figures. According to Lee and Ashby (2001), historical empathy challenges students to "know what past agents thought, what goals they may have been seeking, how they saw their situation, and connect all this with what they did” (p. 24). Implementation of historical empathy requires examination of multiple sources of evidence and perspectives including students’ own perspectives (Foster, 2001). Method acting (Verducci, 2000) is a group of techniques used in theater education to stimulate authentic performances by encouraging actors to create in themselves the thoughts and emotions of their characters. Based on the early teachings of Russian actor and director Constantin Stanislavski (1936) and promoted by New York actor and director Lee Strasberg, “The Method” utilizes 
exercises that cause actors to draw upon their own backgrounds, including their memories and emotions, and apply them to their characters (Carnicke, 2008 ). Research suggests that it is also a viable set of tools for cultivating empathy offstage (Verducci, 2000). Finally, as mentioned earlier, special educators utilize interventions to promote perspective taking for students with autism as the ability to understand others' thoughts and beliefs is particularly challenging for this population (Heflin \& Alaimo, 2007). Approaches such as video modeling, whereby students view perspective-taking scenarios in which actors explicitly describe their problem-solving strategies, have been shown to significantly increase students' perspective-taking abilities in more generalized social situations (Charlop-Christy \& Daneshvar, 2003). The emphasis on perspective taking in these three disciplines begs the question of whether their successful strategies would transfer effectively to the socioscientific context. These frameworks hold particular promise as curricular sources for analysis in the proposed study due to the extensive body of research supporting them, as well as the fact that they represent a wide range of disciplines and student populations. It is believed that this diversity will provide the researcher with a variety of approaches to perspective taking intervention, thus strengthening the findings and creating a model that transcends any particular framework. And unlike frameworks in professional fields such as management science (Boland \& Tenkasi, 1995) and nursing (Lobchuk, 2006), where perspective taking is also extensively studied, the three disciplines selected for this study are mainstays in K-12 curriculum, thus increasing the likelihood of transferability.

Some might ask whether it would be more efficacious to take the newly-operationalized construct of SSPT and develop and test instruments for its measurement or assess its presence in a classroom. While these are highly worthwhile endeavors, and both clearly representative of the type of work that can follow a conceptual analysis, it is the contention of the researcher that the 
concept of perspective taking must first be clearly examined, contextualized in SSR, and presented to researchers and practitioners in a manner that transcends specific grade levels and classrooms and provides the groundwork for much wider investigation and application.

Moreover, this research is intended for immediate use for practitioners; the examination of existing curriculum frameworks in light of a newly developed perspective taking construct will provide practitioners and action researchers with specific examples of readily-usable interventions that can be evaluated. Most importantly, it is hoped that this dissertation itself can become a metaphor for perspective taking; after all, if common ground can be found between disparate fields by demonstrating respect and understanding of different theoretical approaches, is advocating for a more comprehensive view of perspective taking in the context of SSR that incomprehensible? Shouldn't this work demonstrate the kind of open-mindedness, flexibility, and awareness of different perspectives that is sought for our students? It is hoped that this work answers the call for social science researchers to analyze and reconceptualize assumptions (Wachtel, 1980) in order to provide theoretical grounding that would strengthen empirical studies and allow for more creative and expansive work.

\section{Research Process}

The research process diagram depicted in Figure 7 (See page 52) outlines the major processes associated with the present research. The research proceeds in a sequence aligned with the research questions, beginning with RQ 1 . The analyses associated with each research question will build upon prior analyses and will culminate in the development and evaluation of perspective taking interventions from non-science education fields (RQ 3). More specifically, the research begins with the conceptual analysis of perspective taking, which yields the generic and SSR-specific conditions of the construct, as well as the distinctions between it and related 
constructs. The results of these analyses are then utilized to develop a new construct specific to SSR called, SSPT, which will be portrayed as a concept map or typology, depending on the analyses outcome. The new construct will then be applied to three non-science frameworks via theoretical inquiry in order to identify promising interventions and instruments.

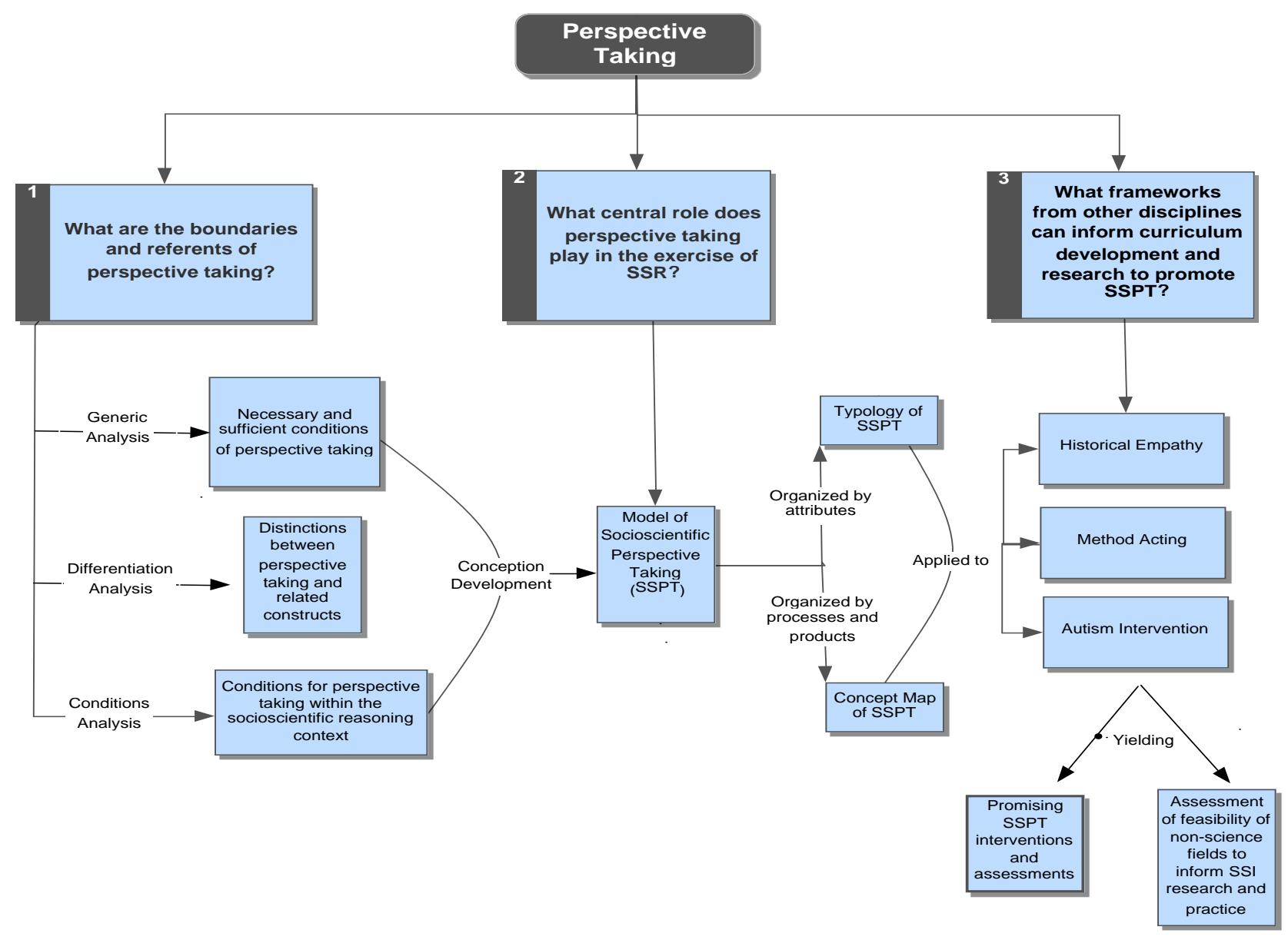

Figure 7. Research Process Map 


\section{Research Challenges and Solutions}

A challenge in fully describing this research is the emergent nature of conceptual analysis, the results of which form the foundation for the remainder of the work. Just as an empirical researcher may be unsure of the choice of statistic or graphical representation of their work at the outset, it is unclear whether the results of the conceptual analysis will yield findings that are more compatible with a typology or a concept map of SSPT, or both. If the conceptual analysis of perspective taking yields attributes or dimensions that are consistent with a classification scheme for perspective taking activities, then a typology (Gilbert \& Boulter, 2000) of SSPT will be developed. If, on the other hand, the conceptual analysis yields attributes that are most closely aligned to the processes, procedures, and products between the SSPT components, then a concept map (Ausubel, 1968; Novak, 2000) would be more appropriate. If both classification and processes are attainable through the conceptual analysis, both a typology and concept map of SSPT will be developed.

Another challenge of the conceptual analysis is developing cases that will help to analyze perspective taking without the use of educational jargon and perhaps not even using education as the context, at least initially. While this may seem counterintuitive, many educational philosophers insist that the concepts being analyzed use cases that do not use education as the context because educators have tremendous preconceived notions of the terms that often differ quite substantially from their everyday usage (Coombs \& Daniels, 1991; Noddings, 2012). Soltis (1978) gives a powerful example of this in his conceptual analysis of the term "discipline" and its varied uses by educators and laypeople. Because the purpose of conceptual analysis is to distill language down to its most basic parts, the cases must be those that can be understood by non-educators using everyday language. Thomas Green (1964), as discussed earlier, utilized the 
context of teaching a dog tricks to distinguish between the terms, "teaching," "training," and "instructing" to eventually arrive at a topology of teaching premised upon belief systems. In some of his other works, he uses economics as a context for his cases (Green, 1988). Similarly, Ennis (1991) utilized a jury’s deliberation as the source of his cases for his conceptual analysis of critical thinking. Once the necessary and sufficient conditions were identified, they were applied to the educational context. While the precise contexts of the cases for this conceptual analysis have not yet been identified, the key will be to develop scenarios that lead to logical, commonsense outcomes.

Insofar as the second part of the dissertation is concerned, the use of perspective-taking frameworks from non-science disciplines to inform science education through theoretical inquiry runs several risks. As Czerniak (2007) pointed out when examining interdisciplinary curriculum, there are both theoretical and practical obstacles to merging science with other disciplines. Specifically, those unique attributes that distinguish disciplines can become displaced or overshadowed when merged (Lederman \& Niess, 1997). Moreover, non-science disciplines may reflect such different epistemologies and paradigms that combining the research or interventions may prove difficult. For example, McGinnis and Stefanich (2007) pointed out that the special education's roots in behaviorism contrast starkly with contemporary science education's emphases on cognitive and sociocultural approaches, thus making the development of research and practice in science for students with disabilities challenging. The same challenges may emerge as the research on perspective taking in autism education is related to perspective taking in SSR. In order to ensure that the integrity of science as a distinct discipline is protected, and to ensure that the unique attributes of the different disciplines are respected, the researcher will remain cognizant of the differences, including historical, epistemological, and paradigmatic, between disciplines and will be vigilant in ensuring that any curricular frameworks or 
interventions devised through this analysis retain an emphasis on science theory and practice. This will in part be accomplished by providing the reader with extensive background on the curricular frameworks and providing detailed, transparent analyses. In addition, overlaps between disciplines will not be "forced;" if perspective taking in the context of SSR is qualitatively different from the perspective taking promoted in the other disciplines, it will be pointed out and superficial connections will not be created if the underlying frameworks seem incompatible. It is strongly believed, however, that even if the selected frameworks are not compatible, this result will inform the field in much the same way that an empirical study demonstrating that an intervention was not effective provides necessary information to the field. In short, we will not know until we try, but the results will nonetheless be valuable. In reviewing the research on literacy in science (Yore, Bisanz, \& Hand, 2003), it is worth noting that while language arts educators' emphases on fluency and remediation differed from science educators' emphases on vocabulary comprehension and argument generation, interventions from language arts were nevertheless transferable to science learning contexts because the underlying skills were the same. Moreover, the emergent field of learning sciences (Sawyer, 2006) is premised upon the notion that a variety of disciplines can contribute to the understanding of deep, underlying skills and conditions associated with learning.

\section{Criteria for Judging Study Completion and Quality}

In any study, the criteria for determining “what is enough?” is critical as there is always more literature to review and more analyses to be undertaken. Identifying the characteristics of a completed study is perhaps most critical in an emergent approach such as the conceptual analysis proposed here, since the "data” are limited only by one’s intellectual abilities and creativity. In reviewing the scholarly work from this form of inquiry, certain themes emerge and may inform 
us as to clues for completion. Based on the researcher's review of leading scholars' indicators of quality conceptual analyses (Coombs \& Daniels, 1991; Green, 1971; Soltis; 1978;Wilson, 1963), the following criteria to determine completion will be utilized:

1) When examples of multiple "cases" are articulated and lead naturally to a common-sense conclusion as to the boundaries and referents of perspective taking;

2) When a clear and logical framework is developed for distinguishing between perspective taking and related constructs;

3) When a rational and precise model of socioscientific perspective taking (SSPT) that clearly reflects the relationship between PT, SSR, and moral development is proposed;

4) When the model for SSPT is applied to non-science education curriculum frameworks in such a way as to provide transparency of analysis and convincing evidence of the feasibility (or lack thereof) of these frameworks as promising sources for science education research and intervention on SSPT.

In sum, the proposed standard not unlike the "clear and convincing" evidentiary standard used in law, which is often described as evidence that suggests an argument is "substantially likely" (Legal Information Institute, n.d.). This standard is less rigorous than the "beyond a reasonable doubt" standard used to validate a criminal conviction, but more than "a preponderance of evidence" which is used in civil cases. It is a standard that requires exceptionally clear logic and substantial supporting evidence so that the jury finds the argument sufficiently persuasive to support the party advancing it. It is believed that this is an appropriate standard for the researcher (as well as the reader or "jury") to employ to assess completion. While there may not be consensus on every piece of "evidence," the overall "case" should be supported by lucid analysis and compelling scholarship. 


\section{Summary}

This chapter served as an introduction to conceptual analysis, a methodology with a venerable history and considerable contemporary application in educational research. While not often used in science education, it is hoped that this chapter presented a coherent and compelling rationale for applying conceptual analysis to the thorny problem of how to operationalize the construct of perspective taking within SSR. Like any methodology, conceptual analysis has its limitations; this work will neither produce empirical data nor will it develop a one-size-fits-all definition of perspective taking. Rather, conceptual analysis will be used to develop a more precise definition of perspective taking within the SSR context. The results of this conceptual analysis will be used to inform theoretical inquiries into three non-science curricular frameworks with extensive research bases in perspective taking, thus laying the groundwork for entirely new areas of research in the field of SSI, providing a model for interdisciplinary scholarship, and immediately influencing classroom practice in science education. 


\section{Chapter 4:}

\section{Conceptual Analysis of Perspective Taking}

\section{Introduction}

If one were to ask a layperson to define perspective taking, the response would probably be something like, “seeing something from another person’s viewpoint.” But what is meant by “seeing?” Is perspective taking limited to perception? Moreover, if perspective taking simply means seeing another’s viewpoint, why don’t we say, “perspective seeing” or even “perspective sharing,” rather than perspective taking? Is there significance to the taking in perspective taking? And how does perspective taking compare to related concepts of role taking, ToM, and empathy, each described in Chapter 2? Conceptual analysis can provide answers to these questions by illuminating the underlying values imbued in language, in part through close inspection of the words involved and through examination of closely related concepts.

The merit of this type of analysis is that it allows for deeper and more precise understanding of language. To illustrate this, imagine that one wished to understand the concept of a "dog;” one could simply define it as a four-legged animal. But one could also consider the conditions that distinguish a dog from a cat or a deer, both of which are also four-legged animals. One could also examine different breeds of dogs, from Great Danes to Chihuahuas, to begin to recognize common features of dogs. Finally, one could examine phrases such as “dogs are man’s best friend” and "puppy dog eyes” to begin to understand the deep affinity humans hold for dogs, or conversely, note the import of context in the insult, "He is such a dog!" simply by examining 
the usage in everyday, accessible contexts. These calisthenics propel us to find meanings and assumptions within concepts rather than settling for simplistic single definitions.

To that end, this chapter begins with a generic analysis of perspective taking that is designed to lead us to the necessary and sufficient features of perspective taking through examination of model, borderline, invented, and contrary cases (Wilson, 1963). Next, we will engage in a conditions analysis of perspective taking that is designed to expose concealed values embedded in this construct in order to better understand its usage specifically in the context of SSR. We will then perform a differentiation analysis that will tease out the fine distinctions between perspective taking, role taking, empathy, and ToM in order to determine the boundaries and referents of each. Finally, we will re-assemble the necessary and sufficient conditions for perspective taking through conception development in order to devise a precise perspective taking construct specifically within the context of SSI.

This journey will promote clearer articulation of what we wish to accomplish through SSI in regard to perspective taking, and will prepare us for more precise examination and critical assessment of perspective taking interventions explored in later chapters. But first, we begin with a generic analysis of perspective taking by utilizing a most familiar and (hopefully) engaging source for our cases...leading characters in motion pictures!

Table 4. Summary of Conceptual Analysis Techniques Utilized in this Chapter.

\begin{tabular}{|l|l|l|l|}
\hline Technique & Prior Question & Page \# & RQ Addressed \\
\hline Generic-Type & $\begin{array}{l}\text { What are the necessary and sufficient conditions } \\
\text { for perspective taking in a generic context? }\end{array}$ & p. 62 & RQ 1 \\
\hline Conditions-Type & $\begin{array}{l}\text { Under what context conditions would it be true to } \\
\text { say that perspective taking is occurring in SSR? }\end{array}$ & p. 70 & RQ 2 \\
\hline Differentiation-Type & $\begin{array}{l}\text { How can perspective taking be distinguished from } \\
\text { related concepts of ToM, empathy, and role } \\
\text { taking? }\end{array}$ & p. 78 & RQ 2 \\
\hline Conception Development & $\begin{array}{l}\text { How can the concept of perspective taking be } \\
\text { restructured to more accurately describe usage } \\
\text { within SSR? }\end{array}$ & p. 91 & RQ \\
\hline
\end{tabular}




\section{Cinematic Saints to Psychopaths - Generic and Conditions Analyses of Perspective Taking \\ Generic Analysis of Perspective Taking. In order to identify the necessary and}

sufficient conditions for perspective taking in a generic context, we begin by thinking about model cases that epitomize our vision of perspective taking, or more accurately, are model perspective takers. Given that most of us have ventured to the movies, or at least viewed Netflix or other cinematic sources at some point in our lives, it would seem logical that motion pictures would provide fertile grounds for identifying characters that might exhibit some aspects of a universal human trait such as perspective taking as envisioned in its most commonly understood "I know it when I see it" meaning. One possible model perspective taker that comes to mind is Mahatma Gandhi, a bigger than life leader brilliantly portrayed on the big screen by actor Ben Kingsley in the movie, Gandhi (Attenborough, 1982). The movie biography traced the life of Mohandas Karamchand Gandhi who dedicated his life's work to causes on behalf of the poor, women, and all Indians, regardless of religion or social class. Although born to an affluent family and trained as a lawyer, Gandhi eschewed material wealth and instead lived modestly among the poor rather than maintaining his social caste. Numerous scenes in the movie show Ghandi leading non-violent protests for equality, as well as many acts of solidarity with others such as taking the place of servants in order to serve tea to dignitaries, riding the trains through India in third class just to better understand the life of India's common people, and spinning thread for cloth which not only incited non-cooperation with the British by supporting Indianmade goods, but also showed that he was not below work that was traditionally held by women. He also undertook fasts to express his commitment to the Untouchables who were acutely impoverished. In one of the most powerful scenes of the movie, Gandhi, a devout Hindu, addresses a crowd declaring, "I am a Muslim and a Hindu and a Christian and a Jew and so are 
all of you” (Gandhi, 1982). In another moving scene, a fasting Gandhi is approached by a Hindu Indian who confesses that he believes he will go to hell for killing a Muslim child. When Gandhi asks why he killed the child, the man tells him that it was in retaliation for them killing his son. Gandhi, in a weak yet confident tone states, I know a way out of hell. Find a child...a child whose mother and father have been killed. A little boy about this high. And raise him as your own. Only be sure that he is a Muslim, and that you raise him as one (Gandhi, 1982). In sum, Gandhi is portrayed as one who didn't simply fight for others' causes, but saw others' causes as his own. He not only sought out commonalities among people, but inspired them to find commonalities among each other... a feat that earned him the title of "Mahatma" or "great souled” (Saka, 2006).

If we think about the behaviors and attributes that made Gandhi a model perspective taker, we might first consider his engagement with people and the issues that impacted them. Gandhi sought out people, always with an eye toward connecting with and understanding them. While Gandhi could have easily turned away from those in need, he desired engagement with others. But is engagement a necessary condition for perspective taking? To answer this question, we need to consider whether we can envision a good perspective taker who didn’t engage with the subject of their perspective taking. This question seems almost a bit ludicrous, as it would seem to be implausible to be a perspective taker without even the slightest hint of engagement with those whose perspectives one would take. Even if one perspective takes from afar, without direct interaction, there would still need to be some moment of engagement; a point at which the perspective taker says, "I’m going to take a moment and think about another." Can we ever imagine saying, "Gandhi was a wonderful perspective taker although he never 
noticed people?” I think not. Yet if we agree that perspective taking requires at least some level of engagement with others, is that enough? Is engagement sufficient for perspective taking? Can we think of a case where engagement with others is present but perspective taking is absent? A character with many similarities to Gandhi is Atticus Finch from the movie, To Kill a Mockingbird (Pakula \& Mulligan, 1962), based on Harper Lee’s novel of the same name. In the movie, Atticus, played by Gregory Peck, is a white southern lawyer who, like Gandhi, is deeply committed to fairness and equity. He takes on a case to defend a black man named Tom Robinson who is accused of raping a white teenage girl, an act that brings the level of racism in the small town to light. The young protagonists of the movie are Atticus' children, Scout and Jem, who undergo transformations in light of their father's advocacy efforts. In one particularly tender scene, Atticus explains his decision to defend Tom Robinson to his children by saying, "You never really understand a person until you consider things from his point of view ... until you climb into his skin and walk around in it.” (To Kill a Mockingbird, 1962). These words seem to capture Gandhi's attempts to live as others lived and put himself into their circumstances. Yet, as admirable as Atticus' words were, one must ask whether he was really able to practice what he preached. In one of the final scenes of the movie, it is learned that a reticent character named Boo Radley (played by Robert Duvall) protected the children from an attack by the drunk father of the allegedly raped girl. Upon learning that Boo had protected his children, Atticus suggests to the sheriff that the highly introverted Boo be publicly recognized for his courage. The sheriff, however, perceptively states that it would be "a sin" to force a shy man like Boo into the spotlight. And it is Atticus' young daughter Scout who suggests that her father's idea would “sorta' be like shootin’ a mockingbird, wouldn’t it?” referring back to her father's admonition against shooting birds that do no harm. While Scout and the sheriff both 
seemed to be able to perceive the situation from Boo's viewpoint, Atticus did not. In essence, although Atticus had tremendous engagement and compassion for others, and worked to defend their rights, his young daughter and the sheriff better understood Boo’s perspective. Similarly, in one of the most emotionally wrenching scenes in the movie, Atticus meets with his client, Tom Robinson, after Tom is found guilty of the rape by an all-white jury notwithstanding compelling evidence showing the crime to be implausible due to Robinson's physical disability. Yet even in light of these frustrating circumstances, Atticus vehemently encourages his client to appeal to the higher all-white court, a prospect understandingly deemed futile by Robinson, who later that night attempted a hopeless escape from prison and was shot. While Atticus can reasonably be viewed as a passionate advocate, perhaps an eternal optimist and indomitable cheer leader for what is good and right, he nonetheless was unable to see the futility of Tom Robinson's situation. Was it Atticus' naiveté that interfered with his ability to appreciate Robinson's viewpoint, or was it that, like most of us, he assigned his own desires or views on others, without stopping to think whether their thinking truly represents that of their subject. In a sense, although unquestionably an admirable and heroic character, Atticus is revealed as a borderline case of perspective taking, as he certainly connected with the interests of others and spoke of climbing into their skin, yet it appears that his own passion and perhaps naiveté at times get in the way of seeing what the other needs. Instead, like most of us, he projects upon others rather than seeing themselves as others. While both Gandhi and Atticus were portrayed as men having high integrity, social commitment, and genuine interest in understanding others, Gandhi engages in a behavior that seems necessary for perspective taking, one that Atticus Finch alluded to but was unable to fully activate; that is, his ability to take on an insider view of other's circumstances. Gandhi was able to position himself in the mindset and circumstances of others, both physically, by living and working as a 
poor person, and emotionally, by understanding and feeling their plight in a manner that resonated with them. In sum, both Gandhi and Atticus Finch had genuine desires to engage with others and their circumstances. Yet engagement alone is not sufficient, as we see that the ability to shift one's mindset from outsider or "etic" to insider or "emic" seems to also be a necessary condition.

Having established the importance of a shift in viewpoint for perspective taking, one might wonder whether our initial determination that engagement with others as a necessary condition might simply be due to the fact that one can't shift viewpoint without engagement. In other words, is it possible that engagement with other's circumstances is simply part and parcel of assuming an insider's viewpoint? Might there only be one necessary condition, that of a shift in viewpoint? To answer this question, we need to consider whether we can think of a perspective taker who can shift their viewpoint yet not be a model perspective taker. Answering this question will clarify whether engagement and shift are separate necessary conditions and if so, is a shift in viewpoint sufficient in and of itself.

Consider the character of Michael Dorsey played by Dustin Hoffman in the Academy Award winning motion picture, Tootsie (Evans \& Pollack, 1982). In this movie, Hoffman portrays a struggling actor who is notorious for being temperamental and difficult to work with. Out of sheer desperation, his character, Michael Dorsey, auditions for a female role in a soap opera under the pseudonym, Dorothy Michaels. Upon getting the role, Hoffman must maintain his female persona outside of work and finds himself becoming a role model for women who admire his strong-willed, female character. Through the movie, Hoffman struggles with the fact that, although he is literally in a woman's shoes, he is a man who only cares about role playing a woman for the sake of keeping his job but doesn't really connect with his female persona or 
other women until late in the movie. Yet eventually, in the final scene, after his love interest, Jessica Lange, learns that her friend Dorothy is really a man, Hoffman (as Michael Dorsey) states, "I was a better man with you as a woman than I ever was with a woman as a man" (Tootsie, 1982). Dorsey’s realization that he only was able to engage in a meaningful way with women while playing a woman suggests that perspective taking requires both engagement and an etic/emic switch. Yet Dorsey is clearly not a model perspective taker in the way Gandhi is, as he lacked any genuine interest in engaging with the character whose perspective he took. Instead, he is revealed as a borderline case of perspective taking through most of the movie, one who does take on an emic viewpoint by living as a woman, but without a desire to engage with or understand his female character.

Are the two conditions outlined above, engagement with others and an etic/emic shift, sufficient for perspective taking? In order to answer this question, we need to envision a case where these attributes are lacking and determine whether such a case is a "non-example" or contrary case of perspective taking. A cinematic character who seemed to lack these attributes was "Raymond Babbitt," the character that won Dustin Hoffman an Oscar in the movie, “Rainman” (Guber \& Levinson, 1988). Raymond was the autistic brother of Charlie Babbitt, played by Tom Cruise, and was characterized by a detachment from other people, lack of concern for others, and was oblivious to the needs and feelings of others. In the movie, Raymond maintains his obsession with his television-watching and eating schedule even when it causes tremendous stress for his brother. And while he had savant-type skills in terms of visual memory and calculation, he is unable to initiate basic interactions with others and shows no understanding of others' feelings or circumstances. This would seem to represent a most dramatic and contrary case of perspective taking and in fact, it could reasonably be stated that 
Raymond had no interest in engaging with others and no ability to shift viewpoints. Ironically, one could argue that his brother Charlie Babbitt, although not autistic, was also a contrary case of perspective taking early in the movie, as he is portrayed as a self-involved Yuppie who was simply attempting to use Raymond for his personal financial gain. Through much of the movie, Charlie also showed no interest in understanding the world from Raymond's viewpoint, a situation which caused him tremendous frustration, when for example, he can't understand why Raymond has to watch “Judge Wapner” at a particular time each day, or why Raymond won’t board a plane because he remembers every instance of air disasters. Yet the movie portrays a transformation in Charlie as one who becomes more compassionate and genuinely understanding of his brothers' needs and mindset, ultimately allowing him to make the unselfish decision of allowing his brother to stay in an institution where he is comfortable while promising to visit regularly with no selfish motives.

Our initial analysis of perspective taking through cinematic characters suggests that perspective taking, in its generic usage, has two necessary and sufficient conditions: 1) Engagement with others and their circumstances; and 2) An etic/emic switch in viewpoint. The manner in which these conditions were arrived at are outlined in Table 5 below.

Table 5. Generic Analysis of Perspective Taking Characters

\begin{tabular}{|c|l|l|l|l|}
\hline Character & Synopsis & Engagement? & Shift? & Case Type \\
\hline Mahatma Gandhi & Advocates for and & Yes & Yes & Model \\
Gandhi (1982) & $\begin{array}{l}\text { lives among the } \\
\text { poor and } \\
\text { disenfranchised, } \\
\text { does “women's } \\
\text { work" in show of } \\
\text { solidarity, sees } \\
\text { himself as Hindu, } \\
\text { Muslim, Christian, } \\
\text { and Jew. }\end{array}$ & & & \\
& & & & \\
& & & & \\
\hline
\end{tabular}


Table 5 (Continued)

\begin{tabular}{|c|c|c|c|c|}
\hline $\begin{array}{l}\text { Atticus Finch } \\
\text { To Kill a Mockingbird (1962) }\end{array}$ & $\begin{array}{l}\text { Advocate for } \\
\text { justice and } \\
\text { minority rights; } \\
\text { makes personal } \\
\text { connections with } \\
\text { African American } \\
\text { client; talks about } \\
\text { "walking in others' } \\
\text { shoes” but doesn't } \\
\text { quite "get” Tom } \\
\text { Robinson or Boo } \\
\text { Radley. }\end{array}$ & Yes & No & Borderline \\
\hline $\begin{array}{c}\text { Michael Dorsey/Dorothy Michaels } \\
\text { Tootsie (1982) }\end{array}$ & $\begin{array}{l}\text { Lives as a woman } \\
\text { solely for the purposes } \\
\text { of getting an acting } \\
\text { job; learns about } \\
\text { female point of view } \\
\text { through experiences } \\
\text { but does not connect } \\
\text { with "Dorothy" I was } \\
\text { a better man with you } \\
\text { as a woman than I } \\
\text { ever was with a } \\
\text { woman as a man." }\end{array}$ & No & Yes & Borderline \\
\hline $\begin{array}{l}\text { Raymond Babbitt } \\
\text { Rain Man (1988) }\end{array}$ & $\begin{array}{l}\text { Autistic brother of } \\
\text { Charlie Babbitt. Has } \\
\text { brilliant savant } \\
\text { characteristics } \\
\text { including memory } \\
\text { recall and calculation } \\
\text { but is indifferent to } \\
\text { connections with } \\
\text { others or their needs. }\end{array}$ & No & No & Contrary \\
\hline
\end{tabular}

While these features are required for perspective taking in its generic usage, we will now consider whether there are additional conditions that might exist that are relevant to our study of perspective taking in relation to SSR.

Conditions Analysis of Perspective Taking. Our generic analysis has suggested that perspective taking requires engagement with others and a shift from outsider to insider view as 
necessary and sufficient conditions for perspective taking in a generic context. But are they sufficient within the context of socioscientific reasoning? Perhaps the answer can be illuminated through conditions analysis. A conditions analysis asks us to consider under what context conditions would it be true to say that perspective taking is present within our specified context. At first glance, our generic analysis seems on target for application within the context of SSR for after all, what more could we ask than to have Ghandi-esque attributes in our students as they negotiate SSI? It's not far-fetched to envision an invented case of a student who, when confronted with a socioscientific dilemma, readily connects to an issue and the stakeholders involved, and then is naturally able to emotionally, intellectually, and perhaps even physically position herself as one of them. To illustrate how this might play out in a classroom, let's imagine for a moment that a high school biology class has just learned about gene therapy, or the use of genetic engineering in newly fertilized human eggs, to eliminate certain genetic traits from a population. The hypothetical class, including a sophomore named, "Sarah,” are challenged to decide whether gene therapy should be used to eliminate myopia, or nearsightedness, from the population, much like the students in Sadler and Zeidler's (2005) study informal reasoning in SSI. Our eager perspective taker Sarah immediately researches myopia and learns that it causes great difficulty as vision is blurred at distances, often requiring glasses, contacts, or surgery. Although she doesn't wear glasses, Sarah decides that to truly appreciate the circumstances of a person afflicted with myopia, she borrows her mother’s “distance correction” glasses and wears them to school for the next several days. Although teased and quite bruised from bumping into walls, Sarah then decides to conduct interviews with an ophthalmologist about the risks and benefits of the surgery, an owner of Lens Crafters to understand the economic impact on her of eliminating myopia, as well as her church minister to discuss his view on this type of 
technological intervention. After considering the diverse viewpoints on the subject, Sarah ultimately decides to crusade for the elimination of myopia by urging her classmates to wear distance correction glasses in solidarity with those afflicted with myopia.

Unquestionably, Sarah's ability to engage with this issue and its stakeholders, and to shift her view from etic to emic for each, is quite exceptional. Like our model case of Gandhi, this exceptional ability to place oneself in the position of others is beyond reproach and we assume that it is a desirable trait. Yet is it not possible that the same perspective taking excellence could be claimed by the movie character Hannibal Lechter, played by Anthony Hopkins, in the Academy Award winning movie, The Silence of the Lambs (Goetzman \& Demme, 1991)? Lechter, a psychopathic criminal with a penchant for eating his victims, was able to understand the mind of the most heinous criminals so much so that he was used by the FBI to capture them. Lechter thrived on using his innate perspective taking abilities to terrorize and torture, impeccably reading his victims thoughts, strengths, and weaknesses and capitalizing on the latter with sadistic zeal. In the opening scene of the movie, the young FBI agent Clarisse Starling walks down the long prison corridor approaching the cell of Dr. Lechter, who summarily picks up her scent like a predator stalking its prey. After a very short exchange, Lechter declares: You're sooo ambitious, aren’t you...? You know what you look like to me, with your good bag and your cheap shoes? You look like a rube. A well-scrubbed, hustling rube with a little, taste... Good nutrition has given you some length of bone, but you're not more than one generation from poor white trash, are you Officer Starling...? That accent you're trying so desperately to shed - pure West Virginia. What was your father, dear? Was he a coal miner? Did he stink of the lamp...? And oh, how quickly the boys found you! All those tedious, sticky 
fumblings, in the back seats of cars, while you could only dream of getting out.

Getting anywhere - yes? Getting all the way - to the F...B...I. (Silence of the

Lambs, 1991).

Lechter’s ability to “size up” Agent Starling by anticipating her reactions, reading her fears, understanding her motivations, and utilizing these understandings to terrify and taunt her suggests a powerful ability to shift his perspective to hers. And while some might say it is sacrilege to compare Lechter to Gandhi (or even Sarah!), it is suggested here that both had exceptional abilities to engage with others and put themselves in others' shoes, so to speak, yet within markedly different contexts. It is argued here that both characters are excellent perspective takers, and that the criteria of a connection and switch are necessary and sufficient conditions for perspective taking, raising Lechter to the status of a model perspective taker in the generic sense. Yet something is certainly amiss; could we possibly find Lechter's behavior to be even tangentially related to a behavior we would want to promote in students? While it does appear that Lechter is a good perspective taker, he is not exhibiting perspective taking in the manner in which we typically think of it, and certainly not in the manner we wish to promote as educators. So what is the problem with our analysis? It appears that a necessary context condition of perspective taking is that a moral context must be present. Motivations and repercussions of perspective takers' actions clearly come into play when determining how we envision perspective taking.

To illustrate with a slightly less heinous example than Hannibal Lechter, we can look at bullies. Bullies are another, perhaps less extreme, example of model perspective takers. A "good” bully doesn't simply use generic tools to exact pain in their victims. Bullies read the state of mind of their victim, understand their desires, their motivations, and behave accordingly. 
Continuing with the cinematic examples of model cases of perspective taking, consider the plight of Carrie (Monash \& DePalma, 1976), the tortured teenager with telekinetic powers who dreams of being accepted by her classmates. How do the class bullies torment Carrie? They don’t just tease her about her looks, her family, or her naiveté. They precisely target in on Carrie’s hopes and dreams; they elect her as prom queen to be paired with her school crush as prom king...only to publicly embarrass and humiliate her, dealing out her worst nightmare. Arguably, those bullies knew exactly how Carrie thought, what she would feel, ...this was not a case of students not knowing that their perspective taking could cause harm, but rather, capitalizing on perspective taking to cause harm. Again, this example suggests that perspective taking in the absence of a moral context can render it a less than desirable attribute.

How could the absence of a context condition for perspective taking play out in a science classroom? Imagine for a moment, another hypothetical scenario whereby the students in Sarah's biology class are provided information on Huntington's Disease, a dominant lethal genetic disorder whose terrible effects often don't surface until after an adult has already passed the genes on to their children. Imagine further that the class participates in an SSI activity where they are asked whether gene therapy should be used to eliminate Huntington's Disease from the population, much like the students in Sadler and Zeidler's (2005) study. Let's consider the following hypothetical exchange between another invented case student, who we'll call, Dante, and his teacher, a master at SSI implementation.

Teacher: “Are you for or against gene therapy being used to eliminate Huntington’s Disease from the population?”

Dante: "I’m against gene therapy because it’s playing God." 
Teacher: “O.K., Dante. But how do you think the family with Huntington’s that we learned about might feel about this issue?”

Dante: "I can understand that the family would want to do gene therapy. It's a terrible disease and they wouldn’t want their kids to suffer.”

The teacher, utilizing a perspective taking instrument that places value on the ability to analyze SSI from “diverse perspectives and recognize substantive challenges to one’s own espoused position” (Sadler, Barab, \& Scott, 2007, p. 376) thinks, “Hooray! Dante is demonstrating strong perspective taking skills!” Yet not more than a moment later, Dante continues his thought:

Dante: "Yeah, I can understand that they would want gene therapy, but I really don’t care what they think. My opinion's the only one that matters. And I kinda' like when people suffer!”

The teacher promptly erases the check mark next to perspective taking skills on her scoring rubric...but should she? Dante actually fulfilled the requirements of current instruments assessing perspective taking skills. He identified a perspective other than his own, not so differently than Sarah; in fact, he appreciated the pain that the disease would cause to others, showing a level of engagement. And yet, something is obviously wrong with this picture...Dante is clearly not an example of the type of thinking pattern SSI is meant to promote. So what is missing in Dante's perspective taking skills (and arguably in the aforementioned instrument)? The answer may lie in a re-examination of one of the key assumptions of this dissertation, that is, that perspective taking is a desirable behavior and worthy of identifying interventions in order to promote SSR. This assumption seems reasonable, given that literature on perspective taking cites it as a precursor or co-requisite to moral development (Selman, 1977), global citizenship (Lee, Chang, Choi, Kim, \& Zeidler, 2012), communication (Batson, 1991; 
Clark \& Marshall, 1981), empathy (Titchener, 1915), and the like. Yet when we position perspective taking in this light, we are assuming that it is a good thing when in fact, perspective taking in and of itself is neutral. One can connect with others and shift their viewpoint to appreciate others' perspectives for good, evil, or for no particular reason. What makes perspective taking appear to be a positive behavior is the assumption of a moral context condition. Our conceptual analysis suggests that our everyday understanding of perspective taking, as well as its usage within the current SSR construct, may have fallen prey to a "dominant subjective contextual use" (Soltis, 1978, p. 13) and exacted a positive aura much the same way "love," "mother," and "puppies” have. In and of themselves, these terms are neutral and their definitions reflect that. Yet we nonetheless assign positive values to them, even though we are aware of the existence of dangerous loves, "Mommy Dearests," and even naughty puppies! Perspective taking is a similarly neutral term, and in common speech, it may be acceptable to tolerate the ambiguity of this assumed value as the meaning can readily be interpreted by the context of the sentence in which it is used. Yet in the context of educational research, this assumption of a positive value leaves our understanding and defining of perspective taking imprecise, and seduces us into overlooking perhaps the most important perspective taking condition within SSR; that of a moral context, the tacit existence of which must be made explicit if perspective taking is to serve as a construct to be fostered and measured in science education. Given that neither the current SSR construct nor instruments measuring the perspective taking component of SSR explicitly cite a moral context condition, there exists a gap which leaves the SSR construct vulnerable to inadequate operationalization. And while the lack of an articulated moral context condition in the SSR construct will not necessarily promote the development of Hannibal Lechters or Dantes, it does leave quite a bit of wiggle room in regard to the behaviors 
that necessarily lead to the type of perspective taking and ultimately, the quality of character we wish to promote. For example, if we assume that the quality of a student's perspective taking ability is aligned with the number of perspectives they are able to take (Sadler, Barab, \& Scott, 2007) without any requirement of a moral context condition, we could well assess a Dante to be a model perspective taker even though his use of this skill is for sadistic ends. In a somewhat less dramatic example, if we define perspective taking ability by the ability to formulate counterpositions and rebuttals (Sadler \& Donnelly, 2006), or to conceptualize a problem beyond one’s own personal framework (Sadler, Barab, \& Scott, 2007), a student may well be able to shift viewpoints like Tootsie, but without any connection to or interest in the stakeholders, and perhaps without concern for the consequences of their actions. Given that a guiding premise of SSI is its contribution to the formation of character, clarifying the basis of character development within the SSR construct itself is essential. Table 6 summarizes the cases utilized in our conditions-type analysis relative to the cultivation of perspective taking characteristics (PTC).

Table 6. Conditions Analysis of Model and Invented Perspective Taking Characteristics

\begin{tabular}{|l|l|l|l|l|l|l|}
\hline Character & Synopsis & Engagement? & Shift? & $\begin{array}{l}\text { Generic } \\
\text { Case } \\
\text { Type }\end{array}$ & $\begin{array}{l}\text { Moral } \\
\text { Context } \\
\text { Condition }\end{array}$ & $\begin{array}{l}\text { PTC for } \\
\text { SSR? }\end{array}$ \\
\hline $\begin{array}{l}\text { High School Science } \\
\text { Student - "Sarah" }\end{array}$ & $\begin{array}{l}\text { Responds to SSI on } \\
\text { myopia by learning } \\
\text { about the } \\
\text { implications of } \\
\text { vision correction } \\
\text { on others and } \\
\text { taking vision issue } \\
\text { on as her own. }\end{array}$ & Yes & Yes & Invented & Present & Yes \\
\hline $\begin{array}{l}\text { Hannibal Lechter } \\
\text { The Silence of the Lambs } \\
\text { (1991) }\end{array}$ & $\begin{array}{l}\text { Psychopathic serial } \\
\text { killer with an } \\
\text { uncanny ability to } \\
\text { read other's } \\
\text { thoughts, anticipate } \\
\text { their actions, and } \\
\text { know what they are } \\
\text { feeling. }\end{array}$ & Yes & Yes & Model & Absent & No \\
\hline
\end{tabular}




\section{Table 6 (Continued)}

\begin{tabular}{|l|l|l|l|l|l|l|}
\hline $\begin{array}{l}\text { Bullies in } \\
\text { Carrie } \\
\text { Carrie (1976) }\end{array}$ & $\begin{array}{l}\text { Students who are able to identify } \\
\text { Carrie's hopes and dreams, target } \\
\text { and appreciate the emotional } \\
\text { harm they will cause. }\end{array}$ & Yes & Yes & Model & Absent & No \\
\hline $\begin{array}{l}\text { High School } \\
\text { Science }\end{array}$ & $\begin{array}{l}\text { In an SSI on Huntington's } \\
\text { Disease, is able to recognize } \\
\text { "Dante" } \\
\text { viewpoints contrary to his own, } \\
\text { appreciate the pain experienced } \\
\text { by HD families, yet only cares } \\
\text { about his own desires. }\end{array}$ & Yes & Yes & Invented & Absent & No \\
\hline
\end{tabular}

Thus far, our generic and conditions analyses have identified three conditions for perspective taking within the context of SSR: 1) Engagement with others and their circumstances; 2) Etic/Emic shift; 3) Moral Context. These necessary and sufficient conditions are outlined in Figure 8. We will examine the specifics of each of these later in this chapter, but first, we will see how our understanding of perspective taking compares to related terms such as empathy, role taking, and ToM by applying a differentiation-type analysis.
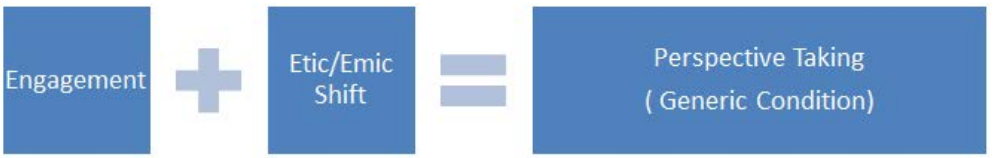

a.

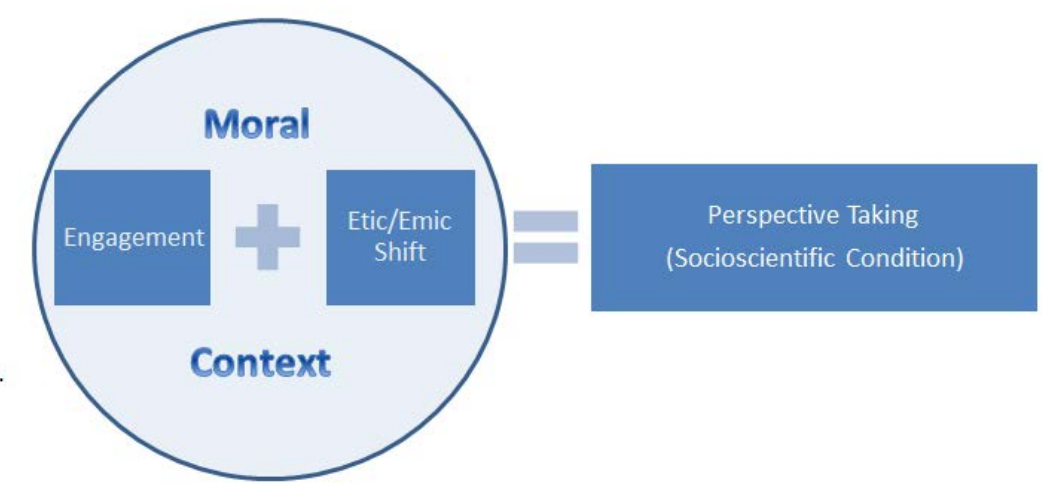

Figure 8. Necessary and Sufficient Conditions for Perspective Taking in (a.) Generic and (b.) SSI Contexts 


\section{Differentiation Analysis to Distinguish Perspective Taking from Related Constructs}

In order to identify the fine distinctions between perspective taking and other closely related constructs, we will utilize a differentiation analysis. This analysis requires us to identify the closely related constructs within an everyday, accessible scenario so that we can spot examples of the constructs and tease out their fine distinctions. To do so, we are going to move from the glitz and glamour of the big screen to that of the most mundane scenarios to which most readers can relate...an elevator ride!

Elevator Thinking and Perspective Taking. Imagine that you enter an elevator and another person is standing there. You quickly acknowledge them and the door closes. What are you thinking? If you are like many people, you might experience a moment of awkwardness as you stare at the advancing floor numbers wondering whether or not to initiate conversation. What cues you to initiate conversation? How do you determine whether you wish to engage with another? Moreover, how do you determine whether the other person wishes to engage with you? Perhaps obvious cues, such as a smile from the other person, hint at their state of mind. The determination of whether to engage in conversation is arguably intuitive; it is a "gut reaction,” one that happens so quickly that we are hardly aware of its presence. In essence, it is a primal attempt at mindreading the other's intentions to determine whether to expose one's vulnerabilities through engagement or protect oneself through isolation.

Let's imagine that upon entering the elevator, you notice that the other person is an amputee. What are you thinking? Do you wonder, "How did they lose their leg?” "Is she/he a veteran?” "Is it o.k. to ask?” “I wonder what life would be like without a leg?” This type of thinking pattern is decidedly more rationalistic than the prior intuitive mindreading. You 
intellectually envision yourself in their place trying to see the world, which includes you, through their eyes.

What if the person lets out a groan? Do you feel their pain? This emotive response is again different from the others. You are able to feel what you perceive them to feel, again putting yourself in their place but this time, not on an intellectual or intuitive basis, but an affective one. Although you may be curious, would you ask, “Hey, how did you lose your leg?” I suspect not, as a voice inside of you tells you that it is not appropriate to do so. Societal norms have informed you that asking about another person's hardships is seen as brutish, unrefined, and insensitive. Your own sense of what is right may also prevent you from asking as you might envision being on the receiving end of such a question. The Golden Rule prohibits you from doing something that you would not want done to you. In a sense, you step outside of yourself and see yourself from the other's and society’s view. If you are like most people, you want that perception to be a positive one. This desire to meet both one's own and society's expectations doesn't just impact our inactions, such as not asking the amputee about their leg, but about our actions as well.

Let us further imagine that moments before you entered the elevator, you ate a triple garlic pizza for lunch. Does the specter of causing another's discomfort compel you to grab a breath mint? Hold your breath? Turn away? Breathe into your collar?? The powerful impetus to do what is right both in terms of how the other person, society, and how you judge yourself drives many acts of omission and commission in our daily lives.

Each of these "elevator thinking” scenarios seem to have something in common: In every case, we demonstrated some level of engagement with the other person in that we thought about their interests (or at least our best guess regarding their interests) or how they or others would 
perceive us as we navigated through this brief interaction. In essence, we took the time to attend to the interaction and concerned ourselves with others. Our earlier analysis of perspective taking suggested that engagement is a necessary condition for perspective taking, and it would appear that each of our scenarios demonstrated this condition. But what about our second condition of perspective taking? Did we exercise a shift in viewpoint? And if we did, can we reasonably be said to have exercised the same kind of perspective taking in each case? Let's take a moment to look more closely at each of our scenarios.

A Typology of Perspective Taking. Our initial response in the elevator ("Does the other person want to talk?”) appeared to be an immediate, intuitive attempt at mindreading the other person's intentions and desires, a behavior that aligns quite closely with ToM (Baron-Cohen \& Wheelwright, 2004), a related construct described in Chapter 2. Can this be done without shifting one's point of view? Probably not successfully, as a shift in viewpoint, no matter how fleeting, is necessary to accurately gauge another's intentions and desires. But is it possible to shift one's point of view without the subsequent act of making a guess about their mental states? I suggest it is. One could simply enter the elevator and think, “I'll bet my garlicky breath won't be noticeable to them because they're a couple of feet away.” While this thought process requires a shift in perceptual perspective, it does not involve any guessing about mental states...simply a physical calculation about the movement of garlic breath. This olfactory estimation is similar to the type of perspective shifting that occurs when two people view a piece of artwork from different positions. Humans are able to make guesses about the perceptual abilities of others from a very young age (Fishbein, et. al. 1975), but this does not invoke the type of mindreading about mental states that ToM does. This suggests that perspective taking is a necessary condition for ToM, yet ToM is not a necessary condition for perspective taking. 
What about our tendency to "narrate" the life of another based on one’s experience, or experiencing the self from the standpoint of another ("I bet he/she’s a veteran" and "I wonder what life would be like without a leg.” This is a decidedly more rationalistic task than simply guessing one's mental state based on intuition, as we gave considerable thought to the other person's experiences. We saw an amputated leg and envisioned a combat experience, and we decided not to ask about our elevator partner's amputation after we put ourselves in their place (to our best estimation) and anticipated how our question would appear. This mental task most closely resembles the construct of role taking (Franks, 2013) described earlier as envisioning how one would think or behave if they were in another's place. Could role taking have occurred without shifting one's viewpoint? I suggest not as one needs to put oneself into the mind of the other, similar to the way an actor "gets into the head" of their character, in order to play the role. However, is it possible to shift perspectives without role taking? I suggest it is, as a director might need to sit in the audience to determine blocking of actors' movements, yet they are not necessarily developing any understanding of the audience members' thoughts or behaviors; it is quite possible for directors to simply (albeit selfishly) consider only what they see in the theater's most convenient seats...those of the audience! While such directors might not win Tony Awards, they are arguably shifting perceptual perspectives, but clearly not role taking. Once again, perspective taking appears to be a necessary condition for role taking, but the converse cannot be said to be true.

When the amputee let out a groan, our affective response (“I feel their pain”), whereby we mirrored what the other person felt (or at least our interpretation of it) is most closely aligned with the construct of empathy, a third related construct and one that taps our emotional responses. Is it possible to feel empathy without taking the other's perspective? I suggest not, as it is 
necessary to shift your perspective in order to comprehend, albeit affectively, their condition. But is it possible to take the other's perspective yet lack empathy? The extreme case might be a psychopath who perpetrates a crime, let’s say rape, but believes the victim's response to be enjoyment. Criminologists have linked psychopathic behavior to lack of empathy (Jolliffe \& Farrington, 2004), but caution that the inability to feel what their victim feels does not negate other perspective taking abilities (Decety, Chen, Harenski, \& Kiehl, 2013). Our earlier analysis of Hannibal Lechter bears this out, as we determined him to be an excellent perspective taker, but not an empathizer. In more familiar scenarios with socially normed people, a lack of empathy is all too familiar in marital counseling sessions when a spouse says, "You know I work all day but still you don’t 'get' why I'm too tired to make dinner!" In this situation, the "unempathetic" spouse may intuitively know that their spouse is angry by the tone of their voice (demonstrating ToM), cognitively understand that the pleading spouse has a rigorous schedule (demonstrating role taking), and yet is unable to feel what the pleading spouse feels. This scenario not only illustrates the pitfalls of a lack of emotional mirroring, but points out that perspective taking is a necessary, yet insufficient condition for empathy.

Thus far, our elevator analysis suggests that perspective taking, construed as requiring engagement and shift, is a necessary yet insufficient condition for ToM, role taking, and empathy. In a sense, this finding explains why there is so much confusion in the literature insofar as perspective taking and these related constructs; while it is not incorrect to refer to ToM, role taking, and empathy as perspective taking, it is imprecise. Just as it would be correct, yet imprecise, to identify Chihuahuas, greyhounds, and St. Bernards as dogs, it is correct, yet imprecise to describe ToM, role taking, and empathy as perspective taking. Just as all breeds of dogs must first meet the conditions of being a dog (but all dogs do not meet the conditions of 
specific breeds), ToM, role taking, and empathy must meet the conditions of perspective taking. What distinguishes these "breeds" of perspective taking appears to be at least the psychological domain. Perhaps there is another distinction... and perhaps these breeds are not alone.

Returning to our elevator scenarios, do you recall the "voices" you heard telling you about society's or the amputee's perspective on your behavior? We can view them as evidence of a type of reflective perspective taking; that is, seeing oneself through others' eyes. This type of perspective taking, however, goes beyond simply seeing...judgment of right or wrong, good or bad, enter into the thought process. One does not simply say, "I see myself asking the amputee about their leg” without a moral compass pointing to the next logical step...”I see myself asking the amputee about their leg and believe it might be hurtful, or be seen as insensitive.” This reflective judgment (Dewey, 1910) requires engagement and a shift in perspective, but these conditions alone are not sufficient to serve as a basis for moral development. Moral development requires the voice of judgment informing one about oneself, thereby contributing to the development of conscience (Green, 1999). But conscience cannot develop from the voice of what others think of our actions alone. When we decide not to ask the amputee about their leg, or to pop a breath mint after garlic, we not only view ourselves through society's eyes, or through the other's eyes, but through our own. This reflexive judgment (Green, 1999) also requires a shift in perspective, but it is as though one steps outside oneself, becoming etic to ones' self. This is not the voice that asks what others would think, but the one that asks, "How do I see myself ?” "How close do I come to the mark?” How do I judge myself against my internal voice to for doing what's right?” Again, perspective taking in a generic sense is not sufficient to meet this standard; it requires engagement and a shift in perspective, combined with a moral judgment to serve as the basis for moral development. This finding, of course, harkens back to our earlier 
discussion of the need for a "moral context" for perspective taking within the socioscientific context when we determined that perspective taking in its generic form was inadequate to serve the needs of an educational framework premised upon moral development (lest we allow Dantes and Hannibal Lechters to pass as model perspective takers within our midst). Although the elements of that moral context eluded us at that time, our elevator scenario has helped us to identify two perspective taking components of the moral context: reflective and reflexive judgment, together contributing to the development of moral judgment. Perspective taking, it is therefore argued, is a prerequisite of ToM, role-taking, empathy, and reflective/reflexive judgment, a relationship depicted in Figure 9 on page 83. Reflective and Reflexive perspective taking, yielding moral judgment, is seen as permeating all other perspective-taking tasks, for as demonstrated in our elevator scenario, the question of how others see us and how we view ourselves is ever-present; it informs all activities.

We have already alluded to the idea that different psychological domains, such as intuitive, affective, and rationalistic, may be necessary in delineating between ToM, role taking, and empathy. But are domain differences sufficient in distinguishing between them? Recall that our earlier analyses led us to conclude that perspective taking requires engagement with others and a shift. In his analysis of the construct validity of egocentrism, Ford (1979) describes egocentrism as a trait to be used to predict absence of various perspective taking abilities. In other words, a low measure of egocentrism would predict a high level of perspective taking ability in some domain. If we consider that each of the psychological domains represents a means of engaging with others and their circumstances, then the particular type of psychological domain invoked informs the type of perspective taking being exercised. We are then left only to consider 


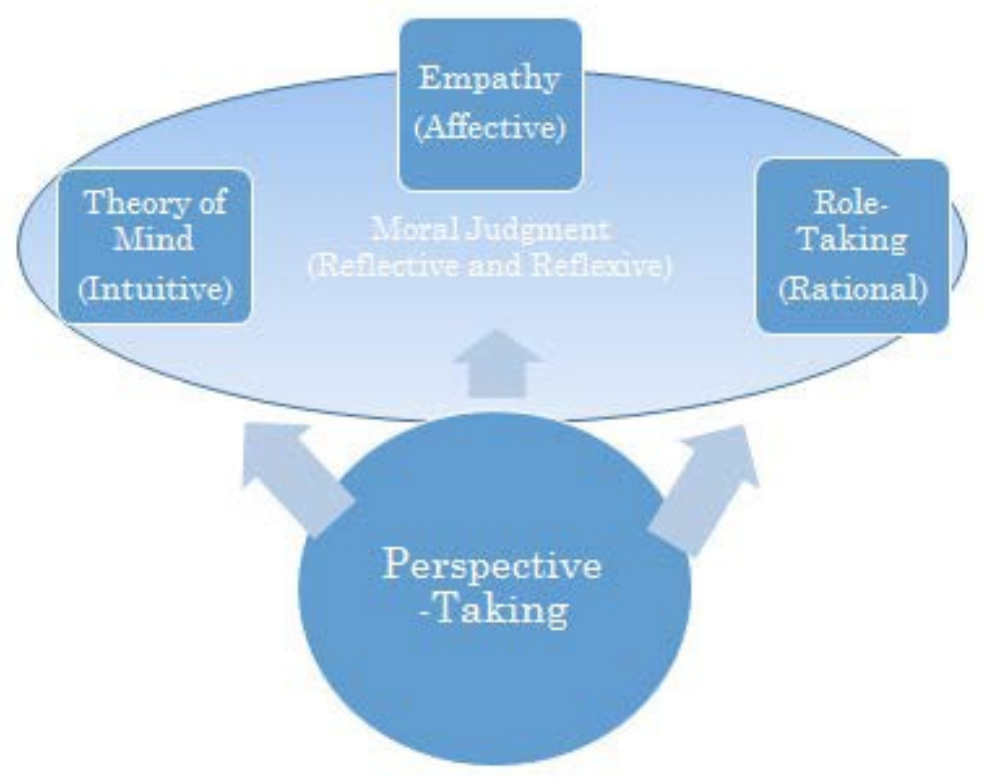

Figure 9. The Components of Perspective Taking

the presence and nature of the shift. In his brilliant argument for the need for both "inside" and “outside” perspectives in understanding baseball, author Bill James (1984) describes the interplay between the quantitative, statistical "outside” perspective of baseball and the qualitative, interpersonal "inside” perspective. This analysis of the etic/emic perspective has relevance to our analysis of perspective taking and related constructs, as the question of whether the perspective-taker actually puts themselves in the other's shoes to develop an "emic" perspective, as in the case of role taking and empathy, or whether the perspective-taker puts themselves in the position of an outsider, or "etic" perspective, to look back at themselves. When we arrange the constructs under consideration here by their respective emic/etic positionalities (i.e., "the shift") alongside their corresponding dominant psychological domain of engagement 
(i.e., “engagement), we can develop a typology of perspective-taking constructs as depicted in Table 7.

Table 7. A Typology of Perspective-Taking Constructs

\begin{tabular}{|l|l|l|}
\hline Construct & Domain of Engagement & Characterization of Shift \\
\hline Theory of Mind (ToM) & Intuitive & Emic \\
\hline Role Taking & Cognitive & Emic and Etic \\
\hline Empathy & Affective & Emic \\
\hline Reflection & Reflective & Etic \\
\hline Reflexivity & Reflexive & Etic \\
\hline
\end{tabular}

It should be noted that when we think about the shift that occurs in perspective taking, we do not mean that a position on an issue must change. Rather, we are referring to its positionality. For example, a student who exercises perspective taking to understand a stakeholder's point of view on a particular issue does not necessarily change their original position...it might stay the same. Rather, what they are shifting is the manner in which they view the issue, whether from their own "outsider" perspective (i.e., what "they" think) to an "insider" perspective (i.e., what would I think if I were in their shoes). To clarify this distinction a bit further, a brief look at the distinctions between perspective, position, and orientation are in order.

\section{A Word About Perspectives, Orientations, and Positions}

Before we proceed with our conception development of perspective taking within the SSR context, it would behoove us to consider the construct of perspective, a constituent term of perspective taking that is itself rather "fuzzy." Perspective is frequently used synonymously with related constructs of orientations and positions, yet by examining everyday language, we can see that there are fine distinctions in the usage of the three. For example, in a discussion about politics, one would be more inclined to ask "What is your position on same-sex marriage?" 
rather than "What is your perspective on same-sex marriage?” Similarly, when discussing the environment, we would more likely ask, "What is your position on fracking?" rather than, "What is your perspective on fracking?” We tend to take positions, rather than perspectives, on issues. Yet we often give our perspectives, as in the sentence, "Here, let me share my perspective on fracking with you." What is the distinction? When we ask others about their positions on issues, we are essentially asking, “Where do you stand?” on this matter, a question that can be summarized quite concisely, be it "for" or "against" an issue. I may be for immigration reform but against nuclear proliferation. I may be for marijuana legalization but against raising speed limits. These are my positions; they tell you where I stand. Yet my perspective requires more explanation...I must share something more with you, not simply where I stand, but why I stand there. If, for example, you learned that someone voted against same sex marriage and marijuana legalization, you would know their positions on those issues. In fact, you might even ascertain their political orientation as perhaps a bit more conservative than liberal, as orientation implies a comparison in relation to others. Yet you would not know their perspective without knowing more about them. Are they against marijuana legalization because they think it is a bridge to other drugs? That it destroys brain cells? That it is bad for the economy? That it is opposed to their religious beliefs? That its implementation has not been sufficiently thought through? Or because they have personally experienced a "bummer trip?”

This suggests that one's perspective is more of a private matter than one's position or orientation. Unlike position and orientation, which can be observed from external actions or conveyed through succinct responses, perspective is private and requires a deeper understanding of the internal machinations of the one whose perspective is being considered. In fact, one might explain or defend their position on an issue by explicating their perspective on that issue, all of 
which might aid the listener in surmising their orientation on such issues. In this way, one's perspective and orientation inform one's position.

The "personal" distinctions between perspective, position, and orientation can be illustrated in the unlikely context of venturing online to purchase tickets for a sporting event, such as a baseball game. The first question you are likely to encounter is what seating type ("loge," "mezzanine," "box”) you would like. This level of response gives the general position of seat within the stadium (e.g., high, low, nosebleed section) and to a large extent determines the price. Once that is decided upon, a diagram or map of the section pops up and shows the orientation of seat in relation to the field (e.g., left field, right field, behind home plate), a necessary bit of information if one is more inclined toward calling outs at home or tags at first base. Finally, thanks to the wonders of technology, one can click on a prospective seat and view a photo showing the field from the perspective of sitting in that seat. In other words, this latter, "virtual venue" function allows the customer to see what they would see if they were in that particular seat. This latter piece is particularly intimate in that it allows the prospective purchaser to experience their seat as though they themselves were already there, thus allowing the purchaser to shift their position from outsider to insider. The relationship between these three terms might be summarized when the lucky ticket purchaser attends the game and then exclaims to a friend, "I had box seats (position) right behind first base (orientation) and the players were so close I could almost touch them!” (perspective). In this instance, perspective becomes an elaboration of position and orientation, enhancing the listener's understanding of the ticket buyer (and their seats) and providing a window into their experience. A parallel situation occurs when homebuyers venture online to investigate a prospective home. Today's real estate search engines ask buyers to input their housing requirements (e.g., number of bedrooms, bathrooms, price 
range, etc...) and voila - up pops a map that shows the home’s position, usually displayed as a dot with a price. Then, one can zoom in using Google Earth or some other satellite imagery system to see the home's orientation; that is, how it is located in relation to other homes, parks, or even the sun, the latter being imperative for those partial to a southern exposure. Finally, one can utilize the "street view" function to get the perspective of one who is standing in front of the house, thus creating a psychological shift from outside purchaser to inside owner. Some realtors even offer "virtual tours" of the home so that the prospective buyer can experience a walk through the home from the perspective of one who is inside.

We can summarize these three terms as follows:

Position - Where one stands on an issue

Orientation - How one approaches an issue in relation to others

Perspective - How one perceives and interprets an issue

Can the distinctions between these terms be demonstrated in science education? In Sadler’s (2004) study on SSI and moral sensitivity, college students were asked about their reactions to two SSI, one on whether gene therapy should be used to eliminate Huntington's disease and whether cloning should be used to combat infertility. The students were provided scenarios that provided background on the controversy and were then assessed on moral sensitivity which was operationalized as the extent to which the student "interpreted the reactions and feeling of others, understanding cause-consequence chains of events and recognizing moral principles and guidelines.” (p. 345). Using our terminology described above, it could be argued that students were examining their positions on the particular issue, be it for or against, and were assessed based on their orientation, be it more or less inclined to utilize moral considerations to justify their position. Moreover, given that some students incorporated, “concern for others” (p. 
348) ( e.g., "I don't like to see people suffer and if there's something like this that can eliminate the suffering, then why not?) and "empathy towards others" (p.349) (e.g., "I thought about the parents”) which was expressed through role playing , this exercise arguably tapped into students' ability to integrate others' perspectives.

In a similar vein, Furberg and Ludvigsen (2008) compared the manner in which two students approached a question about genetically modified foods. The authors suggested that the students' initial approach to researching the question reflected two different orientations as one tended to rely on scientific explanations while the other relied on societal consequences, with both ultimately establishing a fact-finding orientation. These authors' use of the word orientation is in concert with our analysis above, as we see that the authors were comparing the behaviors of the students as they approached the issues, relative to each other. However, this study would not meet our criteria as a study of perspective, and thus could not be seen as evidence of perspective taking as other authors have suggested (Lee, Chang, Choi, Kim, \& Zeidler, 2012) since perspective would have required a closer understanding of the students' thinking about the issue, not solely how they approached the investigation it in relation to others. Questions regarding students' rationales regarding their positions on the issues (which was not the focus of this study) would have illuminated their perspectives.

To reiterate an earlier (and critical) point, when we speak of a "shift" in perspective, we do not mean that a student's position must change in order for perspective taking to occur. We mean that a student shifts their positionality, or viewpoint, to that of another in order to analyze a SSI dilemma. With these understandings in mind, it is time to contextualize perspective taking within the SSR construct. In doing so, we will find the necessity of introducing a new, if not more comprehensive, construct. 


\section{Conception Development to Form a New Construct: Socioscientific Perspective Taking}

(SSPT)

Perspective taking is one of four components of socioscientific reasoning as defined by Sadler, Barab, \& Scott (2007). Based on the present study, the perspective taking component necessitates further refinement into its sub-constructs of role taking, empathy, and ToM, all residing within a context of moral judgment which is comprised of reflective and reflexive judgment. Their interconnection, showing our new model of perspective taking, is depicted below in Figure 10.

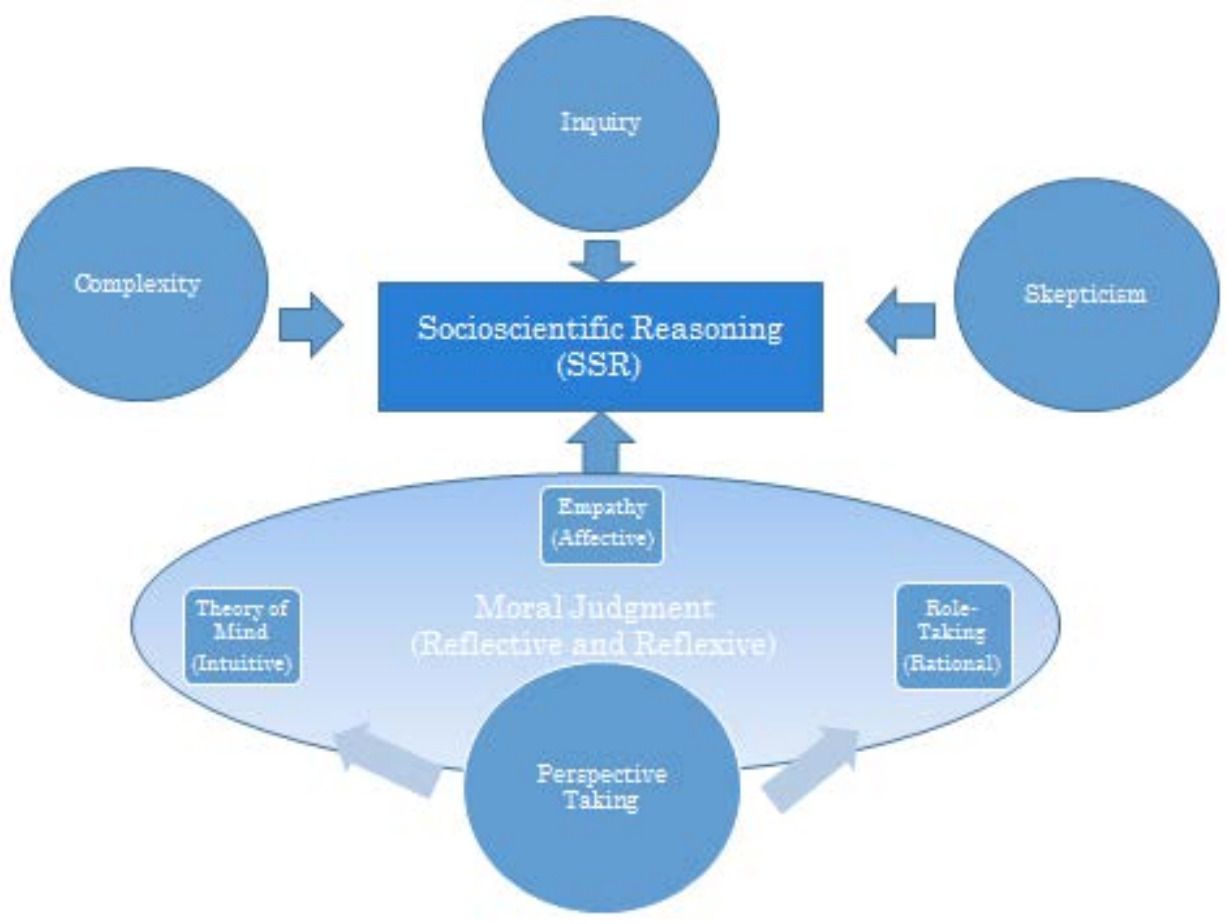

Figure 10. Components of Socioscientific Reasoning 
In trying to determine the manner in which students negotiate and resolve socioscientific issues, Sadler \& Zeidler (2005) identified a framework of “informal reasoning” utilized by students as they worked through SSI scenarios. The framework identified three distinct approaches, which the authors identified as rationalistic, emotive, and intuitive, based on their empirical analysis of the responses given by students as they reasoned through complex issues related to genetic engineering. The authors concluded that the students often utilized multiple patterns of informal reasoning to resolve their issue, and that to some extent, the patterns related to the context of the issue, with some issues garnering greater emotive or intuitive responses.

Rationalistic reasoning was utilized by all participants in at least some of the scenarios, and while science educators often tend to focus on logic and evidence as the driving forces of reasoning, the authors suggest that intuitive and emotive reasoning also plays an essential role in hooking students' interest in the issue, and invoking students’ moral/ethical sensibilities. Interestingly, when students utilized intuitive reasoning, it was always used first before the other two styles. This makes sense when one realizes that the intuitive domain is the most primal (Denes-Raj \& Epstein, 1994). The authors' framework for informal reasoning patterns utilized to negotiate SSI is shown in Figure 11 on page 91.

The authors surmised that, "The display of multiple reasoning patterns was due at least in part to the recognition of the various perspectives that can influence positions taken in response to socioscientific scenarios.” ( p. 129). I would like to extend that thought and suggest that perspective taking parallels the informal reasoning they identified; that their "intuitive" pattern was reminiscent of ToM, whereby students decide whether to engage on a "gut" level in much the same way we decide whether to engage with another person in the elevator. The "emotive" pattern observed by Sadler and Zeidler paralleled empathic perspective taking and was invoked 


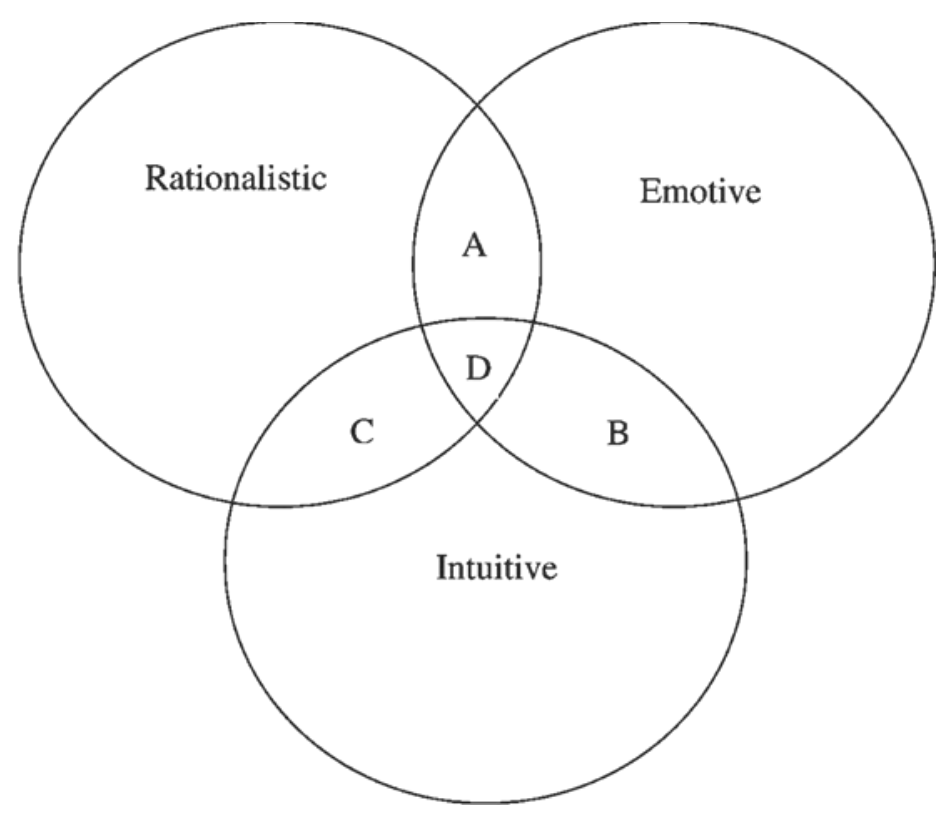

Figure 11. Patterns of Informal Reasoning in SSI (Sadler \& Zeidler, 2005)

by particular scenarios in much the same way that perspective taking with an amputee in the elevator might invoke greater empathy than with a person who did not have an obvious disability. And the "rationalistic" pattern is indicative of the more familiar role-taking form of perspective taking whereby we integrate prior and contemporaneous knowledge to piece together “evidence” to establish our "narrative,” much the same way we did in the elevator as we began to think through life as an amputee. Insofar as moral reasoning was concerned, the authors noted that it permeated through all other considerations contributing to their decision- making. Moral considerations were not "partitioned” (p. 129) but rather, comingled with non-moral factors. I would suggest that one reason it is impossible to tease out morality from other aspects of informal reasoning is that conscience, stemming from reflexive and reflective patterns of perspective taking, becomes subsumed in the patchwork of perspective taking activities utilized in negotiating dilemmas. As we saw in the elevator, our thoughts, actions or inactions were informed by guiding voices, what Thomas Green would refer to as the "voices of conscience" 
(Green, 1999) which are developed through reflexive and reflective judgment, both forms of perspective taking. Whether deciding if and how to engage in conversation, whether to ask a "personal question," or whether to let on to someone that we feel their pain, we are informed and guided by moral judgment. As Green so deftly pointed out, even the exercise of taking another's perspective by "stating the interests of others as others see them, and stating them aloud and, if possible, in the actual presence of those others, is often in itself a powerful exercise in empathy" (p. 81-82). While "prudence” characterized by self-interest may have "primacy” (p. 88), the development of conscience allows us to overcome our brutish natures. Similarly, while egocentrism may be our default state (Fenigstein \& Abrams, 1993), the development of perspective taking allows us to develop empathy, ToM, and role taking, each contributing to the development of conscience. The connections between the negotiation of SSI and the development of moral reasoning and character development, which rest upon conscience, have been well-documented (Sadler \& Zeidler, 2004; Zeidler, 2003; Zeidler, 2009; Zeidler \& Keefer, 2003; Zeidler \& Sadler, 2008; Zeidler, Sadler, Applebaum, \& Callahan, 2009). In discussing the relationship between classroom argumentation of the kind advocated in SSI and moral reasoning, Zeidler \& Sadler (2008) point out that:

"Central to all these studies is the importance placed squarely on understanding how students reason and react reflexively to variant evidence and belief. In doing so, we have sought to provide opportunities for students to negotiate and argue with others and ultimately reflect as they form judgments about controversial issues.” (p. 202)

It is perhaps not surprising that there is such a close overlap between SSR and perspective taking and its related constructs. What emerges from this connection between the patterns of informal 
reasoning in SSI and those of perspective taking is that possibly, a construct more specific than general perspective taking is needed when referring to the component of socioscientific reasoning. The type of perspective taking ideally desired for SSR values not simply applying perspective-taking from a single domain, but from all domains...not necessarily at one time, but competence in SSR would suggest the ability to draw upon different perspective-taking tasks from different domains as the particular SSI requires. Moreover, it would seem desirable to explicitly incorporate reflexive and reflective judgment, as they are essential perspective-taking tasks that educators should strive to promote.

Based on these considerations, I suggest a more robust construct called, "Socioscientific Perspective Taking (SSPT)” which incorporates engagement via various psychological domains, an etic/emic shift, and demonstration of reflexive and reflective judgment (Figure 12). This model suggests an emphasis on the development of a diverse suite of perspective taking skills as well as moral development, all of which are key for the promotion of SSR.

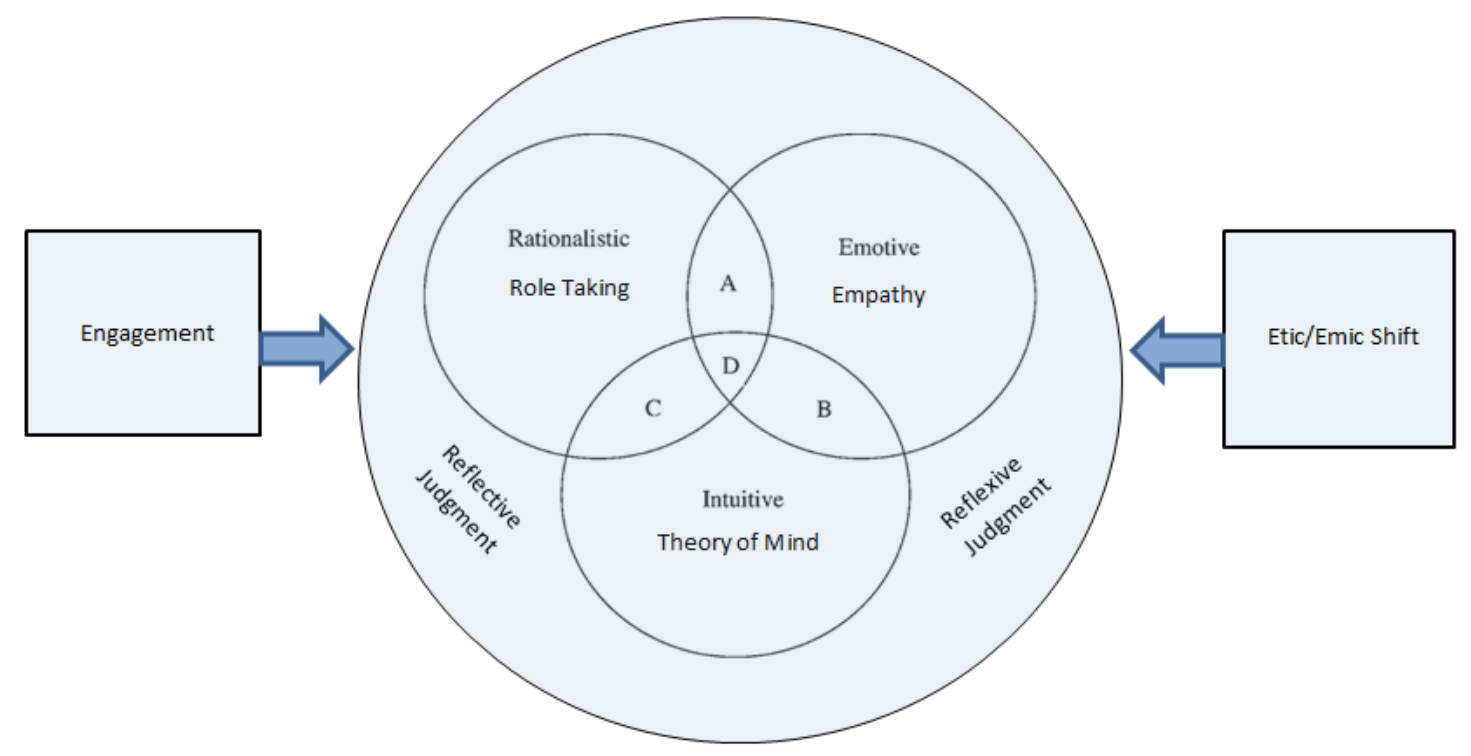

Figure 12. Socioscientific Perspective Taking 
This model depicts the confluence of all perspective-taking tasks within area " $\mathrm{D}$," thus creating a "sweet spot" for the activation of all psychological domains. While students may indeed exhibit patterns more akin to areas “A," "B," or "C" during the negotiation of many SSI, it is suggested that opportunities that tap students' engagement in all domains (i.e., area “D”) are most desirable. When thinking about the manner in which SSPT would be assessed, one might envision the following components of an SSPT instrument:

1. Does the student demonstrate engagement with the issue and its stakeholders? (Engagement) If so, what psychological domain is invoked?

2. Does the student express an etic/emic shift from their viewpoint to others? (Etic/Emic Shift)

3. Does the student recognize potential impacts of their decisions on others? (Reflective judgment)

4. Does the student demonstrate a desire to “do what's right?” (Reflexive judgment)

\section{Summary}

The importance of fostering perspective taking skills cannot be underestimated, yet it is a tall order for any teacher. We have addressed the notion that SSPT requires students to form a meaningful connection with an issue and its stakeholders, not simply to become "Tootsies" playing characters with whom they feel no personal connection, nor even Atticus Finches, who are motivated by a desire to connect and do good, but unable to shift their perspective to appreciate others' circumstances. And certainly, we want to encourage the development of a moral compass that guides students toward using their perspective taking skills for society's benefit rather than for Hannibal Lechter-type (or perhaps simply selfish) motivations. This is a Herculean task for any curriculum, as it no doubt requires more than the use of superficial role 
play or the naïve belief that students will meaningfully connect with any issue that a teacher might select. While recognizing that the SSI framework has no doubt provided an excellent conceptual foundation upon which the desired activities and attributes can flourish, this chapter suggests that the development of socioscientific perspective taking may well require the development of extensive student resources, an array of exercises and interventions, and a thoughtful and willing teacher who is committed to developing young perspective takers who will grapple with SSI with both their heads and their hearts. Fortunately, science educators need not start from scratch to identify and develop such curricula, as several other disciplines have also identified perspective taking as a desirable goal. The question of whether their interpretation of perspective taking and ours overlap can be answered through theoretical inquiry by applying our new SSPT model to existing perspective taking frameworks. By piecing together components that seem to overlap, we can create a bricolage of SSPT interventions and instruments that may provide guidance for science educators and researchers. The next section of this work undertakes this daunting yet necessary task. 


\section{Chapter 5:}

\section{Finding Common Ground: Theoretical Application of Perspective Taking Frameworks from Non-Science Fields to SSI}

\section{Introduction}

In our last chapter, we conducted conceptual analyses of perspective taking in both generic and SSI contexts with the results suggesting that SSPT requires the presence of a connection with others or their circumstances, an etic/emic shift, and a moral context that is comprised of reflective and reflexive judgment. In addition, we argued for the primacy of perspective taking in light of related concepts of ToM, empathy, and role taking, each of which, it is argued, is grounded respectively in intuitive, affective, and cognitive domains, all of which contribute to and align with informal reasoning patterns of students within SSR contexts. These findings suggest that, to advance students' SSPT, the following elements should be promoted through curricular and pedagogical intervention:

1) Promoting engagement with stakeholders and their circumstances in SSI controversies;

2) Advancing an etic/emic shift such that students are able to view other's circumstances as their own;

3) Promoting consideration of the consequences of their actions via reflective judgment;

4) Promoting a desire to “do what's right” via reflexive judgment. 
While this would no doubt present a challenge for any curricular framework, it is perhaps particularly challenging in science education where the emphasis has historically been placed more on transmission of content knowledge than on normative considerations (Zeidler \& Sadler, 2011). While implementation of SSI as currently practiced does arguably tap into each of these areas, it is suggested here that interventions and instruments could be more finely targeted to meet these specific demands, and could conceivably make SSI that much more effective and efficient in regard to SSPT. Fortunately, due to the nearly universal interest in promoting perspective taking within the field of education, science educators may not have to reinvent the wheel to develop effective curriculum. Three frameworks in particular (historical empathy, method acting, and autism intervention) emphasize the development of perspective taking as a primary goal and are each extensively researched. It is therefore the focus of this chapter to examine these frameworks, presented in the order in which they were analyzed, to ascertain whether they are possible sources for SSPT interventions. To accomplish this, theoretical inquiry (Grove \& Short, 1991) will be utilized to compare the non-science frameworks to the SSPT model to see whether there appears to be sufficient overlap for incorporation of practices.

\section{Historical Empathy}

Social studies educators use an approach known as historical empathy (Foster, 2001) to help students and teachers appreciate the perspectives of various historical figures. Historical empathy incorporates a variety of pedagogical strategies, including research, role play, and writing, to promote students' understanding of historical events and the actions of persons who were involved. According to Lee and Ashby (2001), historical empathy challenges students to "know what past agents thought, what goals they may have been seeking, and how they saw their situation, and can connect all this with what they did" (p. 24). Although the term "empathy" is 
used, scholars in the field of social studies education point out that, rather than only focusing on the affective domain, their use of the word empathy is meant in a more expansive manner that refers to "a combination of intellectual and imaginative capacity...sometimes used as a synonym for perspective taking” (Yilmaz, 2007, p. 332), that requires examination of multiple sources of evidence and perspectives including students’ own perspectives (Foster, 2001). Historical empathy "arises or develops from the active engagement in thinking about particular people, events, and situations in their context, and from wonderment about reasonable and possible meanings within...[and] springs from consideration of more than one, even several different, points of view or perspectives” (Davis, 2001, p. 3).

Practitioners of historical empathy frequently rely on primary source documents in order to provide the context for the situation under consideration. This approach not only helps student gain connection with the people, places, and time, but also provides opportunity to present students with authentic evidence of diverse perspectives, thus allowing them to grapple with inconsistencies, conflicts, and gaps in information. Use of primary source documents also compels students to confront discrepant evidence from that which is provided in textbooks. Davis (2001) notes that this is particularly critical since students initially tend to cling to their more familiar texts over unfamiliar documents, even when it is clear that the primary source documents are more accurate, a fact reminiscent of Zeidler’s (1997) observation about students’ tendencies to become more entrenched in their own perspectives when challenged regardless of the evidence advanced. Another interesting commonality between historical empathy and SSI is that the level of engagement and modes of reasoning involved in their negotiation has been found to be context dependent (see Sadler \& Zeidler, 2005 for SSI; Davis, 2001 for historical empathy). In other words, the scenarios presented to students impact their level of engagement 
and their tendency to tap different psychological domains. This suggests that with both frameworks, it is critical to utilize scenarios that are of interest to students and reflect a variety of contexts.

Historical empathy is frequently used to gain understanding of controversial events, such as battles, legal disputes, and other situations that naturally evoke diverse perspectives. Some specific examples include research and re-enactment of the events leading up to World War II (Foster, 1999), reading letters written by soldiers and politicians during the Civil War (Davis, 2001), or researching the historical, religious, and societal context that supported the Anglo Saxon trial by ordeal (Lee \& Ashby, 2001). Even topics such as Nazi Germany and slavery in the United States are studied through the lens of understanding the contexts and motivations of those involved, not necessarily with a goal of having students affiliate with the actors, but more specifically, understand what may have caused them to act and think as they did.

One of the strengths of historical empathy is that it effectively demonstrates that historical knowledge is incomplete. Similar to scientific knowledge, understandings in history are tentative and subject to new findings and interpretations. Yeager and Foster (2001) see historical empathy as a quest to understand and interpret past events using the best, albeit incomplete, evidence available. They position historical empathy as having three elements: context, action, and consequence. The historian uses evidence to develop the context of the historical event, decision, or other action, and similarly uses evidence to identify the consequences. The same context -> action -> consequence heuristic, shown in Figure 13 on page 100, could arguably be applied to SSI, if we consider that each SSI has a scientific and societal context, within which an action (i.e., a decision) is with possible consequences is being considered. It seems the main difference between these two models is what is known, for 
although both can provide reasonably good evidence of the context, be it historical or contemporary, the consequences in SSI must be inferred whereas historical empathy has the benefit of retrospection.

\section{Historical Empathy}
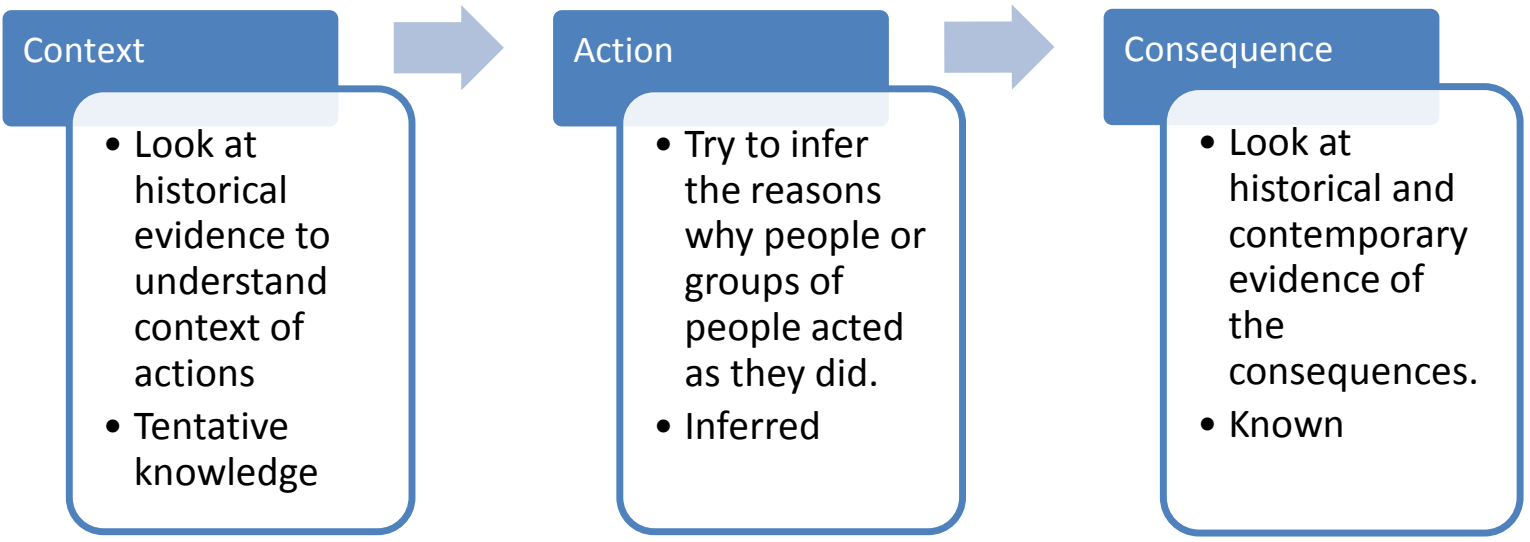

\section{SSI}
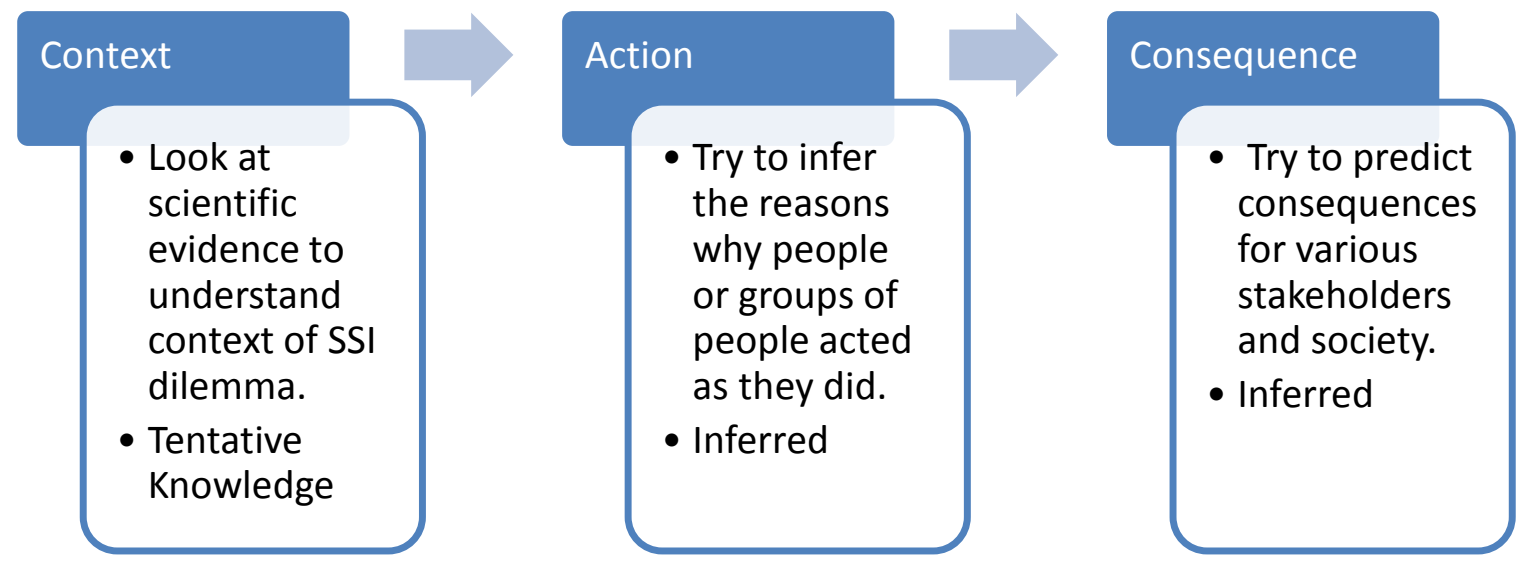

Figure 13. Context/Action/Consequence Model Applied to Historical Empathy and SSI 
Downey (1995) recommends the following considerations in the evaluation of historical empathy:

1) Students recognize that the past is different from the present and that some outcomes/consequences may be specific to time and place;

2) Perspective taking is measured in terms of students' ability to distinguish between perspectives and shift from one to another;

3) Students should be able to explain the perspectives they take and their consequences for the historical stakeholders;

4) The perspectives students take should be grounded in historical evidence.

If we consider the similarity to SSI, we might see evaluation looking something like Table 8:

Table 8. Comparison of Prospective Evaluations in Historical Empathy and SSI

\begin{tabular}{|l|l|}
\hline Historical Empathy & SSI \\
\hline $\begin{array}{l}\text { Students recognize that decisions/actions in } \\
\text { history were taken within specific contexts and } \\
\text { had consequences, many of which were } \\
\text { specific to time and place. }\end{array}$ & $\begin{array}{l}\text { Students recognize the scientific and societal } \\
\text { contexts surrounding their dilemma, and } \\
\text { understand that their decisions/actions will } \\
\text { have consequences for others. }\end{array}$ \\
\hline $\begin{array}{l}\text { Perspective taking is measured in terms of } \\
\text { students' ability to distinguish between } \\
\text { perspectives and shift from one to another }\end{array}$ & $\begin{array}{l}\text { PT is measured in terms of students' ability to } \\
\text { connect with different perspectives and shift } \\
\text { from outsider to insider }\end{array}$ \\
\hline $\begin{array}{l}\text { Students should be able to explain the } \\
\text { perspectives they take and the consequences } \\
\text { for historical stakeholders }\end{array}$ & $\begin{array}{l}\text { Students should be able to explain the } \\
\text { perspectives they take and identify possible } \\
\text { consequences for various stakeholders and } \\
\text { society }\end{array}$ \\
\hline $\begin{array}{l}\text { The perspectives students take should be } \\
\text { grounded in historical evidence. }\end{array}$ & $\begin{array}{l}\text { The decisions students make should be } \\
\text { grounded in scientific evidence. }\end{array}$ \\
\hline
\end{tabular}

In looking at this instrument, the overlaps with the SSPT construct are evident. Historical empathy taps both reflective judgment, in its requirement of consideration of the consequences of one's actions, as well as perspective shifting. Hence, strategies from historical empathy may 
prove fruitful for developing these SSPT skills in the negotiation of SSI. Below are two such strategies.

Use of Historical Controversies. One of the assumptions often applied to SSI is that it must be applied in a contemporary context. Yet it is suggested that there is nothing in the SSI framework that precludes consideration of past SSI in order to foster SSPT. After all, if the study of history is premised upon the notion that understanding past events informs current and future decision making, it is reasonable to consider that study of past SSI can provide students with an appreciation and understanding of historical socioscientific dilemmas whose resolution and subsequent consequences can inform current deliberations. One might consider such critical socioscientific events as the Tuskegee experiments, the Manhattan Project, or Galileo’s imprisonment for promoting a heliocentric model of the universe as potential contexts. We might dub these dilemmas "Historical SSI” as they unquestionably represent situations that were illstructured and, at least at the time they occurred, were subject to diverse perspectives.

Like historical empathy, study of such events as SSI would expose students to the tentativeness of scientific knowledge. Just as it might be difficult to understand the heresy of Galileo's proposition today due to all of the subsequent evidence that supports it, students can consider the parallels to current religious objections to climate change. It is not far-fetched to envision a rich study of the Manhattan Project with students challenged to consider whether they would participate if asked to conduct research: What was known at the time? What was the societal context? What is the role of a scientist? How do scientists decide on the research they are willing to conduct? How does a scientist distinguish between what they are able to do vs. what they should do? Case studies in science are not unknown, and in fact, Sadler \& Zeidler (2003) encourage the use of "bad science” (p. 280) from the past such as Tuskegee and the "Big 
Tobacco" cases to promote moral reasoning by helping students to understand that ethical scientific practice requires restraint. What is suggested in the present study, though, is placing emphasis squarely on the promotion of SSPT so that students are able to shift their perspective to that of an "insider" within the time of the dilemma. Moreover, students must consider the implications of actions (or inactions) from the perspective of the stakeholders at that time. In order to do this, emphasis would be placed on stakeholders' knowledge and contexts. For example, a class could endeavor to understand the tensions between Galileo and the church by reading Galileo’s Daughter, A Historical Memoir of Science, Faith, and Love (Sobel, 1999) which chronicles, through 124 surviving letters written by Galileo’s illegitimate daughter to her father, Galileo’s trial before the Inquisition on his heliocentric model. Use of this type of evidence, in addition to resources describing religious doctrine, laws, and writings on the prevailing geocentric model, and other contextual touchstones could provide students with the tools to engage with the stakeholders and view them from within their own time rather than the present. Once potential consequences of their actions are discussed, teachers can guide students through connections to related contemporary SSI. Role play can likely prove to be an effective tool in "Historical SSI." Duveen and Solomon (1994) describe a role-play about Darwin's On the Origin of Species which involves developing dossiers on seven different historical characters, including Charles Darwin, Thomas Huxley, Samuel Wilberforce, and FitzRoy. The authors note that FitzRoy and Wilberforce, although both representing the religious "anti-evolution" stance, represented different strands of the argument, with FitzRoy being more of a religious fundamentalist. This type of historical role play, which is quite common in historical empathy, could foster engagement for students who might otherwise have difficulty with taking perspectives of stakeholders from the past. 
Use of Primary Sources. Another aspect of historical empathy that could be informative to SSI practice is the use of primary sources for enhancing perspective taking and understanding the context surrounding the controversy. While it is tempting to simply have students assume perspectives of stakeholders based on their careers (e.g., "How would a lumberjack or paper mill owner view this proposed ban on logging in Pacific Northwest forests") or on their predicaments (i.e., "How would the parent of a child with leukemia think about the use of gene therapy to cure leukemia”), historians suggest that accurate and varied sources, and in particular primary sources, prevent students from resting their opinions and ideas on superficial generalizations about people or their situations (Davis, 2001). This approach might prove challenging for science teachers insofar as curriculum development as it would require them to examine and assess resource materials that are less familiar than traditional texts or online journals and web pages. Instruction in identification and evaluation of primary sources, parallel to Zeidler and Kahn's (2014) recommendations for the development of SSI lessons and rubrics for evaluating SSI resources, yet drawing from social studies education's guidelines for primary source materials, might prove facilitative.

Section Summary. This section suggests that there is tremendous overlap between the SSI and historical empathy frameworks, particularly in their sequencing of context/action/consequence, as well as their common goal of engaging students in curriculum that emphasizes moral development. An open question, however, is whether studying past actors in historical SSI contexts actually transfers to contemporary decision-making. While the research on historical empathy strongly suggests that students gain an understanding of past actors' contexts and motivations, there is little empirical evidence of the transferability of this understanding to parallel contemporary dilemmas. While this does raise questions as to the 
viability of historical empathy as a guide for promoting SSPT, it also presents an opportunity for science education researchers to examine the transferability of "historical SSI" to contemporary SSI.

\section{Method Acting (Theater Education)}

Actors portray roles that represent others. To that end, dramatic arts have often been seen as imitating life, or more specifically, the social life of people (Banks \& Kenner, 1997). Actors must often infer their character’s “inner life” (Andres-Hyman, Strauss, \& Davidson, 2007, p.84) since scripts are rarely provide explicit background on characters’ psychological make-ups or motivations. One particular school of acting, known as "Method Acting," or "The Method” is considered a particularly effective way of promoting perspective-taking skills and empathy (Verducci, 2000). Method acting is a group of techniques used in acting to promote authentic performances by encouraging actors to create in themselves the thoughts and emotions of their characters. Based on the early teachings of Russian actor and director Constantin Stanislavski (1936) and promoted by New York actor and director Lee Strasberg and actress Stella Adler, “The Method” utilizes exercises that cause actors to draw upon their own backgrounds, including their memories and emotions, and apply them to their characters (Carnicke, 2008 ). Method acting is not about "becoming the character" but rather, forcing the actor to look inside his/her own history and character to find places that resonate with the characters. As Stanislavski implored, "Never allow yourself externally to portray anything that you have not inwardly experienced” (1936, p. 28). Method acting training has produced many of the world's top actors including Al Pacino, Robert DeNiro, Dustin Hoffman, Jane Fonda, and Jack Nicholson, among many others, and is the predominant approach to contemporary acting. 
Comparative Analysis of Method Acting and SSI Frameworks. Although the quest for "theatrical truth” as Stanislawski envisioned it, has led to slightly different approaches by Stanislawski's disciples, most of the main tenets have remained virtually the same. Specifically, actors are compelled to: 1 ) reproduce recognizable reality; 2) express genuine emotion; 3) draw from one’s own personality to advance psychological truth; and 4) communicate with other actors (Vineberg, 1991). Several authors have suggested that acting experience promotes perspective taking ability (Levy, 1997; Metcalf, 1931; Verducci, 2000). Empirical evidence to support this claim includes Chandler, Greenspan, and Barenboim’s (1974) study of 48 children with social challenges who received 10 weeks of drama training including Method-style roletaking activities that significantly increased participants’ perspective taking ability. Students who were in the drama treatment group were encouraged to develop and portray skits about events and persons their age. The roles or characters they portrayed had perspectives other than their own. Students were assessed using an instrument based on Flavell (1968) and Chandler (1973) which asks students to describe, first from their own perspective and then from the perspective of a late-arriving character in a series of cartoons, who had what information; in other words, students needed to set aside their own privileged knowledge of the story and describe it from the perspective of another who had different information. Additional compelling evidence comes from a study by Nettle (2006) who found that adult actors obtained higher scores than the general public on Baron-Cohen and Wheelright's (2004) Empathy Quotient, a self-report measure of emotional empathy. A challenge to theater education researchers is the difficulty in distinguishing correlational versus causational impacts of acting training. Since most studies examine practicing actors, who may have self-selected acting because of their tendency toward perspective taking, or children who are in voluntary after 
school theater programs, who again may have a propensity toward role play, it is difficult to conclude that dramatic training actually fosters perspective taking abilities. However, Goldstein and Winner's (2012) quasi-experimental study of 35 elementary students and 28 adolescent students receiving either drama training or visual arts training over a one year period provides substantial evidence of the efficacy of drama intervention as significant gains in perspective taking abilities as measured both by quantitative and qualitative indicators were seen in both age cohorts' experimental groups. The authors concluded that dramatic role play activities foster perspective taking skills across age groups suggesting greater plasticity in the development of these skills than previously thought. Notwithstanding the particular limitations of study design in theater education research, acting training appears to promote the type of etic/emic switch and at least the appearance of connection with others that is required for SSPT.

Method acting interventions are also aligned with SSPT insofar as promoting the development of a moral context. Verducci (2000) compared the tenets of Method Acting to those of an Ethic of Care (Noddings, 1984), which Verducci characterizes as, "the Caring practices of cognitive understanding, affective resonance and motivational shifting, as well as the experience of self as a duality, also describe dimensions of dramatic empathy” (Verducci, p.90). The overlap, she contends, comes from the fact that actors must assume their character's perspective by connecting to their own emotional experiences, similar to a caring empathizer. However, a major difference between acting and an Ethic of Care is that acting does not require action outside of the context of the performance; in other words, acting in a caring manner does not make actors caring people. Actors can "become" many kinds of people for the purpose of performance while not transforming offstage. However, the context of acting schools, which 
provide opportunities for decision-making, discussion, and direction can provide opportunities for moral education.

The use of drama in science education is not a new concept, as role plays and physical modelling of scientific phenomena have been utilized since the 1980's (Dorion, 2009). Empirical evidence suggests that dramatic techniques, particularly role play, can promote analytical (Ellington, Addinall, \& Percival, 1981; Harvard-Project-Zero, 2001) and perspective taking abilities (Ødegaard, 2003). Specifically within the realm of method acting, certain strategies may prove particularly informative for promoting SSPT.

Table 9. Comparison of Method Acting and SSI

\begin{tabular}{|l|l|l|}
\hline & Method Acting & SSI \\
\hline Goal of interventions & $\begin{array}{l}\text { To provide realistic scenarios } \\
\text { that prepare students for } \\
\text { authentic performances. }\end{array}$ & $\begin{array}{l}\text { To provide realistic scenarios } \\
\text { that prepare students for the } \\
\text { negotiation of real-world } \\
\text { dilemmas. }\end{array}$ \\
\hline $\begin{array}{l}\text { Relationship to moral } \\
\text { development }\end{array}$ & $\begin{array}{l}\text { Practice in perspective taking } \\
\text { and creates thoughtful and } \\
\text { reflective actors on stage. }\end{array}$ & $\begin{array}{l}\text { Practice in perspective taking } \\
\text { creates thoughtful and } \\
\text { reflective actors in society. }\end{array}$ \\
\hline Open question & $\begin{array}{l}\text { Do method actors apply their } \\
\text { perspective taking skills } \\
\text { outside of the theater context? }\end{array}$ & $\begin{array}{l}\text { Do students of SSI apply their } \\
\text { perspective taking skills } \\
\text { outside of the classroom } \\
\text { context? }\end{array}$ \\
\hline
\end{tabular}

Substitution. While Method techniques are not moral actions in and of themselves, if placed in a context such as SSI, perhaps those techniques can be linked into action. One particular exercise, known as "substitution" asks actors to answer the following question: "What would motivate me, the actor, to behave in the way the character does? (Carnicke, 2008 )" In this way, actors are asked to substitute the character's circumstances with those of the actors. Irving 
\& Reed (2010) characterize substitution as follows: "[the actor] is expected to find the sense and feeling of the character by looking for affective matches in his or her own memory or life experiences (p. 459).

An interesting application of substitution to an SSI scenario would be to modify the questions which have been used to assess SSR and reflective judgment to incorporate substitution. In their study on using SSI to enhance reflective judgment, Zeidler, Sadler, Applebaum, \& Callahan (2009) utilized the Prototypic Reflective Judgment Interview (PRJI; King \& Kitchener, 2004) to assess patterns of reflective judgment in SSI scenarios. The PRJI utilizes a standard set of seven questions which are asked after students are presented with an SSI scenario and given statements regarding the scenarios for response. The questions in the PRJI probe are as follows:

1) What do you think about these statements?

2) How did you come to hold that point of view?

3) On what do you base that point of view?

4) Can you ever know for sure that our position on this issue is correct? How or why not?

5) When two people differ about matters such as this, is it the case that one opinion is right and the other is wrong?

6) How is it possible that people have such different points of view about this subject?

7) How is it possible that experts in the field disagree about this subject? (Zeidler, Sadler, Applebaum, \& Callahan, 2009, p. 97)

The application of substitution would suggest that, rather than beginning the probe with questions about students' personal beliefs and rationales, questioning would begin by prompting 
the student to explore aspects of his/her own past which are in concert with an opposing view. In this way, the probe would begin with a prompt such as this:

"You have just heard/read statements about chemical additives. Do you feel that chemical additives are safe?’ If no, suggest: ‘Dan’ believes that chemical additives are perfectly safe and should be added to all foods to improve them. What would make you think that way?” (Provide the opposite prompt if the student supports additives; either prompt could be used if a student is unsure).

By approaching the questioning in this manner, students do not become immediately entrenched in their own beliefs but rather, are forced to begin with an opposing perspective and look inside themselves for places of possible agreement with an opponent. This could perhaps address the issue of inhibitory control by focusing on another's viewpoint first, thus potentially leading to greater cognitive flexibility and reflection.

This approach might also enhance argumentation skills by overcoming students’ difficulties in identifying and anticipating counterclaims and rebuttals. In Toulmin (1958) terms, the new "substitution" logic would begin with a student articulating a counterclaim immediately after voicing his/her claim, without putting forth data, warrants, or backings for their own claims first. Rather than arguing from adversarial perspectives, this approach might allow students to find points of negotiation and understanding.

Similarly, substitution could be utilized in the specific context of assessing students’ informal reasoning patterns. Sadler \& Zeidler (2005) gave students prompts on a range of SSI topics and analyzed their responses in terms of rationalistic, emotive, or intuitive patterns of integration. Their interview protocol was based on Kuhn’s (1991) work on argumentation and informal reasoning. An example, which deals with Huntington's disease, is as follows: 
1) Should gene therapy be used to eliminate HD from sex cells that will be used to create new human offspring? Why or why not?

2) How would you convince a friend or acquaintance of your position?

3) Is there anything else you might say to prove your point?

4) Can you think of an argument that could be made against the position that you have just described? How could someone support that argument?

5) If someone confronted you with that argument, what could you say in response? How would you defend your position against that argument?

6) Is there anything else you might say to prove that you are right? (Sadler \& Zeidler, 2005, p. 134)

This form of probing is again following a Toulmin form of logic whereby the student is asked to put forth a claim, warrant, and backing. It is not until question \#4 that a counterclaim (i.e., an opposing perspective) is considered, and then it is immediately followed with a prompt for a rebuttal to that opposing perspective. Perhaps use of substitution could be used as follows:

1) Should gene therapy be used to eliminate HD from sex cells that will be used to create new human offspring? Yes or no?

2) If yes, "Dan believes that gene therapy should not be used to eliminate HD. What would make you think that way? (Note: use the opposite prompt for a 'no' response).

This approach might require some coaching in that students are used to the pattern of being asked for an opinion and backing it up. They are not used to looking inside themselves for places of congruence with opponents or opposing points of view, yet this is precisely the skill that we are trying to build in order to prepare students to approach multi-faceted problems. This is not to suggest that student shouldn't be trained to advocate for their positions; rather, it is 
suggesting that their positions not get "solidified" until consideration of other perspectives are identified within themselves and through others. Theoretically, the seeds of additional student research and data collection might find fertile ground on which to grow well-reasoned decisions rather than landing on firmly-packed egocentric cement. Starting with multiple perspectives, including those hidden deeply within ourselves, and working backwards to analyze and assess them, might just do the trick.

Section Summary. At first glance, an arts field such as theater education might seem an unlikely resource for science education. Yet the shift in viewpoint that characterizes perspective taking is precisely the basis upon which method actors practice their craft. This section proposed the use of a particular tool of method actors, known as substitution, in science education in order to move argumentation away from using perspective taking to prove one's point, but rather, to find consonance with others' viewpoints. While there is considerable research demonstrating the relationship between such acting interventions and perspective taking, limitations on experimental design make it difficult to ascertain whether it is the interventions that are promoting the development of perspective taking, or simply that those drawn to acting are proficient perspective takers. Longitudinal studies in this area are currently being performed by scholars in this area of theater education (T. Goldstein, personal communication, June 18, 2014) and will provide critical insights toward the determination of whether this is a viable approach for science educators.

\section{Autism Interventions from Special Education}

Autistic Spectrum Disorders (ASD) refers to a variety of disabilities which are differentially characterized by deficits in communication, socialization, and interests and activities (Heflin \& Alaimo, 2007). ASD are among the fastest growing disabilities with current 
prevalence rates estimated at as many as 1 in 110 children (Centers for Disease Control and Prevention, 2009), which places it at nearly 5\% of all students with disabilities (U.S. Department of Education, 2011). The term, “autism” was coined by Leo Kanner (1943) upon his observation that children with this unusual constellation of symptoms seemed to be self-absorbed with little need for external interaction, thus the prefix, auto. In addition to many other attributes, ASD students tend to be quite rigid in their thinking and are typically unable to naturally see others' perspectives or empathize (Decety \& Jackson, 2004). This tendency obviously impedes socialization and communication; therefore, development of perspective taking is a primary goal of interventions for students with ASD.

Comparative Analysis of Autism Education and SSI Frameworks. The use of the term perspective taking when used in literature related to students with ASD tends to focus on students' ability to understand that others might hold different viewpoints than their own, and that this may affect their actions (Baron-Cohen \& Wheelwright, 2004). Although autism was originally envisioned as a form of childhood onset schizophrenia (Rapoport, Chavez, Greenstein, Addington, \& Gogtay, 2009), more contemporary research focuses on the understanding of ASD as a distinct developmental disorder that, perhaps due to excessive early brain growth and/or over “pruning” during the nervous system’s natural processes, leads to dysfunction in several regions of the brain (Minshew \& Keller, 2010). The notion of autism as a developmental disorder is an outgrowth of many autistic students' tendency to appear stuck in the early egocentric levels of perspective taking development. While most children are able to recognize that others may not see situations exactly as they see them by an early age, children with autism are often puzzled by others' behaviors as they cannot connect them to their own understandings. 
Moreover, students with ASD are often unable to recognize that others might hold false beliefs, particularly when the student is given privileged information (Frith, 2001).

In addition, students with ASD often demonstrate a lack of ToM, that is, they have difficulty inferring the mental states of others (Minshew \& Keller, 2010). For example, a student with ASD might not understand by looking at a person who is crying that it is not a good time to approach to discuss their particular interest in dinosaurs or weather. In addition, reading facial expressions, a skill that is intuitive to most children, is often quite perplexing for students with ASD. These mindreading skills often need to be taught explicitly to students with ASD, through picture recognition or video interventions.

Key goals of autism intervention are to foster students' ability to consider: 1)What are others thinking and feeling? 2) Is it different from my own thoughts and feelings? and 3) How will my action/inaction appear to others? (Gutstein \& Whitney, 2002). While the goal of these reflections is to foster social competence in students with ASD, they are not qualitatively different from the concerns of SSI, in which students are compelled to consider the manner in which others think about controversial issues, how those beliefs differ from their own, and what repercussions might stem from their actions/inactions. It is suggested here that the goals of autism interventions and SSI differ more in degree than in kind; in other words, students with ASD are not grappling with a different kind of perspective taking but rather, are at a less advanced stage of the same developmental progression. Some key elements of autism interventions and SSI are compared in Table 10 on page 115.

Although many interventions have been used to foster social interaction including perspective taking in this population, surprisingly, very few interventions qualify as evidencebased practices that withstand the scrutiny demanded for funding under the Individuals with 
Table 10. Comparison of Key Elements Between Autism Intervention and SSI

\begin{tabular}{|c|c|c|}
\hline & Autism Intervention & SSI \\
\hline $\begin{array}{l}\text { Central Role of } \\
\text { Perspective Taking }\end{array}$ & $\begin{array}{l}\text { Promotes students' } \\
\text { understanding of the thoughts } \\
\text { and feelings of others, as well as } \\
\text { the consequences of their actions } \\
\text { or inactions in social situations. }\end{array}$ & $\begin{array}{l}\text { Promotes students' } \\
\text { understanding of the beliefs and } \\
\text { circumstances of others, as well } \\
\text { as the consequences of their } \\
\text { socioscientific decision making } \\
\text { on others. }\end{array}$ \\
\hline $\begin{array}{l}\text { Application of Reflective } \\
\text { Judgment }\end{array}$ & $\begin{array}{l}\text { Emphasis on helping students to } \\
\text { develop an internal voice that } \\
\text { questions, "Should I?” in social } \\
\text { situations. }\end{array}$ & $\begin{array}{l}\text { Emphasis on helping students to } \\
\text { develop an internal voice that } \\
\text { questions, "Should I?” in } \\
\text { socioscientific dilemmas. }\end{array}$ \\
\hline $\begin{array}{l}\text { Key Questions Addressed } \\
\text { Through Curricular } \\
\text { Interventions }\end{array}$ & $\begin{array}{l}\text { 1)What are others thinking and } \\
\text { feeling? } \\
\text { 2) Is it different from my own } \\
\text { thoughts and feelings? } \\
\text { 3) How will my action/inaction } \\
\text { appear to others? }\end{array}$ & $\begin{array}{l}\text { 1) What are stakeholders } \\
\text { thinking and feeling? } \\
\text { 2) How can I reconcile their } \\
\text { thoughts and feelings with my } \\
\text { own? } \\
\text { 3) How will my socioscientific } \\
\text { decisions affect others? }\end{array}$ \\
\hline
\end{tabular}

Disabilities Education Act or recommendation by the National Center for Response to Intervention, who define evidence-based interventions as those "for which data from scientific, rigorous research designs have demonstrated the efficacy of the intervention” (National Center on Response to Intervention, 2010, p. 6). One such intervention that has been identified as effective for the development of perspective taking is video modeling.

Use of video modeling. Video modeling (VM) refers to a set of interventions in which students with autism view videos of themselves, other children, or adults engaging in a target social behavior. Grounded in social learning theory (Bandura, 1969), the intervention emphasizes observational learning to teach desired behaviors. While there are different video techniques utilized in VM, videos often zoom in on specific behaviors, such as making eye contact, and include explicit discussion of key problem-solving strategies. For example, in a video that is 
targeting the skill of understanding how to approach others, a student model might be shown approaching a group of other students while questioning, "Should I interrupt the other students?" “What cues can I look for to know when it’s o.k.?” Video viewing is frequently followed by processing with a teacher to identify the key thoughts and behaviors that led to a successful interaction. In video self-modeling, a variant of VM, students analyze their own social interactions that are recorded on video. Occasionally, students will actually wear video equipment so that the interaction is recorded from their visual perspective.

Several studies suggest that VM is a powerful intervention for targeting perspective taking. Charlop-Christy \& Daneshvar (2003) used VM to teach perspective taking skills to three students with autism using a multiple baseline design. In their study, the children viewed adults performing skits in which one adult (and the student viewing the video) were privy to some information that another adult in the skit was not. The goal of the video was to foster the student's ability to take the perspective of the uninformed adult even though they themselves had the secret information. Results indicated that all three students increased their perspective taking abilities on multiple measures and generalized their perspective taking skills to novel situations. The researchers surmised that the success of VM, particularly in its ability to foster generalization of the target skill to novel contexts, was in part due to the relaxed and unstructured nature of viewing videos for students, as compared to more formal educational settings. The researchers also credited the ability of a video to zoom in on key reactions or cues in a way that live interactions cannot. In addition, the use of combined visual and auditory may have bolstered VM’s effectiveness. In a related set of studies, LeBlanc, et al., (2003) similarly reported the effectiveness of VM on three students' perspective-taking behavior using similar tasks. The main difference between these two studies was that students in the LeBlanc study 
received reinforcements such as stickers for positive responses while those in the CharlopChristy study did not. Delano’s (2007) meta-analysis of 19 studies published between 1985 and 2005 indicated that VM was a highly effective tool for teaching various skills, including perspective taking, to students with autism. Of particular note was the authors' finding that video self-modeling (in which the student is a participant in the video) was among the most consistent in fostering positive skills. The researchers also noted that ensuring the intervention goals have social validity and have particular relevance to the participants are key to successful VM, a finding not so different from Sadler and Zeidler (2005) concluding that SSI contexts are relevant to students' reasoning patterns and to ensuring success with SSI interventions.

While the perspective-taking tasks used in these studies are arguably less sophisticated than those targeted by SSI, they are common skills nonetheless, and it would seem plausible that VM could be utilized to model key SSPT components. For example, a video might involve a group of students engaged in a town hall meeting role play to discuss whether a nuclear power plant should be located near their town. The video could include a student portraying the town's mayor leading the meeting and, in a manner that would not appear contrived to student viewers, promoting positive SSPT tasks. For example, a portion of the script might read as follows:

Town Parent: I read a study that showed that children who are exposed to even low levels of radiation are more likely to have developmental disabilities or develop cancer. I have two young children and I am worried about their health.

Nuclear Plant Rep: There's extensive research supporting the fact that nuclear plants pose minimal risk in terms of radiation exposure to nearby residents. Statistically speaking, you are less likely to be exposed to radiation from our plant than to be struck by lightning. 
Town Parent: (Holding up photos from the Chernobyl nuclear accident) As a parent, I am less concerned about your statistics than I am about the possibility of the devastating effects like these! (camera focuses on the parent’s tearing eyes).

Nuclear Plant Rep: I can see that you are very concerned about this, and the photos from that terrible disaster can seem very persuasive. But I'm asking you to think about the fact that I can show you photos of children injured or killed in car accidents and yet you still drive cars. We can’t avoid every risk.

Parent: I’m still very against this, but you do have a point.

Mayor: I really appreciate the discussion that is taking place here. (To the Parent) I can understand your concern about the health of your children; it's very frightening to see those photos and I share your same concerns for all of our town's children. I am grateful that the Nuclear Plant Rep was willing to acknowledge these concerns. However, I can also see the Nuclear Plant Rep’s point; we often disregard statistics when thinking about isolated tragedies. To your credit, Parent, you admitted this as well. We need to think very hard about this decision as there are potential economic and safety repercussions for our town. And believe it or not, as your mayor, I don’t only think about your votes; I think about doing the right thing for our town. We have a lot more to discuss but at least we're having a productive debate!

The video could then be discussed with a class to process the manner in which the video modeled role taking (by having students play parts), empathy (by sharing fears about the radiation), ToM (by recognizing the Parent's concern), and reflective and reflexive judgment (by being open to opposing views, recognizing repercussions of decisions, and thinking about one's internal conscience). For many students, this type of video could provide a first glimpse of 
productive sociomoral discourse (and for some, perhaps any type of productive discourse) and serve as a starting point for implementing SSI in a classroom. Moving VM into a more natural context, a teacher could video their students engaging in SSI discourse and edit examples of SSPT. The clips could then be shown to the class for analysis, in much the same way that sports coaches or trainers show game clips to athletes to analyze plays. A more sophisticated approach might involve video self-modeling, whereby students create their own videos of themselves and other students during the negotiation of SSI dilemmas. The students could be challenged to assess their own perspective taking skills, or even edit the video into a teaching tool for others. Each of these variations utilizes the key features of successful VM including explicit discussion of successful perspective-taking tasks, use of video to focus on positive behaviors, and using scenarios that are relevant to the student participants.

Use of instruments. Special education researchers have developed several instruments to identify and evaluate challenges in perspective taking, and ultimately, to develop interventions to foster it. One instrument used for assessing students' conceptual perspective-taking abilities is the "Sally-Anne” test, also known as a "False Belief Test.” (Baron-Cohen, Leslie, \& Frith, 1985; Frith, 2001). The test, depicted in Figure 14 on page 120, shows two little girls, Sally and Anne. The story, which is either read to students as they look at the visual, enacted with dolls, or enacted with people, tells of Sally, who has a ball and puts it in a basket. When she walks away, her tricky friend Anne moves the ball into her box. Upon Sally's return, the student is asked, "Where should Sally look for her ball?” The correct answer is “in the basket,” where Sally left it. While this may seem like a simple analysis, it is actually quite complex as it requires maintenance of a changing set of facts as well as a change in perspective from Sally, to Anne, and back to Sally. Moreover, it requires the child to maintain Sally's perspective even though 


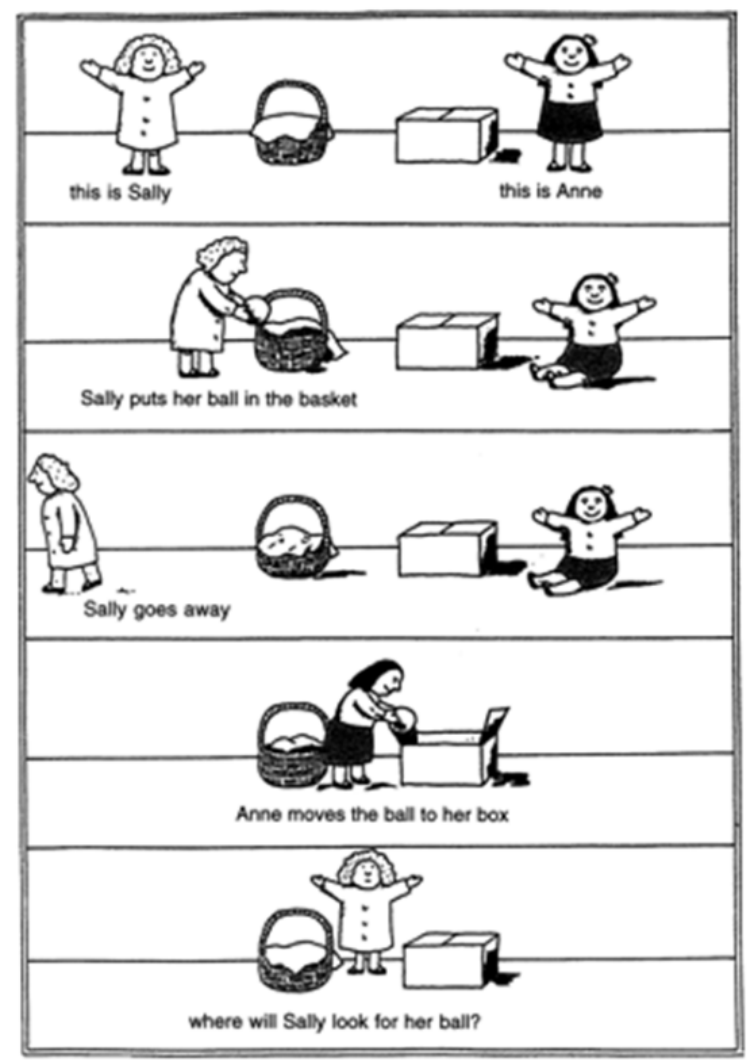

Figure 14. The Sally-Anne Test of Perspective-taking/False Belief. Note. Reprinted from "Mind Blindness and the Brain in Autism” by U. Frith, 2001, Neuron, 32(6), p. 971. Copyright 2001 by Elsevier. Reprinted with permission.

he/she knows that her perspective is false. Children with autism tend to be quite concrete and factual; the task of maintaining another person's perspective, particularly when it is a known false one, is highly problematic; most autistic children say that the ball is in Anne's box, which is factually true but not related to Sally’s perspective (Baron-Cohen, Leslie, \& Frith, 1985, p. 42).

This is an important test of conceptual perspective taking as it incorporates elements of reflection; that is, the ability to maintain one's own perspective while integrating another's...in essence, appreciating the difference between their own and the character's knowledge (p. 43). It should be noted that this is used as a screening test, not as a diagnostic test. Poor performance does not by itself lead to a diagnosis of autism but might instead indicate that further testing is 
warranted. Moreover, typically-developing children do not develop the skills to respond correctly on this type of test until age four (Perner \& Lang, 1999).

We can transform this validated instrument into a socioscientific context for use in science classrooms in order to assess perspective-taking skills. Additionally, we can expand it to include discussion points for use as an intervention. The "SSI Conceptual Perspective-Taking" test depicted in Figure 15 is based on a scenario presented by Zeidler, Sadler, Applebaum, \& Callahan (2009) in which students were given statements about artificial sweeteners and asked about their opinions in order to assess reflective judgment. One student in particular was noted as having a high level of reflective judgment based on her ability to maintain her own beliefs about the safety of artificial sweeteners, based on her own research, weighed against her mother's conflicting belief, while still appreciating her mother's position. In a sense, it was analogous to the aforementioned Sally-Anne test in that conceptual perspective taking requires the ability to maintain and distinguish one's perspective while integrating another's, even when the other's is believed to be false.

The prompts at the end of the test follow those of Zeidler and colleagues, and offer the opportunity for assessing important insights into students' reasoning patterns, while also serving as launching points for discussions about decision-making, knowledge integration, and of course, perspective taking. This type of intervention can be done in verbal, written, or acted formats, the latter of which would be particularly appropriate for young students. Using dolls or cutoutfigures to represent the characters would allow even the youngest students to engage in the negotiation of socioscientific dilemmas and might allow researchers to gauge their progress longitudinally. The Sally-Anne test has already been widely interpreted and correlated to different developmental age ranges. This might help researchers or teachers leading discussions 


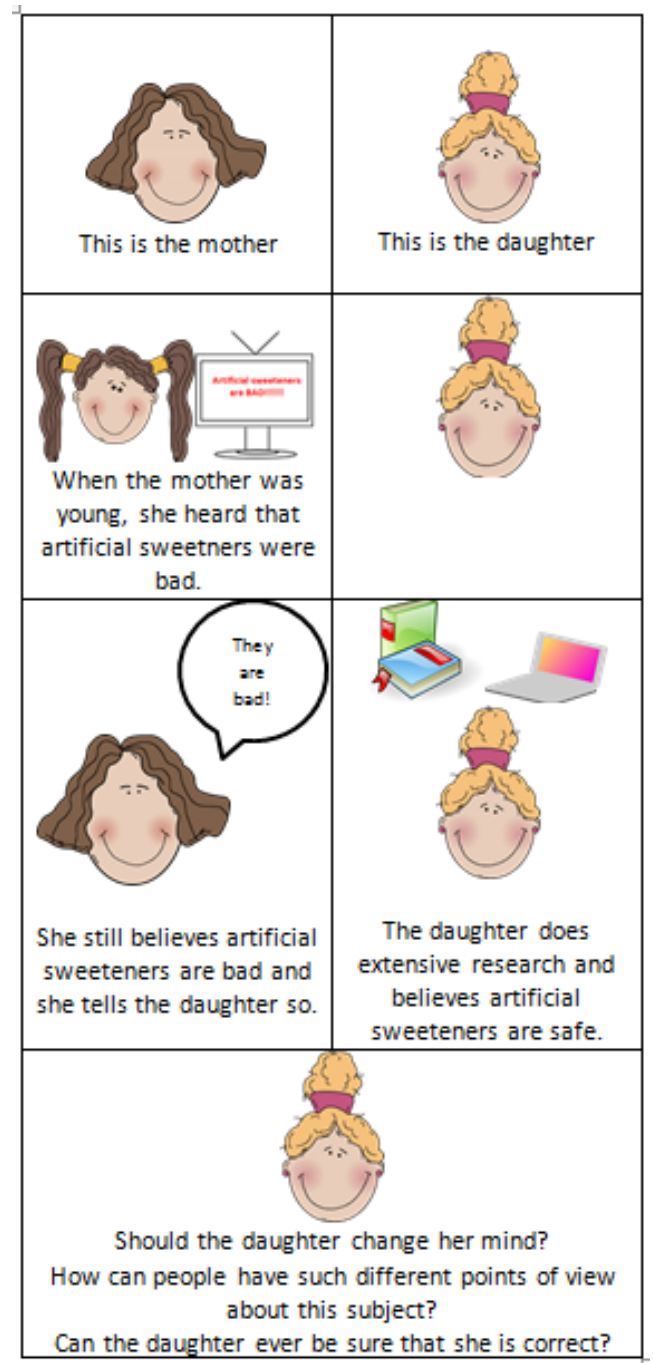

Figure 15. The SSI Conceptual Perspective-Taking Test.

that require SSR to understand the natural developmental capabilities of their students, as well as assess the impact of possible SSI interventions that require the development of perspective taking.

Section Summary. Again we see a framework that at first glance seems distant from SSI. Yet upon closer examination, it appears feasible that perspective-taking instruments and interventions used in autism education might be instructive for science educators wishing to promote the same skills. Although the tasks undertaken in these studies seem somewhat 
rudimentary compared to those sought in SSI, they are nonetheless tapping the same types of perspective taking behaviors desired in SSPT; that is, they emphasize ToM, empathy, role taking, as well as reflection.

A particular limitation of the autism research, however, is that it is typically conducted in single-case studies and within the limited population of students with autism. It is not clear whether the interventions and instruments utilized in these studies would be generalizable to larger samples and to students without autism. Nonetheless, the interventions and instruments identified in this section are readily scalable to the intellectual and emotional levels of students in typical SSI classrooms and, given the need for targeted approaches to SSPT, provide what appear to be promising and novel approaches for fostering this critical set of skills.

\section{Summary}

This chapter evaluated the potential for transferring perspective-taking interventions and instruments from three non-science fields to SSI. Using theoretical inquiry, we identified common threads, as well as key differences, between the frameworks in order to elucidate those activities deemed most promising for the field of science education. While there is much to celebrate in the knowledge that science educators are not alone in their quest to promote skills that can ultimately contribute to the development of SSPT, there are also caveats that must be considered. Each of these non-science frameworks involves research with limitations that raise questions as to their transferability to SSI. Moreover, although it appears that each intervention considered taps on some aspect of SSPT, there is no one panacea for attending to all that constitutes this very complex construct.

Science educators and researchers must likely combine an array of interventions that enhance the already powerful SSI framework specifically for the purpose of fostering SSPT. 
However, the fact that scholars in other fields have found considerable success in targeting similar skills should provide sufficient evidence (if not motivation) for further enthusiastic exploration into each of these fields. Table 11 summarizes the key findings from this chapter. In the following final chapter, we will review our findings from this study and identify the key implications for science education teaching and research.

Table 11. Key Findings From Theoretical Inquiry Into Study Frameworks

\begin{tabular}{|c|c|c|c|c|}
\hline Framework & Intervention & $\begin{array}{c}\text { SSPT } \\
\text { Component(s) } \\
\text { Addressed } \\
\end{array}$ & Strengths & Caveats \\
\hline \multirow[t]{2}{*}{$\begin{array}{l}\text { Historical } \\
\text { Empathy }\end{array}$} & Historical SSI & $\begin{array}{l}\text { Engagement } \\
\text { Role Taking } \\
\text { Empathy } \\
\text { Reflective } \\
\text { Judgment }\end{array}$ & $\begin{array}{l}\text { Employs real-world } \\
\text { issues that can be } \\
\text { viewed with the } \\
\text { benefit of } \\
\text { retrospection. }\end{array}$ & $\begin{array}{l}\text { Little evidence of } \\
\text { transferability to } \\
\text { deliberation of } \\
\text { contemporary } \\
\text { dilemmas. }\end{array}$ \\
\hline & $\begin{array}{l}\text { Use of Primary } \\
\text { Sources }\end{array}$ & Engagement & $\begin{array}{l}\text { Provides depth and } \\
\text { authenticity to } \\
\text { controversial issues. }\end{array}$ & $\begin{array}{l}\text { Difficult to identify } \\
\text { appropriate materials; } \\
\text { some may be seen as } \\
\text { not sufficiently science- } \\
\text { related. }\end{array}$ \\
\hline $\begin{array}{l}\text { Method } \\
\text { Acting }\end{array}$ & Substitution & $\begin{array}{l}\text { Shift } \\
\text { Empathy } \\
\text { Role Taking } \\
\text { Reflexive } \\
\text { Judgment }\end{array}$ & $\begin{array}{l}\text { Emphasis is on } \\
\text { finding } \\
\text { commonalities } \\
\text { rather than } \\
\text { differences among } \\
\text { perspectives and } \\
\text { perspective takers. }\end{array}$ & $\begin{array}{l}\text { Correlational studies } \\
\text { leave questions as to the } \\
\text { causal effects of PT } \\
\text { interventions. }\end{array}$ \\
\hline \multirow[t]{2}{*}{$\begin{array}{l}\text { Autism } \\
\text { Education }\end{array}$} & Video Modeling & $\begin{array}{l}\text { Shift } \\
\text { ToM } \\
\text { Reflective } \\
\text { Judgment }\end{array}$ & $\begin{array}{l}\text { Concretely provides } \\
\text { students with an etic } \\
\text { perspective on the } \\
\text { manner in which } \\
\text { they navigate } \\
\text { through social } \\
\text { interactions and } \\
\text { decision making }\end{array}$ & $\begin{array}{l}\text { Research primarily } \\
\text { done with special } \\
\text { populations using single } \\
\text { case designs; unclear } \\
\text { on efficacy in typical } \\
\text { populations }\end{array}$ \\
\hline & $\begin{array}{l}\text { False Belief } \\
\text { Instrument }\end{array}$ & $\begin{array}{l}\text { Engagement } \\
\text { Shift } \\
\text { ToM } \\
\text { Reflective } \\
\text { Judgment } \\
\text { Reflexive } \\
\text { Judgment }\end{array}$ & $\begin{array}{l}\text { Provides a targeted } \\
\text { and validated } \\
\text { instrument that can } \\
\text { be used as both an } \\
\text { educational } \\
\text { assessment and an } \\
\text { intervention. }\end{array}$ & $\begin{array}{l}\text { Could be misinterpreted } \\
\text { as a diagnostic rather } \\
\text { than screening tool for } \\
\text { autism by } \\
\text { educators/researchers } \\
\text { lacking background. }\end{array}$ \\
\hline
\end{tabular}




\section{Chapter 6:}

\section{Implications for Science Education Research and Practice}

\section{Introduction}

The purpose of this work was to clarify perspective taking so that the totality of this complex concept could be integrated within the SSR construct. Prior research had suggested that moral development was a key outcome of SSI, yet the precise nature of the relationship between SSR and moral development had yet to be articulated. Thus, it was concluded that a gap existed in the SSR construct such that moral development was assumed rather than explicitly identified. Remedying this gap involved identification of the necessary and sufficient conditions of PT within SSR leading to a more robust construct called SSPT. To see the practical applications of SSPT, and to address the need for SSI interventions and instruments specifically targeted toward fostering and assessing this construct, SSPT was then applied to a series of non-science curricular frameworks in an effort to identify promising practices for science education. Of course, in order to accomplish all of this, we traveled to Hollywood, rode in conceptual elevators, and considered everything from birds and dogs to baseball parks! To an uninformed eye, it might seem as though we left the austere realm of science education to dally in frivolity. Yet, closer inspection reveals that these seemingly

unrelated, everyday contexts provided precisely the type of intellectual fodder required of conceptual analysis; that is, they helped us to identify the meanings and assumptions within 
our disciplinary language, thus bringing greater precision and opportunities for expansive analysis to our field.

The interventions and instruments identified in Chapter 5 are perhaps the most obvious implications of this work for science education research and practice as they can readily be implemented and evaluated for efficacy, thus providing the basis for expansive SSI curriculum development and research. Yet it is believed that this work provides even broader implications for the field. These implications are described below.

\section{Implications for Science Education Research}

Perhaps the most critical aspect of this study is confirmation of the complexity of perspective taking within the SSI context. Sadler and colleagues' (2011) insightful reflection that consideration of perspective taking as a subconstruct of SSR rather than an independent construct led to underestimation of its intricacy was quite prescient and suggestive of a need to develop better instruments for its measurement. The operationalization of SSPT in the present research makes this development possible and strongly suggests that measurement of SSPT must transcend unitary indicators such as the number of different viewpoints identified or whether counterpositions or rebuttals can be articulated, in favor of multidimensional instruments that incorporate engagement, etic/emic shift, reflective judgment, and reflexive judgment. Although it is this author's tendency to simplify rather than complicate matters, this is arguably one circumstance where a molehill is indeed a mountain.

Another outcome of this study is clarification of related constructs including orientations, positions, empathy, and the like. It is the finding of this work that these are indeed sufficiently unique constructs that should not be used interchangeably, suggesting that it would behoove science education researchers to revisit studies utilizing these terms to clarify 
their usage, perhaps through conceptual analysis, to ensure that future studies are more precise in their language and can more effectively ensure construct validity.

The promotion of students' SSPT through the use of targeted SSI-based interventions begs the question of whether such activities affect perspective taking in more generalized contexts. For example, do students who receive SSPT interventions demonstrate open mindedness about such factors as race, gender, or disability? Is promotion of SSPT transferable to other perspective taking situations? While Zeidler and Sadler (2011) use of the word "inclusive" to refer to SSI's facilitation of a broad interpretation of scientific literacy, one that compels students to apply scientific content knowledge, argumentation skills, and ethical decision making into their lives as citizens, it seems plausible that exposure to activities specifically targeted to overcome egocentrism while expanding the quality of perspective taking within the SSI context might also impact students’ inclusive reasoning in everyday life, including interactions with peers. Permeation of perspective taking outside of the SSI context, if found to exist, would bolster the import of Lee and colleagues' (2013) empirical finding that SSI is capable of cultivating global citizenship when applied within the SSI context. Moreover, it would be a shining example of science's ability to shape global morality as described by Harris (2010) in his book, The Moral Landscape. The potential for SSI to have impact beyond the borders of science education through the cultivation of SSPT seems particularly feasible when building upon interventions that were developed and empirically tested outside of the science field. Using this model, we are emphasizing development of a human character trait that is globally valued via interventions that have withstood scrutiny from eyes that may not themselves envision or even favor the repositioning of their work into science education. Yet if this repositioning is found to be effective, it might lead to greater cross-fertilization of scholarship between science education and non-science fields, thus upping the ante of what it 
means to foster truly inclusive moral citizenship. In doing so, it would further substantiate Zeidler, Berkowitz, \& Bennett's (2013) assertion that “thinking in scientifically responsible ways” (p. 83) transcends the boundaries of disciplines and nations, and thus empowers moral agency.

A related question is whether incorporation of activities that promote SSPT enhances teachers' SSPT. Zeidler, Applebaum, \& Sadler (2011) remind us that the goal of SSI curriculum is to transform both students' and teachers' epistemological beliefs about science in real-world contexts. Teacher change theory (Guskey, 2002) posits that it is not professional development per se that changes teachers' beliefs or actions, but rather, successful implementation of such training with clear connections to improved student outcomes that facilitates such change. It does not seem far-fetched to imagine that that the act of designing and implementing activities that target and lead to improvement in students' SSPT might broaden teacher's understanding of their students' perspectives, and perhaps even precipitate self-reflection as to their own core beliefs, as well as their biases. McGinnis' (2003) study of pre-service students' ability (or inability) to plan for the full inclusion of a hypothetical student with a developmental disability illuminates the interconnectedness of teachers' moral beliefs and their ability to enact methods of moral teaching. In that study, students who believed inclusion to be a moral imperative, rather than simply a legal or practical necessity, were more inclined to identify and implement practices that demanded respect for and full engagement of all students. This suggests that it is essential for science teachers to recognize the value of moral development in their students and perhaps equally important, to view themselves as moral change agents if the vast potential of SSPT is to be realized. Continued and expanded research on teachers' epistemological beliefs in SSI, with particular attention to SSPT, seems warranted. 


\section{Implications for Science Education Practice}

In addition to further development of the interventions and instruments discussed in Chapter 5, several other implications for science teaching emerge from this study. Ensuring that teachers and curriculum developers understand the distinctions between perspectives, positions, and orientations illuminated in this study can avert the potentially deleterious pedagogical impacts that arise when they are confounded. Science textbooks and curriculum guides frequently include scenarios for sparking classroom debate, such as whether logging should be stopped to protect an endangered species such as the Northern Spotted Owl, or whether wolf reintroduction should continue in Yellowstone Park and other sites (Raven \& Berg, 2004). Students are typically assigned roles such as, environmentalist, lumberjack, paper mill owner, rancher, park ranger, etc... and encouraged to debate. While one might be tempted to think that this exercise promotes an understanding of different perspectives, our analysis suggests that, at most, students are arguing their best guess at positions that a person would likely hold (e.g., for or against a ban on tree clearing to protect the Spotted Owl). Perhaps students can also make conjectures as to whether their character might be environmentally, economically, or politically oriented in comparison to others, based on their career. But in light of our analysis, students would need to develop considerably more background to appreciate the perspectives of those whose roles they are playing. Our analysis of historical empathy suggests that the inclusion of primary sources such as televised or written interviews, letters, or autobiographies by stakeholders, or other personal insights would certainly bolster the ability of students to gain perspective on the different views involved. For younger students, it might be helpful for teachers to create age-appropriate first-person readings based on primary sources in order to facilitate student engagement. But what is of particular import here is that in order to understand 
a stakeholder's perspective, there needs to be more than a generic understanding of their position or orientation, and certainly more than their occupation, race, gender, age, etc... lest we form hasty generalizations based on our own notions about others' perspectives rather than truly taking other's perspectives.

Another interesting implication for science teaching is the present study's accordance with Sadler and Zeidler's (2005) empirical finding that students' informal reasoning through SSI naturally taps into multiple psychological domains, including intuitive, affective, and cognitive. Our analysis suggests that the patterns of reasoning that Sadler \& Zeidler observed constitute modes of engagement with SSI scenarios, the presence of which is a necessary condition of SSPT. Hence, the implication here is that science educators must craft SSI lessons that spur student engagement in all domains, in part by selecting issues of relevance to students, humanizing the stakeholders involved in the issue, and providing students with opportunities to role play. These factors should facilitate the emergence of ToM, empathy, and role taking, particularly if implemented using interventions that encourage etic/emic shift, such as substitution (from theater education) and VM (from autism education). It should be noted, however, that it will likely require an array of interventions and scenarios to adequately address the multifaceted nature of SSPT.

A final implication for the science classroom is the critical need for teacher training for the implementation of SSI with specific emphasis on the promotion of SSPT. Case in point: If one were to focus on the development of historical SSI scenarios, a science teacher would need to receive instruction on the identification and evaluation of primary sources, many of which would be outside the typical realm of science educator materials. Similarly, video modeling interventions based on the work of special educators would require training that is typically 
foreign to science teachers. Zeidler and Kahn (2014) provide extensive critical background for teachers as they develop SSI units. Yet perhaps even more important than the specific strategies utilized is the development of an understanding of the interconnectedness of normative and nonnormative components of scientific literacy (Zeidler \& Sadler, 2008); that is, the need for fostering teachers' buy in as to the interconnected nature of what science can do (i.e., nonnormative components) and what science ought to do (i.e. normative components) in order to ensure that a sense of social responsibility is imbued in their students. While perspective taking could easily be dismissed by science educators as a warm and fuzzy activity that is unrelated to, or even diminishes the rigor of the practice of science, teacher training in the roots of the SSI framework and SSPT gives credence to the necessity of providing students not only with the skills to do science, but a moral compass to guide the application of those skills.

\section{Concluding Statement}

A final goal of this study was to develop a heuristic for the use of conceptual analysis in science education. While this was admittedly a rather lofty (and perhaps audacious) goal, it is believed that this dissertation presents a compelling argument for the use of conceptual analysis as a fruitful and necessary form of inquiry for clarifying language and exposing underlying assumptions within our terms of art. At the outset, we agreed that our work would be completed when we had developed a lucid and compelling analysis of perspective taking within the SSR context such that you, the "jury," felt reasonably persuaded by the clear and convincing evidence put forth. I hope that this work has achieved this challenging standard. But more importantly, I hope that this work will serve as enticement to the field for embracing philosophical inquiry in their work, and to emerging science education scholars to consider theoretical dissertations when appropriate to address their research questions. The value of a theoretical dissertation is not 
simply that it puts the "Ph.” back in the Ph.D., but rather, when we are unbounded by four walls, we are reminded that the beauty of education as a social science is our ability to rely on a variety of inquiry models... and take a variety of perspectives. 


\section{References}

Abd-El-Khalick, F. (2006). Socioscientific issues in pre-college science classrooms. In D. L. Zeidler (Ed.), The role of moral reasoning and discourse on socioscientific issues in science education (pp. 41-61). Dordrecht, the Netherlands: Springer.

Andres-Hyman, R. C., Strauss, J. S., \& Davidson, L. (2007). Beyond parallel play: Science befriending the art of method acting to advance healing relationships. Psychotherapy: Theory, Research, Practice, Training, 44(1), 78. DOI: 10.1037/0033-3204.44.1.78

Attenborough, R. (Producer/Director). (1982). Gandhi. [Motion picture]. Los Angeles, CA: Columbia Pictures.

Ausubel, D.P. (1968). Educational Psychology: A Cognitive View. New York, NY: Holt, Rinehart \& Winston.

Ayer, A. J. (1956). The Problem of Knowledge. London, UK: Macmillan.

Bandura, A. (1969). Social-learning theory of identiflcatory pro cesses. In D. A. Goslin (Ed.), Handbook of socialization theory and research. Chicago, IL: Rand McNally.

Banks, S., \& Kenner, A. N. (1997). Are actors more socially skilled?: Behavioral and self-report measures. Psychological reports, 81(3f), 1115-1123.

Baron-Cohen, S, Leslie, A. M., \& Frith, U. (1985). Does the autistic child have a theory of mind”? Cognition, 21, 37-46. 
Baron-Cohen, S., \& Wheelwright, S. (2004). The empathy quotient: An investigation of adults with Asperger syndrome or high-functioning autism, and normal sex differences. Journal of Autism and Developmental Disorders, 34, 163-175. DOI: 10.1023/B:JADD.0000022607.19833.00

Barrow, R. (1990). The Role of Conceptual Analysis in Curriculum Inquiry: A Holistic Approach. Journal of Curriculum and Supervision, 5(3), 269-78.

Batson, C.D. (1991). The altruism question: Toward a social-psychological answer. Hillsdale, NJ: Lawrence Erlbaum Associates, Inc.

Bealer, G. (1998). Intuition and the Autonomy of Philosophy. In M. DePaul \& W. Ramsey (Eds.), Rethinking Intuition: The Psychology of Intuition and Its Role in Philosophical Inquiry (pp. 201-239). Lanham, MD: Rowman \& Littlefield.

Beaney, M. (Summer 2014). Analysis. The Stanford Encyclopedia of Philosophy. Retrieved from http://plato.stanford.edu/archives/sum2014/entries/analysis/.

Berkowitz, M. W. (1997). The complete moral person: Anatomy and formation. In J. M. DuBois (Ed.), Moral issues in psychology: Personalist contributions to selected problems (pp. 11-42). Lanham, MD: University Press of America.

Blackburn, S. (1996). The Oxford Dictionary of Philosophy. Oxford, UK: Oxford University Press.

Blakemore, S., \& Choudhury, S. (2006). Development of the adolescent brain: Implications for executive function and social cognition. Journal of Child Psychology and Psychiatry, 47(3/4), 296-312. DOI: 10.1111/j.1469-7610.2006.01611.x 
Bloom, B. S., Engelhart, M. D., Furst, F. J . Hill, W. H., \& Krathwohl, D. R. (1956). Taxonomy of educational objectives: Cognitive domain. New York, NY: McKay.

Boland, R. J., \& Tenkasi, R. V. (1995). Perspective making and perspective taking in communities of knowing. Organization Science, 6, 350-372.

Boulter, C. J., \& Buckley, B. C. (2000). Constructing a typology of models for science education. In Developing models in science education (pp. 41-57). Dordrecht, The Netherlands: Springer.

Bozeman, B., \& Feeney, M. K. (2007). Toward a useful theory of mentoring a conceptual analysis and critique. Administration \& Society, 39(6), 719-739. DOI: $10.1177 / 0095399707304119$

Carnicke, S. (2008). Stanislavsky in Focus: An Acting Master for the Twenty-First Century. New York, NY: Routledge Theatre Classics.

Center for Disease Control. (2009). Prevalence of Autism Spectrum Disorders: Autism and Developmental Disabilities Monitoring Network, United States, 2006. Morbidity and Mortality Weekly Report. Surveillance Summaries. Volume 58, Number SS-10.

Chandler, M. J. (1973). Egocentrism and antisocial behavior: The assessment and training of social perspectivetaking skills. Developmental Psychology, 9, 326-332.

Chandler, M. J., Greenspan, S., \& Barenboim, C. (1974). Assessment and training of role-taking and referential communication skills in institutionalized emotionally disturbed children. Developmental Psychology, 10(4), 546.

Charlop-Christy, M. H., \& Daneshvar, S. (2003). Using video modeling to teach perspective taking to children with autism. Journal of Positive Behavior Interventions, 5(1), 12-21. 
Chinn, C.A. \& Brewer, W.F. (1993). The role of anomalous data in knowledge acquisition: a theoretical framework and implications for science instruction. Review of Educational Research, 63, 1-49.

Clark, H. H., \& Marshall, C. R. (1981). Definite reference and mutual knowledge. In A. K. Joshi, B. L. Webber, \& I. A. Sag (Eds.), Elements of discourse understanding (pp. 1063). Cambridge, UK: Cambridge University Press.

Coke, J., Batson, C., \& McDavis, K. (1978). Empathic mediation of helping: A two-stage model. Journal of Personality and Social Psychology, 36, 752-766.

Coombs, J. R. \& Daniels, L.B. (1991). Philosophical Inquiry: Conceptual Analysis. In Short, E. C. (Ed.). (1991). Forms of curriculum inquiry. (p. 27-42). Albany, NY: SUNY Press.

Corcoran, K., \& Mallinckrodt, B. (2000). Adult attachment, self-efficacy, perspective-taking, and conflict resolution. Journal of Counseling \& Development, 78, 473-483.

Cronbach, L. J., \& Meehl, P. E. (1955). Construct validity in psychological tests. Psychological Bulletin, 52, 281-302.

Czerniak, C. M. (2007). Interdisciplinary science teaching. In S. K. Abell \& N. G. Lederman (Eds.), Handbook of research on science education (pp. 537-559). Mahwah, NJ: Lawrence Erlbaum.

Davis, M. H. (1983). Measuring individual differences in empathy: Evidence for a multidimensional approach. Journal of Personality and Social Psychology, 44, 113-126.

Davis, O. L. (2001). In pursuit of historical empathy. In O. L. Davis, E. A. Yeager, and S. J. Foster (Eds), Historical empathy and perspective taking in the social studies. (pp. 112). Lanham, MD: Rowman and Littlefield. 
Decety, J., Chen, C., Harenski, C., \& Kiehl, K. A. (2013). An fMRI study of affective perspective taking in individuals with psychopathy: imagining another in pain does not evoke empathy. Frontiers in Human Neuroscience, 7, 489.

doi:10.3389/fnhum.2013.00489

Decety, J., \& Jackson, P. L. (2004). The functional architecture of human empathy. Behavioral and cognitive neuroscience reviews, 3(2), 71-100.

Delano, M. E. (2007). Video modeling interventions for individuals with autism. Remedial and Special Education, 28(1), 33-42. doi: 10.1177/07419325070280010401

Demurie, E., De Corel, M., \& Roeyers, H. (2011). Empathic accuracy in adolescents with autism spectrum disorders and adolescents with attention-deficit/hyperactivity disorder. Research in Autism Spectrum Disorders, 5, 126-134. DOI 10.1016/j.rasd.2010.03.002

Denes-Raj, V., \& Epstein, S. (1994). Conflict between intuitive and rational processing: when people behave against their better judgment. Journal of personality and social psychology, 66(5), 819.

Descartes, R. (1968). Discourse on method and the meditations. Harmondsworth, England: Penguin. (Original work published 1637)

Dewey, J. (1910). How we think. DC Heath: Lexington, MA.

Dorion, K. R. (2009). Science through drama: A multiple case exploration of the characteristics of drama activities used in secondary science lessons. International Journal of Science Education, 31(16), 2247-2270.

Downey, M.T. (1995). Perspective taking and historical thinking: Doing history in a fifthgrade classroom. Paper presented at the annual meeting of the American Educational Research Association, San Francisco 
Duschl, R., \& Osborne, J. (2002). Supporting and promoting argumentation discourse. Studies in Science Education, 38, 39-72.

Duveen, J., \& Solomon, J. (1994). The great evolution trial: Use of role-play in the classroom. Journal of research in science teaching, 31(5), 575-582.

Eastwood, J. L., Sadler, T. D., \& Jiménez-Aleixandre, M. P. (2011). Metalogue: SSI in undergraduate science education. In T. D. Sadler (Ed.), Socio-scientific Issues in the Classroom (pp. 127-131). Dordrecht, The Netherlands: Springer.

Eisenberg, N. (2000). Emotion, regulation, and moral development. Annual review of psychology, 51(1), 665-697.

Ellington, H. I., Addinall, E., \& Percival, F. (1981). Games and simulations in science education. London, England: Kogan Page

Ennis, R. (1991). Critical thinking: A streamlined conception. Teaching Philosophy, 14(1), 5-24.

Ennis, R. H. (1993). Critical thinking assessment. Theory into Practice, 32(3), 179-186.

Erduran, S., Simon, S. \& Osborne, J. (2004). TAPping into argumentation: Developments in the application of Toulmin’s argument pattern for studying science discourse. Science Education, 88, 915-933. DOI 10.1002/sce.20012

Evans, C. (Producer), \& Pollack, S. (Director). (1982). Tootsie. [Motion Picture]. Los Angeles, CA: Columbia Pictures.

Facione, P. A. (2000). The disposition toward critical thinking: Its character, measurement, and relationship to critical thinking skill. Informal Logic, 20(1), 61-84.

Fenigstein, A. \& Abrams, D. (1993) Self-attention and the egocentric assumption of shared perspectives. Journal of Experimental Social Psychology, 29, 287-303.

Fenstermacher, G. D. (1994). The knower and the known: The nature of knowledge in research on teaching. Review of Research in Education, 20(1), 3-56. 
Finfgeld, D. L. (2003). Metasynthesis: The state of the art—so far. Qualitative Health Research, 13(7), 893-904. doi: 10.1177/1049732303253462

Fishbein, H. D., Lewis, S., \& Keiffer, K. (1972). Children's understanding of spatial relations. Developmental Psychology, 7, 21-33.

Flavell, J. H. (1968.) The development of role-taking and communication skills in children. New York, NY: Wiley.

Flinders, D. J., Noddings, N., \& Thornton, S. J. (1986). The null curriculum: Its theoretical basis and practical implications. Curriculum Inquiry, 33-42.

Ford, M. E. (1979). The construct validity of egocentrism. Psychological Bulletin, 86(6), 1169.

Foster, S. J. (2001). Historical empathy in theory and practice: Some final thoughts, in O. L. Davis, E. A. Yeager, and S. J. Foster (Eds.), Historical empathy and perspective taking in the social studies. Lanham, MD: Rowman and Littlefield.

Fowler, S.R., Zeidler, D.L., \& Sadler, T.D. (2009). Moral sensitivity in the context of socioscientific issues in high school science students. International Journal of Science Teacher Education, 31(2), 279-296. DOI: 10.1080/09500690701787909.

Franks, D.D. (2013). Why we need neurosociology as well as social neuroscience: Or-why role-taking and theory of mind are different concepts. In D. D. Franks \& J. H. Turner (Eds.), Handbook of neurosociology, handbooks of sociology and social Research (pp. 27-32). Dordrecht, Netherlands: Springer Science \& Business Media B.V. Frith, U. (2001). Mind blindness and the brain in autism. Neuron, 32(6), 969-979. 
Furberg, A., \& Ludvigsen, S. (2008). Students’ meaning-making of socio-scientific issues in computer mediated settings: Exploring learning through interaction trajectories. International Journal of Science Education, 30(13), 1775-1799. DOI: $10.1080 / 09500690701543617$

Gadamer, H. G. (1977). The scope of hermeneutic reflection. Philosophical Hermeneutics, 3104.

Gilbert, J. K., \& Boulter, C. (Eds.). (2000). Developing models in science education. Dordrecht, The Netherlands: Kluwer.

Goetzman, G. (Producer), \& Demme, J. (Director). (1991). The Silence of the Lambs. [Motion Picture]. Los Angeles, CA: Orion Pictures.

Goldstein, T. R., \& Winner, E. (2012). Enhancing empathy and theory of mind. Journal of Cognition and Development, 13(1), 19-37. DOI:10.1080/15248372.2011.573514

Goldstein, T. R., Wu, K., \& Winner, E. (2009). Actors are skilled in theory of mind but not empathy. Imagination, Cognition and Personality, 29(2), 115-133. DOI: 10.2190/IC.29.2.C

Gorovitz, S. \& Williams, R. G. (1965). Philosophical analysis: An introduction to its language and techniques. New York, NY: Random House.

Green, T. F. (1964). A topology of the teaching concept. Studies in Philosophy and Education, 3(4), 284-319.

Green, T. F. (1971). The activities of teaching. New York, NY: McGraw-Hill.

Green, T. F. (1988). The economy of virtue and the primacy of prudence. American Journal of Education, 127-142. 
Green, T.F. (1999). Voices: The educational formation of conscience. Notre Dame, IN: University of Notre Dame

Grove, R., \& Short, E. C. (1991). Theoretical inquiry: components and structure. Forms of curriculum inquiry, 211-224.

Guber, P. (Producer), \& Levinson, B. (Director). (1988). Rain Man [Motion picture]. Los Angeles, CA:MGM/UA Distribution Company.

Gurucharri, C., \& Selman, R. L. (1982). The development of interpersonal understanding during childhood, preadolescence, and adolescence: A longitudinal follow-up study. Child Development, 924-927.

Guskey, T. R. (2002). Professional development and teacher change. Teachers and Teaching: theory and practice, 8(3), 381-391. DOI: 10.1080/135406002100000512

Gutstein, S. E., \& Whitney, T. (2002). Asperger syndrome and the development of social competence. Focus on Autism and Other Developmental Disabilities,17(3), 161-171.

Häkkinen, P., \& Järvelä, S. (2006). Sharing and constructing perspectives in web-based conferencing. Computers \& Education, 47(4), 433-447. doi:10.1016/j.compedu.2004.10.015

Harper, D. (2014). Online etymology dictionary. Retrieved from http://www.etymonline.com/index.php?term=analysis

Harris, S. (2011). The moral landscape: How science can determine human values. New York, NY: Simon and Schuster.

Heagle, A.R. \& Rehfeldt, I.A. (2008). Teaching perspective-taking skills to typically developing children through derived relational responding. In J.E. Ormrod (Ed.), Educational psychology developing learners. Upper Saddle River, NJ: Prentice Hall. 
Heflin, L. J., \& Alaimo, D. F. (2007). Students with autism spectrum disorders: Effective instructional practices. Upper Saddle River, NJ: Pearson Merrill Prentice Hall.

Hirst, P. H. (1974). Knowledge and the curriculum. London, UK: Routledge.

Hodson, D. (2011). Teaching Ethics. In Looking to the Future (pp. 195-221). SensePublishers.

Horkheimer, M. (1982). Critical Theory. Seabury Press, New York, NY.

Ibáñez-Orcajo, M. T. \& Martínez-Aznar, M. M. (2007). Solving problems in genetics, part III:

Change in the view of the nature of science International Journal of Science Education,29,(6), 747-769.

Irving, A., \& Reed, A. (2010). Is it useful to talk of a 'cosmopolitan method'? Social Anthropology, 18(4), 454-463.

Jackson, F. (1998). From Metaphysics to Ethics: A Defense of Conceptual Analysis. Oxford, UK: Oxford University Press.

James, B. (1984). The Bill James Baseball Abstract. New York, NY: Ballantine Books.

Jacobellis v. Ohio. (1964). 378 U.S. 184

Johnson, D. W., \& Johnson, R. T. (1979). Conflict in the classroom: Controversy and learning. Review of Educational Research, 49(1), 51-69.

Jolliffe, D., \& Farrington, D. P. (2004). Empathy and offending: A systematic review and metaanalysis. Aggression and violent behavior, 9(5), 441-476.

Kanner, L. (1943). Autistic disturbances of affective contact. Nervous Child, 2, 217-250.

Kincheloe, J. L. (2005). On to the next level: Continuing the conceptualization of the bricolage. Qualitative Inquiry, 11(3), 323-350.

King, P.M. \& Kitchener, K.S. (2004). Reflective judgment: Theory and research on the development of epistemic assumptions through adulthood, Educational Psychologist, 39(1), 5-18. DOI: 10.1207/s15326985ep3901_2 
Kohlberg, L. (1968). Early education: A cognitive developmental approach. Child Development, 39, 1013-1062.

Komisar, B. P. (1968). Teaching: Act and enterprise. Studies in Philosophy and Education, 6(2), 168-193.

Kornblith, H. (2002). Knowledge and Its Place in Nature. Oxford, UK: Oxford University Press.

Krathwohl, D.R. (1993). Methods of educational and social science research: An integrated approach. New York, NY: Longman.

Krauss, R.M. \& Fussell, S.R. (1996) Social psychological models of interpersonal communication. In E.T. Higgins \& A. Kruglanski (Eds.), Social psychology: Handbook of basic principles (pp. 655-701). New York, NY: Guilford Press.

Ku, K. Y. (2009). Assessing students’ critical thinking performance: Urging for measurements using multi-response format. Thinking skills and creativity, 4(1), 70-76. http://dx.doi.org/10.1016/j.tsc.2009.02.001

Kuhn, D. (1992). Thinking as argument. Harvard Educational Review, 62, 155-178.

Kurdek, L. A. (1977). Structural components and intellectual correlates of cognitive perspective taking in first-through fourth-grade children. Child Development, 1503-1511.

Lamm, C., \& Majdandzic, J. (2015). The role of shared neural activations, mirror neurons, and morality in empathy - A critical comment. Neuroscience Research, 90, 15-24. http://dx.doi.org/10.1016/j.neures.2014.10.008

Latour, B., \& Woolgar, S. (1986). Laboratory life: The construction of scientific facts (2nd ed.). Princeton, NJ: Princeton University Press. 
LeBlanc, L. A., Coates, A. M., Daneshvar, S., Charlop-Christy, M. H., Morris, C. and Lancaster, B. M. (2003), Using video modeling and reinforcement to teach perspective-taking skills to children with autism. Journal of Applied Behavioral Analysis. 36(2), 253-257. doi: 10.1901/jaba.2003.36-253

Lederman, N. G., \& Niess, M. L. (1997). Integrated, interdisciplinary, or thematic instruction. Is this a question or is it questionable semantics, 57-58.

Lee, P., \& Ashby, R. (2001). Empathy, perspective taking, and rational understanding. In O. L. Davis Jr., E. A. Yeager, \& S. J. Foster (Eds.), Historical empathy and perspective taking in the social studies (pp. 21-50). Lanham, MD: Rowman \& Littlefield Publishers, Inc.

Lee, H., Chang, H., Choi, K., Kim, S. W., \& Zeidler, D. L. (2012). Developing character and values for global citizens: Analysis of pre-service science teachers’ moral reasoning on socioscientific issues. International Journal of Science Education, 34(6), 925-953. DOI:10.1080/09500693.2011.625505

Lee, H., Yoo, J., Choi, K., Kim, S., Krajcik, J., Herman, B., \& Zeidler, D. L. (2013). Socioscientific issues as a vehicle for promoting character and values for global citizens. International Journal of Science Education, 35(12), 2079-2113. DOI: 10.1080/09500693.2012.749546

Legal Information Institute (n.d.). Clear and convincing evidence. Retrieved from http://www.law.cornell.edu/wex/clear_and_convincing_evidence

Levy, J. (1997). Theatre and moral education. Journal of Aesthetic Education, 31(3),65-75. Lobchuk, M. M. (2006). Concept analysis of perspective-taking: meeting informal caregiver needs for communication competence and accurate perception. Journal of Advanced Nursing, 54(3), 330-341. DOI: 10.1111/j.1365-2648.2006.03815.x 
Margolis, E. \& Laurence, S. (Spring, 2014). Concepts. The Stanford Encyclopedia of Philosophy. Retrieved from http://plato.stanford.edu/archives/spr2014/entries/concepts/.

Martin, J., Sokol, B. W., \& Elfers, T. (2008). Taking and coordinating perspectives:

From prereflective interactivity, through reflective intersubjectivity, to metareflective sociality. Human Development, 51(5-6), 294-317.

DOI: $10.1159 / 000170892$

McGinnis, J. R. (2003). The morality of inclusive verses exclusive settings. In Zeidler, D.L. (Ed.) The role of moral reasoning on socioscientific issues and discourse in science education (p. 195-216). Dordrecht, The Netherlands: Springer.

McGinnis, J. R., \& Stefanich, G. P. (2007). Special needs and talents in science learning. In S. K. Abell \& N. G. Lederman (Eds.), Handbook of research on science education (p. 287-317). Mahwah, New Jersey: Lawrence Erlbaum.

Mead, G. H. (2009). Mind, self, and society: From the standpoint of a social behaviorist (Vol. 1). Chicago, IL: University of Chicago press.

Metcalf, J. T. (1931). Empathy and the actor's emotion. Journal of Social Psychology, 2, 235238.

Minshew, N. J., \& Keller, T. A. (2010). The nature of brain dysfunction in autism: functional brain imaging studies. Current opinion in neurology, 23(2), 124. http://dx.doi.org/10.1097/WCO.0b013e32833782d4

Monash, P. (Producer). \& De Palma, B. (Director). (1976). Carrie. [Motion Picture]. Los Angeles, CA: United Artists. 
National Center on Response to Intervention. (2010). Essential components of RTI-A closer look at response to intervention. Washington, DC: U.S. Department of Education, Office of Special Education Programs.

National Research Council. (2011). The need for new science standards: Next Generation Science Standards. Retrieved from http://www.nextgenscience.org/overview-0

National Science Teachers Association (NSTA). 2010. Position statement on teaching science and technology in the context of societal and personal issues. Retrieved from http://www.nsta.org/about/positions/societalpersonalissues.aspx

Nettle, D. (2006). Psychological profiles of professional actors. Personality and individual differences, 40(2), 375-383.

Neumann, R., Parry, S., \& Becher, T. (2002). Teaching and learning in their disciplinary contexts: A conceptual analysis. Studies in Higher Education, 27(4), 405-417.

Next Generation Science Standards Lead States. (2013). Next Generation Science Standards: For States, By States. Washington, DC: The National Academies Press.

Nilsen, E. S., \& Fecica, A. M. (2011). A model of communicative perspective-taking for typical and atypical populations of children. Developmental Review, 31(1), 55-78. doi:10.1016/j.dr.2011.07.001

Noddings, N. (1984). Caring: a feminine approach to ethics \& moral education. Berkeley, CA: University of California Press.

Noddings, N. (2012). Philosophy of education. Boulder, CO: Westview Press.

Novak, J.D. (2000). Concept Mapping: A useful tool for science education. Journal of Research in Science Teaching, 27(10), 937-949. 
Ødegaard, M. (2003). Dramatic science: A critical review of drama in science education. Studies in Science Education, 39, 75-102.

Oliver, M. (1983). Social Work with Disabled People. London, UK: Macmillan.

Pakula, A. J. (Producer), \& Mulligan, R. (Director). (1962). To kill a mockingbird.[Motion Picture]. Universal City, CA: Universal Studios.

Papineau, D. (1993). Philosophical Naturalism. Oxford, UK: Blackwell.

Perner, J. (1998) Simulation as explication of predication-implicit knowledge about the mind. In Theories of Theories of Mind (Carruthers, P. and Smith, P.K., eds), pp. 90-104, Cambridge University Press

Perner, J., \& Lang, B. (1999). Development of theory of mind and executive control. Trends in Cognitive Sciences, 3, 337-344.

Peshkin, A. (1988). In search of subjectivity—One’s own. Educational Researcher,17, 17-21.

Piaget, J. (1926). The language and thought of the child. New York: Harcourt Brace.

Premack, D., \& Woodruff, G. (1978). Does the chimpanzee have a 'theory of mind'? Behavioral and Brain Sciences, 4, 515-526.

Pring, R. (2004). Philosophy of Educational Research. London, UK: Continuum.

Rapoport, J., Chavez, A., Greenstein, D., Addington, A., \& Gogtay, N. (2009). AutismSpectrum Disorders and Childhood Onset Schizophrenia: Clinical and Biological Contributions to a Relationship Revisited. Journal of the American Academy of Child and Adolescent Psychiatry, 48(1), 10-18. doi:10.1097/CHI.0b013e31818b1c63

Raven, P.H. \& Berg, L.R. (2004). Environment (4E). Hoboken, NJ: John Wiley \& Sons. Riffert, F. (2012). Analytic philosophy, Whitehead, and theory construction. Process Studies, 41(2), 235-260. 
Rizzolatti, G., \& Fabbri-Destro, M. (2010). Mirror neurons: from discovery to autism. Experimental Brain Research, 200(3-4), 223-237. DOI 10.1007/s00221-009-2002-3

Roberts, D.A. (2007). Scientific literacy/Science literacy. In S. K. Abell \& N. G. Lederman (Eds.), Handbook of research on science education (pp. 729-280). Mahwah, NJ: Lawrence Erlbaum Associates.

Roberts, D.A. (2011). Competing visions of scientific literacy: The influence of a science curriculum policy image. In C. Linder, L. Ostman, D.A. Roberts, P. Wickman, G. Erickson, \& A. MacKinnon (Eds.), Promoting scientific literacy: Science education research in transaction (pp. 11-27). New York, NY: Routledge/Taylor \& Francis Group.

Rogers, R. R. (2001). Reflection in higher education: A concept analysis. Innovative Higher Education, 26(1), 37-57.

Ruby, P. \& Decety, J. (2003). What you believe versus what you think they believe: a neuroimaging study of conceptual perspective-taking. European Journal of Neuroscience, 17, 2475-2480. DOI: 10.1046/j.1460-9568.2003.02673.x

Sadler, T. (2004). Informal reasoning regarding socioscientific issues: A critical review of research. Journal of Research in Science Teaching, 41, 513-536.

DOI: 10.1002/tea.20009

Sadler, T.D., Barab, S.A. \& Scott B. (2007). What do students gain by engaging in socioscientific inquiry? Research in Science Education, 37, 371-391. DOI: $10.1007 / s 11165-006-9030-9$

Sadler, T. D., Chambers, F. W., \& Zeidler, D. L. (2004). Student conceptualizations of the nature of science in response to a socio-scientific issue. International Journal of Science Education, 26, 387-409. DOI: 10.1080/0950069032000119456 
Sadler, T. D., \& Donnelly, L. A. (2006). Socioscientific argumentation: The effects of content knowledge and morality. International Journal of Science Education, 28(12), 1463-1488. DOI: 10.1080/09500690600708717

Sadler, T. D., Klosterman, M. L., \& Topcu, M. S. (2011). Learning science content and socioscientific reasoning through classroom explorations of global climate change. In Sadler, T. D. (Ed.), Socio-scientific issues in the classroom (pp. 45-77). Dordrecht, The Netherlands: Springer.

Sadler, T. D., \& Zeidler, D. L. (2003). Scientific errors, atrocities and blunders. In D.L. Zeidler (Ed.), The role of moral reasoning and discourse on socioscientific issues in science education (pp. 261-285). Dordrecht: Kluwer.

Sadler, T.D. \& Zeidler, D.L. (2004). The morality of socioscientific issues: Construal and resolution of genetic engineering dilemmas. Science Education, 88, 4-27. DOI: $10.1002 /$ sce.10101

Sadler, T.D. \& Zeidler, D.L. (2005). Patterns of informal reasoning in the context of socioscientific decision making. Journal of Research in Science Teaching, 42(1) 112138. DOI 10.1002/tea.20042

Saka, P. (2006). The demonstrative and identity theories of quotation. The Journal of philosophy, 103(9), 452-471.

Sawyer, R. K. (Ed.). (2006). The Cambridge handbook of the learning sciences. Cambridge, UK: Cambridge University Press.

Saxe, R. (2005). Against simulation: the argument from error. Trends in cognitive sciences, 9(4), 174-179.

Scheffler, I. (1960). The language of education. Springfield, IL.: Thomas. 
Selman, R.L. (1971). Taking Another's Perspective: Role-Taking Development in Early Childhood, Child Development, 42(6), 1721-1734.

Selman, R. L. (1977). A structural-developmental model of social cognition: Implications for intervention research. The Counseling Psychologist, 6(4), 3-6.

Selman, R. (1981). The development of interpersonal competence: The role of understanding in conduct. Developmental Review, 1, 401-422.

Short, E. C. (Ed.). (1991). Forms of curriculum inquiry. Albany, NY: SUNY Press.

Simonneaux, L. (2008). Argumentation in socio-scientific contexts. Argumentation in science Education. In Erduran, S. and Jiménez-Aleixandre, M.P. (Eds.) Argumentation in science education: Perspectives from classroom-based research (pp. 179-199). Dordrecht, The Netherlands: Springer.

Smith, B. (1960). A concept of teaching. The Teachers College Record, 61(5), 229-241.

Smith, D. G. (1991). Hermeneutic inquiry: the hermeneutic imagination and the pedagogic text. In E. Short (Ed.), Forms of curriculum inquiry (pp. 187-209.). New York, NY: SUNY Press.

Sobel, D. (1999). Galileo's Daughter: A Historical Memoir of Science, Faith, and Love. New York, NY: Walker \& Co.

Soltis, J.F. (1967). The language of visual perception. In Komisar, B. P., \& Macmillan, C. J. B. (Eds.), Psychological concepts in education (pp. 83-95). Chicago: Rand McNally. Soltis, J. F. (1978). An introduction to the analysis of educational concepts (2nd Ed). Boston, MA: Addison-Wesley Publishing Company.

Stanislavski , C. (1936) An Actor Prepares. New York, NY: Theater Arts Books. 
Tal, T., Kali, Y., Magid, M., \& Madhok, J. (2011). Enhancing the authenticity of a webbased module for teaching simple inheritance. In T. D. Sadler (Ed.), Socio-scientific issues in science classrooms: Teaching, learning and research (pp. 11-38). The Netherlands: Springer.

Taylor, M., Cartwright, B. S., \& Bowden, T. (1991). Perspective taking and theory of mind: Do children predict interpretive diversity as a function of differences in observers' knowledge?. Child Development, 62(6), 1334-1351.

Titchener, E. (1915). A beginner's psychology. New York, NY: Macmillan.

Toulmin, S. E. (1958). The uses of argument. Cambridge, UK: Cambridge University Press. U.S. Department of Education, National Center for Education Statistics. (2011). The Digest of Education Statistics 2010 (NCES 2011-015), Table 46.

Verducci, S. (2000). A moral method? Thoughts on cultivating empathy through method acting. Journal of Moral Education, 29(1), 87-89. http://dx.doi.org/10.1080/030572400102952

Vilardaga, R. (2009). A relational frame theory account of empathy. International Journal of Behavioral Consultation and Therapy, 5(2), 178-184.

Vineberg, S. (1991). Method actors: Three generations of an American acting style. New York, NY: Schirmer.

Wachtel, P. L. (1980). Investigation and its discontents: Some constraints on progress in psychological research. American Psychologist, 35(5), 399.

Walker, L. J. (1980). Cognitive and perspective-taking prerequisites for moral development. Child Development, 131-139. 
Walker, K. A., \& Zeidler, D. L. (2007). Promoting discourse about socioscientific issues through scaffolded inquiry. International Journal of Science Education, 29(11), 1387-1410. DOI: 10.1080/09500690601068095

Wilson, J. (1963). Thinking with concepts. Cambridge, UK: Cambridge University Press.

Wu, Y. T., \& Tsai, C. C. (2007). High school students’ informal reasoning on a socio-scientific issue: Qualitative and quantitative analyses. International Journal of Science Education, 29(9), 1163-1187. DOI: 10.1080/09500690601083375

Yager, R. E. (Ed.). (1996). Science/technology/society as reform in science education. Albany, NY: SUNY Press.

Yeager, E. A., \& Foster, S. J. (2001). The role of empathy in the development of historical understanding. In O. L. Davis, E. A. Yeager, and S. J. Foster (Eds), Historical empathy and perspective taking in the social studies. (pp. 13-19). Lanham, MD: Rowman and Littlefield.

Yilmaz, K. (2007). Historical empathy and its implications for classroom practices in schools. The History Teacher, 331-337.

Yore, L., Bisanz, G. L., \& Hand, B. M. (2003). Examining the literacy component of science literacy: 25 years of language arts and science research. International Journal of Science Education, 25(6), 689-725. DOI: 10.1080/09500690305018

Zeidler, D. L. (1997). The central role of fallacious thinking in science education. Science Education, 81(4), 483.

Zeidler, D. L. (2002). Tangled up in views: Beliefs in the nature of science and responses to socioscientific dilemmas. Science Education, 86(3), 343.

DOI: $10.1002 /$ sce. 10025 
Zeidler, D.L. (2003). The Role of Moral Reasoning on Socioscientific Issues and Discourse in Science Education. Dordrecht, The Netherlands: Kluwer Academic Publishers.

Zeidler, D. L. (2005). Beyond STS: A research-based framework for socioscientific issues education. Science Education, 89(3), 357.

Zeidler, D.L. (2014). Socioscientific Issues as a Curriculum Emphasis: Theory, Research, and Practice. In N. G. Lederman \& S.K. Abell (Eds.), Handbook of Research on Science Education, Vol. II. (pp. 697-726). New York, NY: Routledge.

Zeidler, D. L., Applebaum, S. M., \& Sadler, T. D. (2011). Enacting a socioscientific issues classroom: Transformative transformations. In Socio-scientific issues in the classroom (pp. 277-305). Springer Netherlands.

Zeidler, D. L., Berkowitz, M. W., \& Bennett, K. (2013). Thinking (scientifically) responsibly: The cultivation of character in a global science education community. In M. P. Mueller, et. al., (Eds.), Assessing schools for generation R (Responsibility), Contemporary Trends and Issues in Science Education 41. (pp. 83-99). Dordrecht, The Netherlands: Springer. DOI: 10.1007/978-94-007-2748-9_7.

Zeidler, D. L., \& Kahn, S. (2014). It’s Debatable! Using Socioscientific Issues to Develop Scientific Literacy, K-12. Arlington, VA: National Science Teachers Press.

Zeidler, D. L., \& Keefer, M. (2003). The role of moral reasoning and the status of socioscientific issues in science education. In D. L. Zeidler (Ed.), The role of moral reasoning on socio- scientific issues and discourse in science education (pp. 7-38). Dordrecht, The Netherlands: KluwerAcademic Publishers.

Zeidler, D. L., \& Nichols, B. H. (2009). Socioscientific issues: Theory and practice. Journal of Elementary Science Education, 21(2), 49-58. 
Zeidler, D.L., Osborne, J., Erduran, S., Simon, S., \& Monk, M. (2003). The role of moral reasoning and the status of socioscientific issues in science education: Philosophical, psychological and pedagogical considerations. In D.L. Zeidler (Ed.), The role of moral reasoning and discourse on socioscientific issues in science education (pp. 97-116).

Dordrecht: Kluwer.

Zeidler, D. L., \& Sadler, T. D. (2008). The role of moral reasoning in argumentation:

Conscience, character and care. In S. Erduran \& M. Pilar Jimenez-Aleixandre (Eds.), Argumentation in science education: Perspectives from classroom-based research (pp. 201-216). Dordrecht, The Netherlands: Springer Press.

Zeidler, D. L. \& Sadler, D. L. (2011). An inclusive view of scientific literacy: Core issues and future directions of socioscientific reasoning. In C. Linder, L. Ostman, D. A. Roberts, P. Wickman, G. Erickson \& A. MacKinnon, A. (Eds.), Promoting scientific literacy: Science education research in transaction.(pp. 176-192). New York, NY: Routledge / Taylor \& Francis Group.

Zeidler, D. L., Sadler, T. D., Applebaum, S., \& Callahan, B. E. (2009). Advancing reflective judgment through socioscientific issues. Journal of Research in Science Teaching, 46(1), 74-101. DOI: 10.1002/sce.10025

Zeidler, D. L., Sadler, T. D., Simmons, M. L., \& Howes, E. V. (2005). Beyond STS: A research- based framework for socio-scientific issues education. Science Education, 89(3), 357-377. DOI 10.1002/sce.20048 


\section{Appendix A:}

\section{IRB Letter of Exemption}

\section{USF}

UNIVERSITY OF

SOUTH FLORIDA

June 3, 2014

Sami Kahn

Teaching and Learning

Tampa, FL 33612

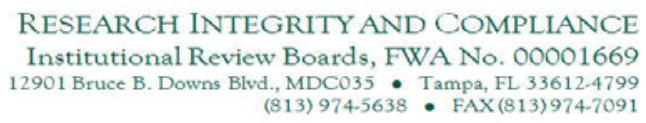

(813) 9745638 EAX(813)9747091

\section{RE: $\quad$ NOT Human Research Activities Determination}

IRB\#: Pro00017784

Title: A Conceptual Analysis of Perspective Taking in Support of Socioscientific Reasoning

Dear Ms. Kahn:

The Institutional Review Board (IRB) has reviewed the information you provided, on June 3, 2014 , regarding the above referenced project and has determined the activities do not meet the definition of human subjects research. Therefore, IRB approval is not required. If, in the future, you change this activity such that it becomes human subjects research, IRB approval will be required. If you wish to obtain a determination about whether the activity, with the proposed changes, will be human subjects research, please contact the IRB for further guidance.

All research activities, regardless of the level of IRB oversight, must be conducted in a manner that is consistent with the ethical principles of your profession and the ethical guidelines for the protection of human subjects. As principal investigator, it is your responsibility to ensure subjects' rights and welfare are protected during the execution of this project

Also, please note that there may be requirements under the HIPAA Privacy Rule that apply to the information/data you will use in your activities. For further information about any existing HIPAA requirements for this project, please contact a HIPAA Program administrator at 813-974-5638.

We appreciate your dedication to the ethical conduct of human subject research at the University of South Florida and your continued commitment to human research protections. If you have any questions regarding this matter, please call 813-974-5638.

Sincerely,

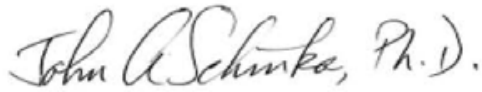

John Schinka, Ph.D., Chairperson

USF Institutional Review Board 


\section{Appendix B:}

\section{Copyright License for Figure 2}

Copyright
Clearance
Center

\section{Order Completed}

Thank you very much for your order.

This is a License Agreement between Sami Kahn ("You") and Springer ("Springer"). The license consists of your order details, the terms and conditions provided by Springer, and the payment terms and conditions.

Get the printable license.

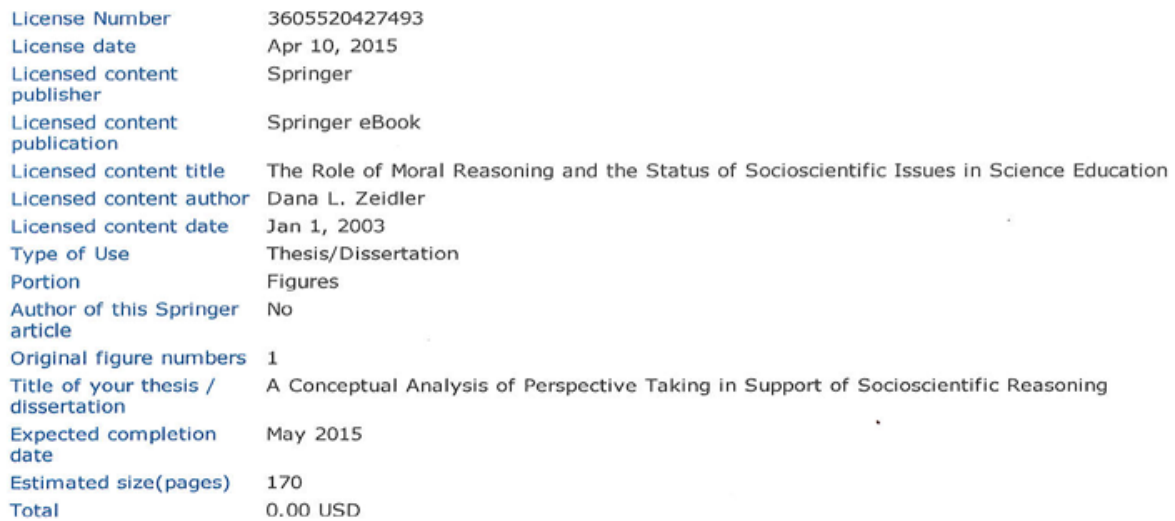

\section{CLOSE WINDOW}

Copyright (c) 2015 Copyright Clearance Center, Inc. All Rights Reserved. Privacy statement. Terms and Conditions. Comments? We would like to hear from you. E-mail us at customercare@copvriaht.com 


\section{Appendix C:}

\section{Copyright License for Figure 5}

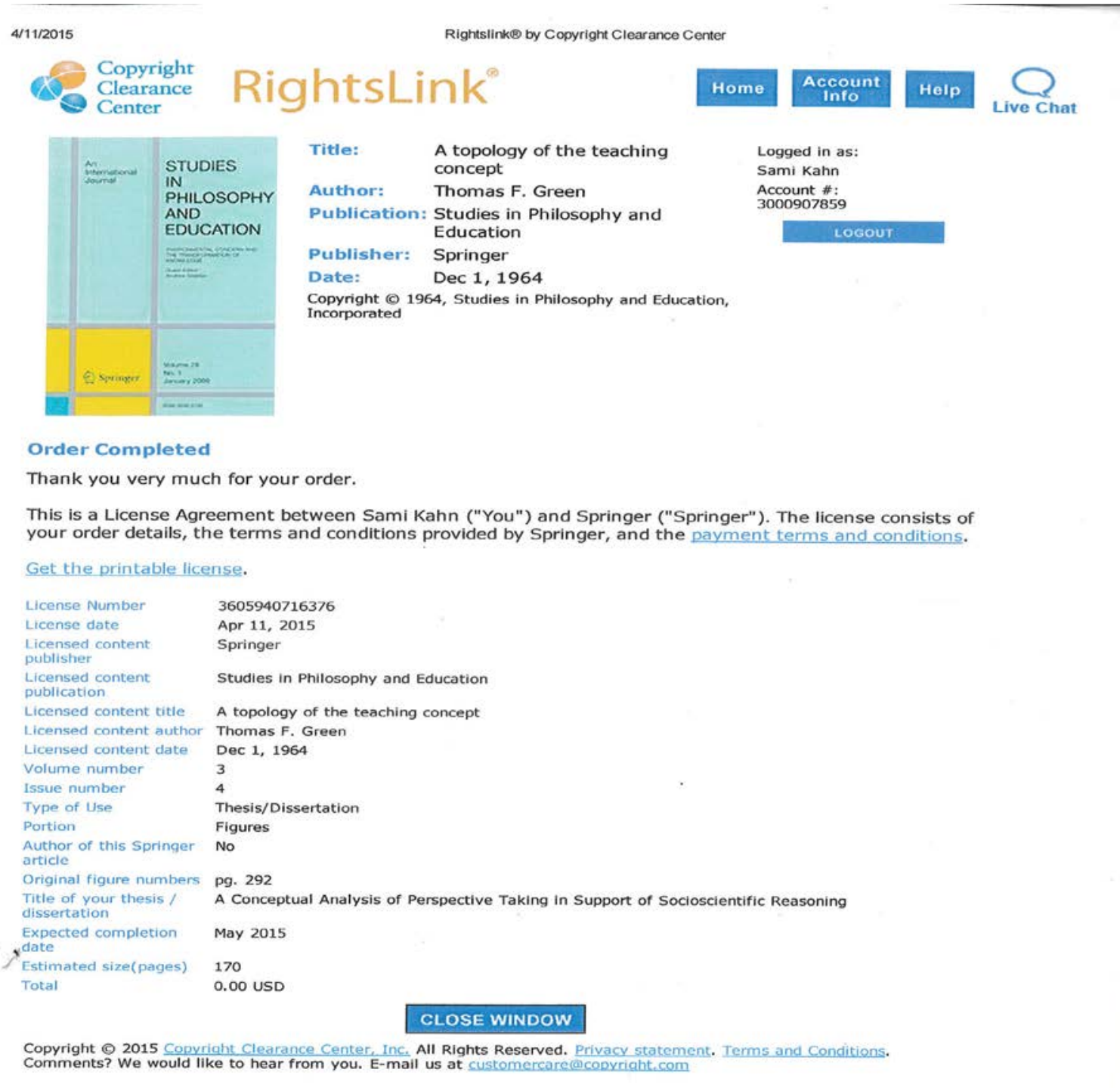




\section{Appendix D:}

\section{Copyright License for Figure 14}

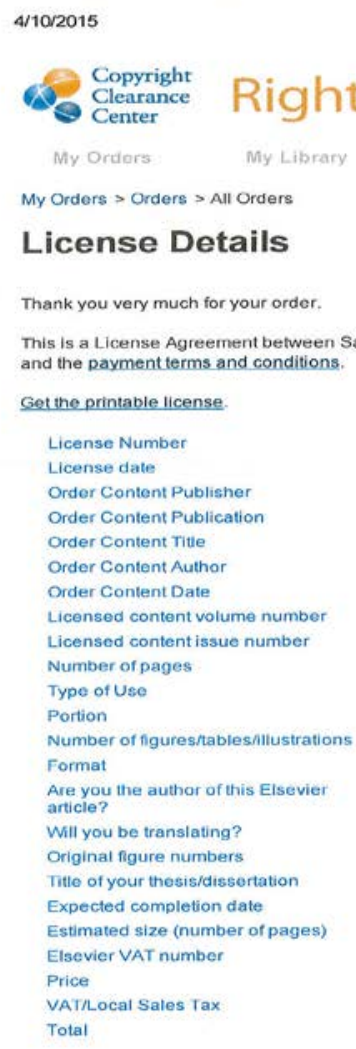

\section{License Details}

Thank you very much for your order. and the payment terms and conditions.

Get the printable license.

License Number
License date
Order Content Publisher
Order Content Publication
Order Content Title
Order Content Author
Order Content Date
Licensed content volume number
Licensed content issue number
Number of pages
Type of Use
Portion
Number of figures/tablesnillustrations
Format
Are you the author of this Elsevier
article?
Will you be transiating?
Original figure numbers
Titte of your thesis/dissertation
Expected completion date
Estimated size (number of pages)
Elsevier VAT number
Price
VATLocal Sales Tax
Total

This is a License Agreement between Sami Kahn (You") and Elsevier ("Elsevier"), The license consists of your order details, the terms and conditions provided by Elsevier.

3605500032458

Apr 10, 2015

Elsevier

Neuron

Mind Blindness and the Brain in Autism

Uta Frith

20 December 2001

6

reuse in a thesis/dissertation

figures/ablesfillustrations

both print and electronic

No

No

Figure 1

A Conceptual Analysis of Perspective Taking in Support of Socioscientific Reasoning

May 2015

170

GB 494627212

0.00 USD

0.00 USD $/ 0.00 \mathrm{GBP}$

0.00 USD

RightsLink - Your Account 


\section{Appendix E:}

\section{Letter Confirming Open Source Status of Clipart in Figure 15}

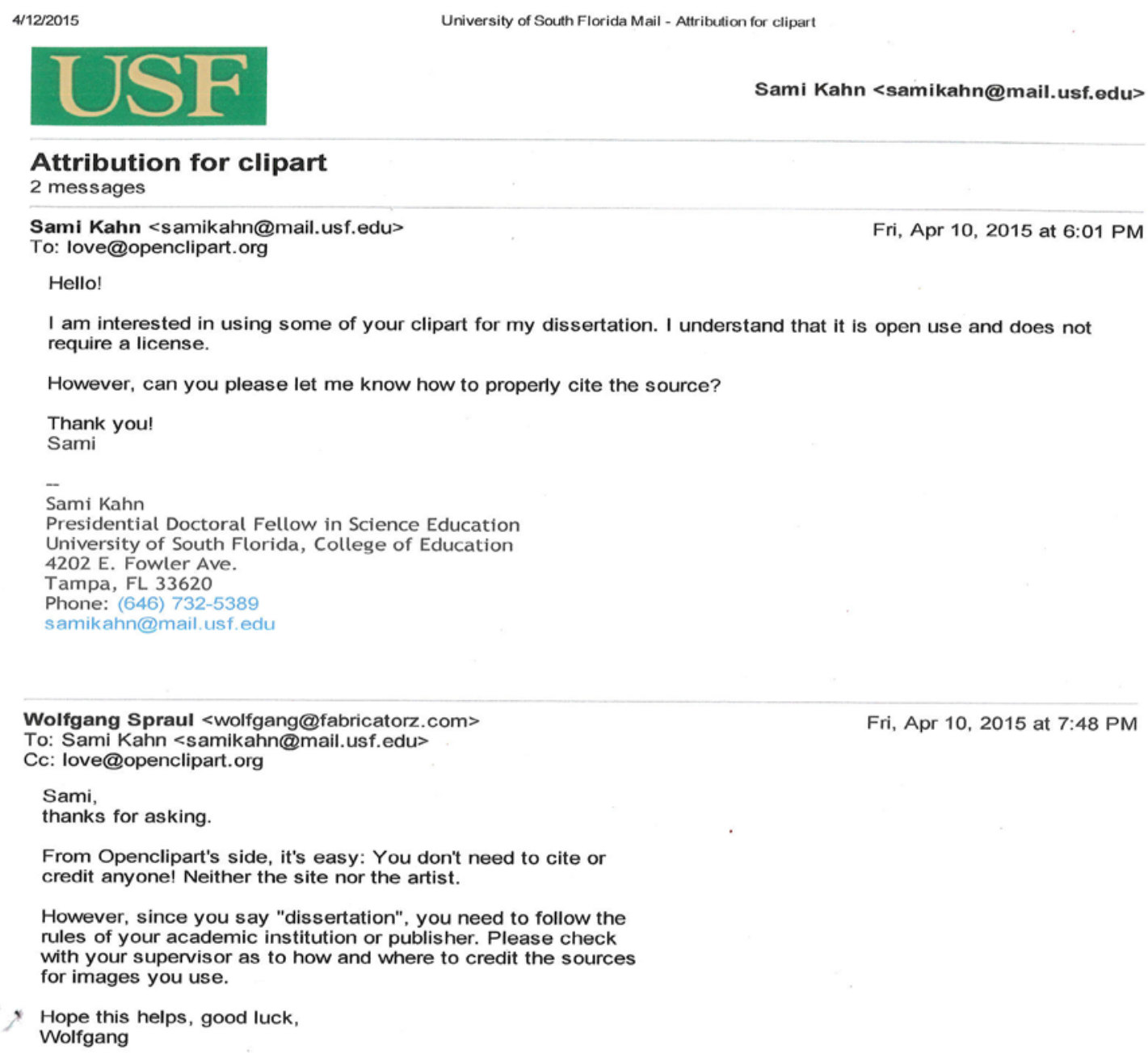

